\title{
Thermal and Molecular Investigation of Laser Tissue Welding
}

\author{
W. Small IV \\ (Ph.D. Thesis)
}

June 1998 


\section{DISCLAIMER}

This document was prepared as an account of work sponsored by an agency of the United States Government. Neither the United States Government nor the University of California nor any of their employees, makes any warranty, express or implied, or assumes any legal liability or responsibility for the accuracy, completeness, or usefulness of any information, apparatus, product, or process disclosed, or represents that its use would not infringe privately owned rights. Reference herein to any specific commercial product, process, or service by trade name, trademark, manufacturer, or otherwise, does not necessarily constitute or imply its endorsement, recommendation, or favoring by the United States Government or the University of California. The views and opinions of authors expressed herein do not necessarily state or reflect those of the United States Government or the University of California, and shall not be used for advertising or product endorsement purposes.

This report has been reproduced

directly from the best available copy.

Available to DOE and DOE contractors from the Office of Scientific and Technical Information

P.O. Box 62, Oak Ridge, TN 37831

Prices available from (615) 576-8401, FTS 626-8401

Available to the public from the

National Technical Information Service

U.S. Department of Commerce

5285 Port Royal Rd,

Springfield, VA 22161

Work performed under the auspices of the U.S. Department of Energy by Lawrence Livermore National Laboratory under Contract W-7405-ENG-48. 
UCRL-LR-130533

Distribution Category UC-700

\title{
Thermal and Molecular Investigation of Laser Tissue Welding
}

\author{
W. Small IV \\ (Ph.D. Thesis)
}

June 1998

\section{LAWRENCE LIVERMORE NATIONAL LABORATORY}

University of California $\bullet$ Livermore, California $\bullet 94551$ 
Thermal and Molecular Investigation of Laser Tissue Welding

By

WARD SMALL IV

B.S. (University of California, San Diego) 1993

M.S. (University of California, Davis) 1994

DISSERTATION

Submitted in partial satisfaction of the requirements for the degree of

DOCTOR OF PHILOSOPHY

in

' Engineering-Applied Science

in the

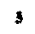

OFFICE OF GRADUATE STUDIES

of the

UNIVERSITY OF CALIFORNIA

Davis

Approved:

Committee in Charge 


\section{Contents}

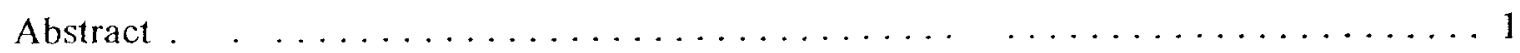

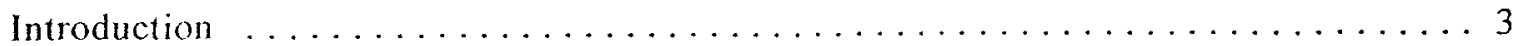

Chapter 1: Investigation of Laser Tissue Welding Dynamics via $\ldots \ldots \ldots \ldots$ Experiment and Modeling

Chapter 2- Dye-Enhanced Protein Solders and Patches in Laser-......... 20 Assisted Tissue Welding

Chapter 3: Experimental and Computational Laser Tissue Welding ......... 31 Using a Protein Patch

Chapter 4: Indocyanine Green Dye-Mediated Laser Tissue Welding . . . . . . . 46 and Collagen Crosslinks

Chapter 5: Temperature Feedback and Collagen Crosslinking in $\ldots \ldots \ldots \ldots \ldots$ Argon Laser Vascular Welding

Chapter 6: Two-Color Mid-Infrared Thermometer Using a Hollow . . . . . . . . . 73 Glass Optical Fiber

Chapter 7: Effect of $527 \mathrm{~nm}$ Laser Light on Collagen Crosslinks: ......... 91 Implications for Tissue Welding

Chapter 8: Spectroscopic Study of the Effect of Laser Heating on . . . . . . 103 Collagen Stability: Implications for Tissue Welding 
Ward Small IV

June 1998

Engineering--Applied Science

Thermal and Molecular Investigation of Laser Tissue Welding

\begin{abstract}
$\underline{\text { Abstract }}$
Despite the growing number of successful animal and human trials, the exact mechanisms of laser tissue welding remain unknown. Furthemore, the effects of laser heating on tissue on the molecular scale are not fully understood. To address these issues, a multi-front attack on both extrinsic (solder/patch mediated) and intrinsic (laser only) tissue welding was launched using two-color infrared thermometry, computer modeling, weld strength assessment, biochemical assays, and vibrational spectroscopy. The coupling of experimentally measured surface temperatures with the predictive numerical simulations provided insight into the subsurface dynamics of the laser tissue welding process. Quantification of the acute strength of the welds following the welding procedure enabled comparison among trials during an experiment, with previous experiments, and with other studies in the literature. The acute weld integrity also provided an indication of the probability of long-term success. Moleculat effects induced in the tissue by laser irradiation werc investigated by moasuring the concentrations of specific collagen covalent crosslinks and characterizing the Fourier Transform infrared (FTIR) spectra before and after the laser exposure.
\end{abstract}

This investigation yielded results pertaining to both the methods and mechanisms of laser tissue welding. The combination of two-color infrared thermometry to obtain accurate surface temperatures free from emissivity bias and computer modeling illustrated the importance of including evaporation in the simulations, which effectively serves as an inherent cooling mechanism during laser irradiation. Moreover, the hydration state predicted by the model was useful in assessing the role of electrostatic versus covalent bonding in the 
fusion. These tools also helped elicit differences between dye-enhanced liquid solders and solid-matrix patches in laser-assisted tissue welding. demonstrating the significance of repeatable energy delivery. Surprisingly, covalent bonds between collagen molecules (crosslinks) were formed in tissue when exposed to the commonly used absorbing chromophore indocyanine green (ICG) prior to laser irradiation, which restored the crosslink concentrations to their native levels. Crosslinks were either created or destroyed during exposure to green laser light without any extrinsic materials or chromophores, which may impact the acute and long-term strength and stability of laser welded tissues. FTIR spectra revealed changes in collagen conformation (molecular structure) induced by laser heating as a function of temperature, elucidating the dynamics of the denaturation process.

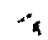




\section{Introduction}

Laser tissue welding is a generic phrase used to describe the act of using laser light to join or seal biological tissues. The deposited energy is believed to alter the molecular structure of the tissues such that bonds may form. In particular, the triple helical protein collagen is believed to play a major role in the tissue fusion mechanism--thermal denaturation (uncoiling of the triple helix) and subsequent intertwining of adjacent collagen fibers may be at least partly responsible for the tissue fusion [1]. Clinical experience has demonstrated its advantages over the conventional tissue closure techniques of suturing and stapling: faster, reduced foreign body response (improved healing), and less susceptible to leakage. In addition, sutures can be difficult to apply under some circumstances, such as in laparascopic procedures, and impossible under others, such as in minimally invasive endoscopic catheter-based procedures or in places too small to permit their use. Because the laser light can be delivered remotely using small-diameter optical fibers without the need to perform any intricate "stitching" maneuvers, most areas of interest can be accessed using laser tissue welding. It is worth mentioning that many laser tissue welding applications currently employ sutures to maintain tissue apposition during the welding procedure and bear some of the tensile forces following its completion. Nevertheless, the number of sutures is reduced and, hence, the time needed to complete the frequently superior repair is decreased.

The parameter space spanned by laser tissue welding models is vast. Chosen wavelengths range from visible argon laser radiation to far-infared $\mathrm{CO}_{2}$ laser radiation, while tissue models encompass the circulatory, digestive, reproductive, skeletal, respiratory, and nervous systems [1]. Further, the developing practice of laser tissue welding can be divided into two general methods: extrinsic laser tissue welding and intrinsic laser tissue welding. Extrinsic laser tissue welding (also called laser tissue soldering) incorporates an extrinsic proteinacious bonding material, in the form of a solder or patch, which becomes attached to the tissue when heated 
by laser radiation Early studies employed blood [2] and egg white albumin [3] as the solder material. Often, the material is doped with a chromophore to selectively absorb the laser wavelength, as described by $\mathrm{Oz}$ et al [4,5], which reduces the extent of collateral thermal damage of the underlying tissue. The bond between the extrinsic material and the tissue serves to fill holes and/or hold adjacent tissues in apposition until the physiologic healing response can complete the repair. Intrinsic laser tissue welding also creates a temporary bond which is later reinforced by the deposition of new collagen and the other aspects of wound healing. However, no extrinsic bonding materials are used; the laser is used to join tissue to tissue. Various incarnations of both methods have found vascular applications such as vessel anastomoses and grafts [6-9], dermatologic applications such as skin wound closure [10,11], urologic applications such as urethral closure and vasovasostomy [3,12-14], and neurosurgical applications such as nerve repair [15-17]. However, the usefulness of laser tissue welding in these and many other areas is limited by a lack of strength and reproducibility. These problems stem partly from a lack of understanding of the fundamental laser tissue welding mechanisms, which has made optimization of the various procedures extremely difficult.

Despite the growing number of successful animal and human trials, the exact mechanisms of laser tissue welding remain unknown. Furthemore, the effects of laser heating on tissue on the molecular scale are not fully understood. To address these issues, a multi-front attack on both extrinsic and intrinsic tissue welding was launched using two-color infrared thermometry, computer modeling, weld strength assessment, biochemical assays, and vibrational spectroscopy [18-30]. The coupling of experimentally measured surface temperatures with the predictive numerical simulations provided insight into the sub-surface dynamics of the laser tissue welding process. Quantification of the acute strength of the welds following the welding procedure enabled comparison among trials during an experiment, with previous experiments, and with other studies in the literature. The acute weld integrity also provided an indication of the probability of long-term success. Molecular effects induced in the tissue 
by laser irradiation were investigated by measuring the concentrations of specific collagen covalent crosslinks and characterizing the Fourier Transform infrared (FTIR) spectra before and after the laser exposure.

This investigation yielded results pertaining to both the methods and mechanisms of laser tissue welding. The combination of two-color infrared thermometry to obtain accurate surface temperatures free from emissivity bias and computer modeling illustrated the importance of including evaporation in the simulations, which effectively serves as an inherent cooling mechanism during laser irradiation. Moreover, the hydration state predicted by the model was useful in assessing the role of electrostatic versus covalent bonding in the fusion. These tools also helped elicit differences between dye-enhanced liquid solders and solid-matrix patches in 1 laser-assisted tissue welding, demonstrating the significance of repeatable energy delivery: Surprisingly, covalent bonds between collagen molecules (crosslinks) were formed in tissue when exposed to the commonly used absorbing chromophore indocyanine green (ICG) prior to laser irradiation, which restored the crosslink concentrations to their native levels. Crosslinks were either created or destroyed during exposure to green laser light without any extrinsic materials or chromophores, which may impact the acute and long-term strength and stability of laser welded tissues. FTIR spectra revealed changes in collagen conformation (molecular structure) induced by laser heating as a function of temperature, elucidating the dynamics of the denaturation process.

\section{References:}

1. Bass LS, Treat MR. Laser tissue welding: A comprehensive review of current and future clinical applications. Lasers Surg Med 1995; 17:315-349.

2. Krueger RR, Almquist EE. Argon laser coagulation of blood for the anastomosis of small vessel. Lasers Surg Med 1985; 5:55-60.

3. Poppas DP, Schlossberg SM, Richmond IL, Gilbert DA, Devine CJ. Laser welding in urethral surgery: Improved results with a protein solder. J Urology 1988; 139:415-417.

4. $\mathrm{Oz}$ MC, Chuck RS, Johnson JP, Parangi S, Bass LS, Nowygrod R, Treat MR. Indocyanine green dye enhanced vascular welding with the near infrared diode laser. Vasc Surg 1990; 24(8):564-570. 
5. Oz MC, Johnson JP, Parangi S, Chuck RS, Marboe CC, Bass L.S, Nowygrod R, Treat MR. Tissue soldering using indocyanine green dye enhaneed tihminogen with the near infrared diode laser I Vasc Surg 1990. 11(5) 718-725.

6 Okata M, Shimiru h, Jkula H, Horii H. Nahamua h An ahematic mothod of vascular anastomosis by laser. Experimental and clinical study. Lasers Surg Med 1987; 7(3):240248.

7. Okada M, Ikuta H, Shimizu K, Horii H, Tsuji Y, Yoshida M, Nakamura K Experimental and clinical studies on the laser application in the cardiovascular surgery: Analysis of clinical experience of 112 patients. Nippon Geka Gakkai Zasshi 1989; 90(9):15891593. (in Japanese)

8. White RA, White GH, Fujitani RM, Vlassak JW, Donayre CE, Kopchok GE, Peng SK. Initial human evaluation of argon laser-assisted vascular anastomoses. J Vasc Surg 1989; 9(4):542-547.

9. Oz MC, Bass LS, Williams MR, Libutti SK, Benvenisty AI, Hardy M, Treat MR, Nowygrod R. Clinical experience with laser enhanced tissue soldering of vascular anastomoses. (Abstract) Lasers Surg Med Suppl 1991; 3:74.

10. Abergel RP, Lyons R, Dwyer R, White RA, Uitto J. Use of lasers for closure of cutaneous wounds: Experience with Nd:YAG, argon and $\mathrm{CO}_{2}$ lasers. J Dermatol Surg Oncol 1986; 12(11):1181-1185.

11. De Coste SD, Farinelli W, Flotte $T$, Anderson RR. Dye-enhanced laser welding for skin closure. Lasers Surg Med 1992; 12(1):25-32.

12. Burger RA, Gerhárz CD, Bunn H, Engelmann UH, Hohenfellner R. Laser assisted urethral closure in the rat: Comparison of $\mathrm{CO}_{2}$ and neodymium-YAG laser techniques. J Urol 1990; 144:1000-1003.

13. Lynne CM, Carter M, Morris J, Dew D, Thomsen S, Thomsen C. Laser-assisted vas anastomosis: A prcliminary report. Lasers Surg Med 1983; 3:261-263.

14. Lowe BA, Poage MD. Vasovasostomy in th murine vas deferens: Comparison of the $\mathrm{Nd}: Y \Lambda \mathrm{G}$ laser at 1.06 microns and 1.318 microns to the $\mathrm{CO}_{2}$ laser. Lasers Surg Med $1988 ; 8: 377-380$.

15. Fischer DW, Beggs JL, Kenshalo DL, Shetter AG. Comparative study of microcpineural

- anastomoses with the use of $\mathrm{CO}_{2}$ laser and suture techniques in rat sciatic nerve: Part I: Surgical technique, nerve action potentials, and morphological studies. Neurosurgery $1985 ; 17: 300-308$.

16. 'Beggs JL, Fischer DW, Shetter AG. Comparative study of rat sciatic nerve microepineural anastomoses made with carbon dioxide laser and suture techniques: Part 2: A morphometric analysis of myelinated nerve fibers. Neurosurgery 1986; 18:266269.

17. Bass I.S, Moazami N, Avellino A, Trosaborg W, Treat MR. Feasibility studies for laser solder neurorrhaphy. Proc SPIE 1994; 2128:472-475.

18. Small IV W, Heredia NJ, Celliers PM, Da Silva I.B, Fder DC, Glinsky ME, London RA, Maitland DJ, Matthews DL, Soltz BA. Laser tissue welding mediated with a protein solder. In: Lasers in Surgery: Advanced Characterization, Therapeutics, and Systems VI, Proc SPIE 1996; 2671:256-260.

19. Small IV W, Heredia NJ, Celliers PM, Da Silva LB, Eder DC, London RA, Maitland DJ, Matthews DL. Experimental and computational laser tissue welding. Lasers Surg Med Suppl 1996; 8:44.

20. Heredia NJ, Small IV W, Celliers PM, Chang TD, Da Silva LB, Maitland DJ. Experimental formulas of dye-enhanced protein solders for laser tissue welding. Lasers Surg Med Suppl 1996; 8:49.

21. Small IV W, Maitland DJ, Heredia NJ, Eder DC, Celliers PM, Da Silva LB, London RA, Matthews DL. Investigation of laser tissue welding dynamics via experiment and modeling. J Clin Laser Med Surg 1997; 15(1):3-7.

22. Small IV W, Celliers PM. Single-fiber multi-color pyrometry. US Patent Pending. 
23. Small IV W, Celliers PM, Da Silva LB, Matthews DL, Soltz BA. Two-color infrared thermometer for low-temperature measurement using a hollow glass optical fiber. In. Specialty Fiber Optics for Biomedical and Industrial Applications, Proc SPIE, 1997. $2977115-120$

24. Small IV W, Celliers PM, Kopchok GE, Reiser KM, Heredia NJ, Maitland DJ, Eder DC, London RA, Heilbron M, Hussain F, White RA, Da Silva LB, Matthews DL. In vivo argon laser vascular welding using thermal feedback: open and closed loop patency and collagen crosslinking. In: Lasers in Surgery: Advanced Characterization, Therapeutics, and Systems VII, Proc SPIE 1997; 2970:252-256.

25. Reiser KM, Small IV W, Maitland DJ, Heredia NJ, Da Silva LB, Matthews DL, Last JA. Laser welding and collagen crosslinks. In: Lasers in Surgery: Advanced Characterization, Therapeutics, and Systems VII, Proc SPIE 1997; 2970:261-264.

26. Small IV W, Celliers PM, Da Silva LB, Matthews DL. Two-color mid-infrared thermometer using a hollow glass optical fiber. Engineering Foundation Conference on Advances in Optical Technologies for Medicine and Surgery, July 1997.

27. Small IV W, Heredia NJ, Mailland DJ, Da Silva LB, Matthews DL. Dye-enhanced protein solders and patches in laser-assisted tissue welding. J Clin Laser Med Surg 1997; 15(5):205-208.

28. Small IV W, Heredia NJ, Maitland DJ, Eder DC, Celliers PM, Da Silva LB, London RA, Matthews DL. Experimental and computational laser tissue welding using a protein patch. J Biomedical Optics 1998; 3(1):96-101.

29. Small IV W, Celliers PM, Kopchok GE, Reiser KM, Heredia NJ, Maitland DJ, Eder DC, London RA, Heilbron $M$, Hussain F, White RA, Da Silva LB, Matthews DL. Tempcrature feedback and collagen crosslinking in argon laser vascular welding. Lasers Med Sci, in press.

30. Small IV W, Da Silva LB, Matthews DL. Spectroscopic study of the effect of laser heating on collagen stability: Implications for tissue welding. In: Lasers in Surgery: Advanced Characterization, Therapeutics, and Systems VIII, Proc SPIE 1998; 3245, in press. 


\title{
Chapter 1
}

Investigation of Laser Tissue Welding Dynamics via Experiment and Modeling

\begin{abstract}
An in vitro study of laser tissue welding mediated with a dye-enhanced protein solder was performed. Freshly harvested sections of porcine aorta were used for the experiments. Arteriotomies approximately $4 \mathrm{~mm}$ in length were treated using an $805 \mathrm{~nm}$ continuous-wave diode laser coupled to a $1 \mathrm{~mm}$ diameter fiber. Temperature histories of the surface of the weld site were obtained úsing a fiber optic-based infrared thermometer. The experimental effort was complemented by the LATIS (LAser-TISsue) computer code, which numerically simulates the exposure of tissue to near-infrared radiation using coupled Monte Carlo, thermal transport, and mass transport models. Comparison of the experimental and sImulated thermal results shows that the inclusion of water transport and evaporative losses in the model is necessary to determine the thermal distributions and hydration state in the tissue. The hydration state of the weld site was correlated with the acute weld strength.
\end{abstract}

\section{INTRODUCTION}

Laser tissue welding is a time-temperature dependent process. The development of the welding procedure has been characterized by the empirical evolution of laser parameters, added chromophores, cooling water drips, and visual cues that meter delivery endpoints [1]. More recently, investigators have utilized feedback control via surface temperature [2] to quantify dynamic changes in parameters relevant to the fusion process. Alone, such a surface-based diagnostic cannot provide information through the depth of the weld site. 
However, computer modeling of the laser-issue interaction can quantify the volumetric energy-based changes that occur durime tissue fusion The combination of experiment and simulation can yield volumetric thermal and hydration information. Hence, when coupled with modeling, a surface temperature diagnostic provides some physical insight to the tissue fusion process. This investigation used a surface temperature monitoring system to measure tissue hydration dynamics, and the results were correlated with weld burst pressure measurements. The LATIS (LAser-TISsue) computer code simulated the exposure of tissue to near-infrared radiation using coupled Monte Carlo, thermal transport, and mass transport models [3].

\section{MATERIALS AND METHODS}

\section{Tissue preparation}

Porcine aortas were freshly harvested and kept in sealed, refrigerated $\left(5^{\circ} \mathrm{C}\right)$ containers prior to welding. Arterial wall thickness ranged from $2-3 \mathrm{~mm}$. The arteries were cut into approximately $3 \times 3 \mathrm{~cm}$ slabs, and an incision $4 \mathrm{~mm}$ in length was made through the thickness of each slab. The slabs were bathed in phosphate-buffered saline to remove any blood and inhibit desiccation prior to welding. No stay sutures were used to appose the edges of the incision. The purpose of using slabs rather than the innate tubular structure of the arteries is associated with the method used for strength assessment. A burst/leak pressure chamber was used to test the acute strength of the welds.

\section{Energy delivery}

Laser energy from an $805 \mathrm{~nm}$ continuous-wave diode laser was delivered to the weld site via a $1 \mathrm{~mm}$ diameter fiber. The fiber tip was positioned $13 \mathrm{~mm}$ away from the intima surface at an 
angle of incidence of about $30^{\circ}$ from normal, yielding a spot size approximately $1 \mathrm{~cm}$ in diamete ( $/$ WHM) Approximately $15 \mu$ of a water-based solder consisting of human albumin $(40 \%$ weight-by-volume $(w / v))$ and indocyanine green (ICG) dye was applied to the intima using a micropipette. Some welds were done using the solder with $0.25 \% \mathrm{w} / \mathrm{v}$ ICG, and others were done using $0.50 \% \mathrm{w} / \mathrm{v}$ ICG. The solder was injected directly into the incision and applied to the surrounding area covered by the laser spot.

\section{Temperature monitoring}

A fiber optic-based infrared thermometry system was constructed to acquire surface temperatures during the course of the welding procedure. Radiation was collected from the surface of the weld site using two silver halide fibers directed to a common spot within the

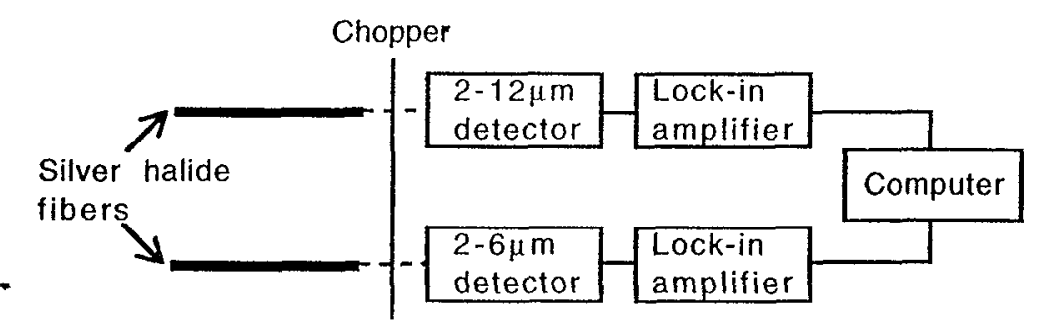

Fig. 1. The infrared thermometry system. Radiation is collected via two silver halide fibers directed to a common spot, modulated by a chopper, and transported to two detectors of different spectral bandpass. The modulated signals are recovered using lock-in amplification and sent to a computer for real-time temperature calculation. laser spot, modulated by an optical chopper, and transported to two thermoelectrically-

cooled $\quad \mathrm{HgCdZnTe}$ photoconductors. The spectral bandpasses of the detectors were $2-6$ $\mu \mathrm{m}$ and $2-12 \mu \mathrm{m}$, respectively. Lock-in amplification was used

to recover the modulated detector signals. The system was calibrated using a blackbody of known temperature varied from $10^{\circ} \mathrm{C}$ to $170^{\circ} \mathrm{C}$. A calibration formula was determined and encoded into a computer for real-time temperature data acquisition. A schematic diagram of the system is shown in Figure 1. 


\section{Modeling}

The LATIS computer code simulated the exposure of solder-covered artery to near-intrared radiation using coupled Monte Carlo, thermal transport, and mass transport numerical models. LATIS was applied in a two-dimensional geometry using a gaussian laser spot of 1 $\mathrm{cm}$ (FWHM) to characterize the dynamic changes associated with the laser irradiation. All results are derived at the center of the laser spot for a solder layer thickness of $200 \mu \mathrm{m}$. The solder inside the incision was not modeled.

\section{Strength assessment}

Burst pressure was used to quantify the integrity of each weld immediately following completion of the welding procedure. Each artery slab was positioned in a pressure chamber such that the intima faced the inside to simulate actual blood flow. Phosphatebuffered saline was pumped into the pressure chamber at a rate of $3 \mathrm{ml} / \mathrm{min}$. The pressures indicated by a pressure

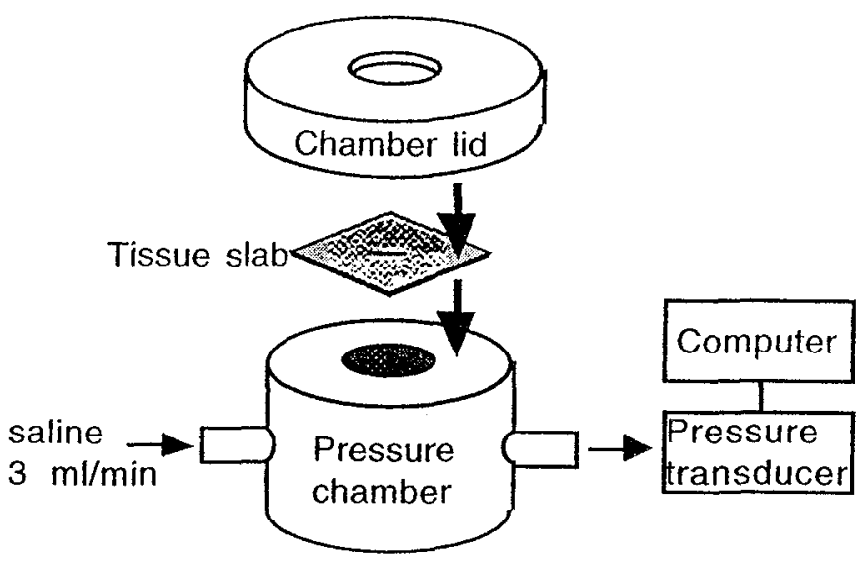

Fig. 2. Burst pressure measurement apparatus. The welded tissue slab is clamped between the lid and body of the chamber (intima down). Saline is infused into the chamber at a rate of $3 \mathrm{ml} / \mathrm{min}$ until the weld bursts. A computer records the pressures measured by the pressure transducer as a function of volume of infused saline. transducer connected to the chamber were recorded by a computer as a function of volume of infused saline. The burst pressure was noted as the highest pressure reached, corresponding to 
the observed bursting of the weld. A schematic diagram of the burst pressure measurement apparatus is shown in figure 2

\section{RESULTS}

\section{Thermal dynamics}

Figure $\quad 3 \quad$ shows experimentally measured solder surface temperature histories at the center of the laser spot for various lạser powers. The solder surface temperature remained below $100^{\circ} \mathrm{C}$ initially, but would sometimes begin to increase again to much higher temperatures. A sharp decrease in temperature occurred when the laser was turned off. The solder and tissue surface appeared drier for trials in which the peak temperature exceeded $100^{\circ} \mathrm{C}$ relative to the surface

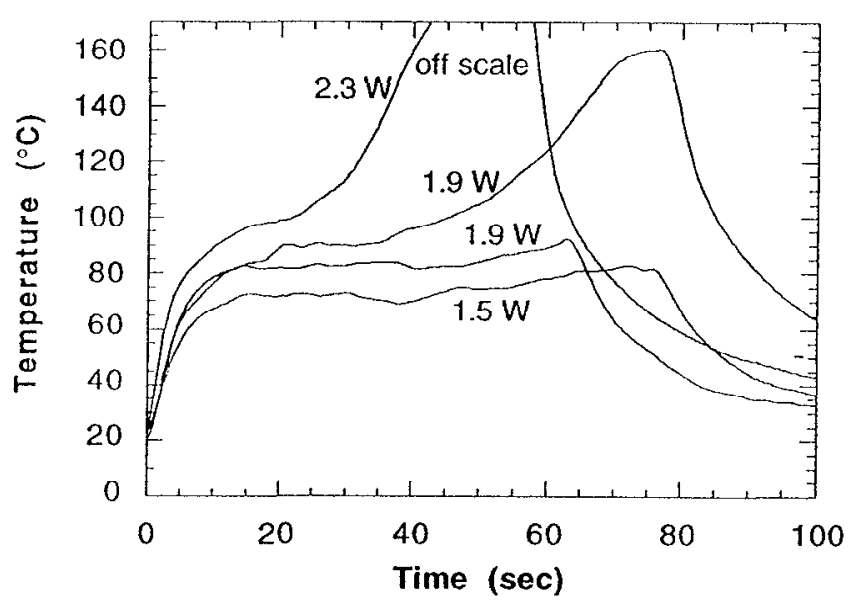

Fig. 3. Experimental temperature histories of the solder surface for laser powers of 1.5, 1.9, and $2.3 \mathrm{~W}$. After the laser is turned on, the temperature rises and settles within the first 15 seconds, never reaching $100^{\circ} \mathrm{C}$, and then sometimes rises again beyond $100^{\circ} \mathrm{C}$ before the laser is turned off. The data for $2.3 \mathrm{~W}$ exceeded the thermometer calibration limit of $170^{\circ} \mathrm{C}$. The laser exposure time varied for the four cascs shown. The exposure time can be read from the peak temperature in each curve (e.g. $75 \mathrm{sec}$ for $1.5 \mathrm{~W}$ ). The exposure time for the $2.3 \mathrm{~W}$ case (off scale), was $50 \mathrm{sec}$.

appearance for those trials where the peak temperature remained below $100^{\circ} \mathrm{C}$. In general, higher laser powers caused the second temperature increase to occur sooner, and the 
temperature at which the surface settled prior to the second increase varied directly with the laser power However, differing behaviors of the temperature histories for the same laser power sometimes resulted.

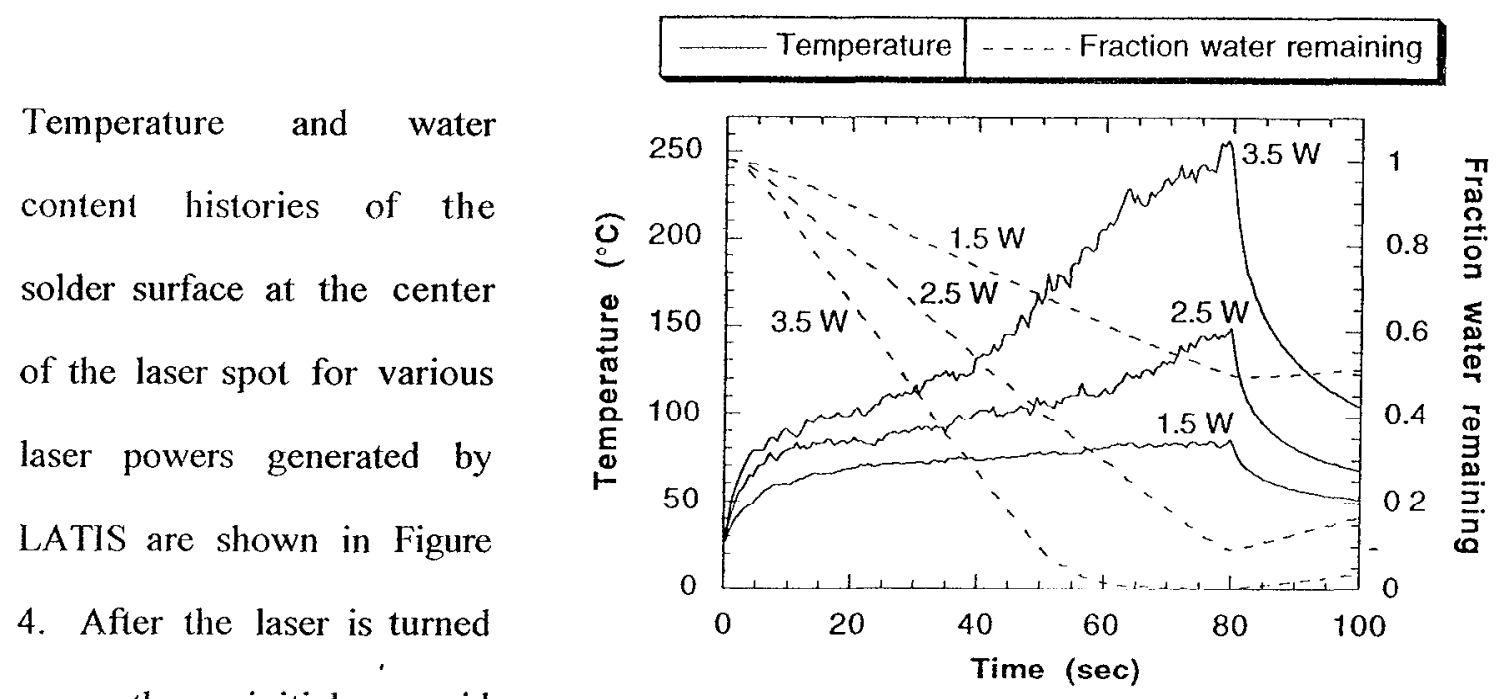

on, the initial rapid temperature rise begins to slow down before the surface reaches $100^{\circ} \mathrm{C}$, and the water content of the solder gradually decreases. For sufficiently high laser power, a second temperature increase occurs when the water content drops to $20 \%$ of its initial value. The temperature achieved prior to the second increase varies directly with the laser power. A sharp decrease in

Fig. 4. Simulated temperature and surface water content histories of the solder surface for laser powers of 1.5, 2.5, and $3.5 \mathrm{~W}$. The laser is turned on from 0 to 80 seconds. After the laser is turned on, the initial temperature rise begins to slow down before the surface reaches $100^{\circ} \mathrm{C}$, and the water content gradually decreases. For the $2.5 \mathrm{~W}$ and $3.5 \mathrm{~W}$ data, the slope of the temperature rise increases again when the fraction of water remaining drops to 0.20 . The increase in the surface water content that occurs after the laser is turned off is a result of water diffusing from the subsurface to the surface. The solder layer thickness is $200 \mu \mathrm{m}$. The temperature curves are noisy due to the Monte Carlo laser transport model. 
temperature and an increase in water content occur at the solder surface after the laser is turned off

Figure 5 shows the simulated temperature and water content profiles through the depth of the solder-covered tissue at the center of the laser spot for the same laser powers of Figure 4. The profiles correspond to the time of laser shutoff. The entire thickness of the tissue is heated, with the highest temperature occurring in the middle of the solder layer. The entire solder layer and top $200 \mu \mathrm{m}$ of the tissue experience a decrease in water content. Higher laser powers result in deeper and more severe water loss.

\section{Weld strength}

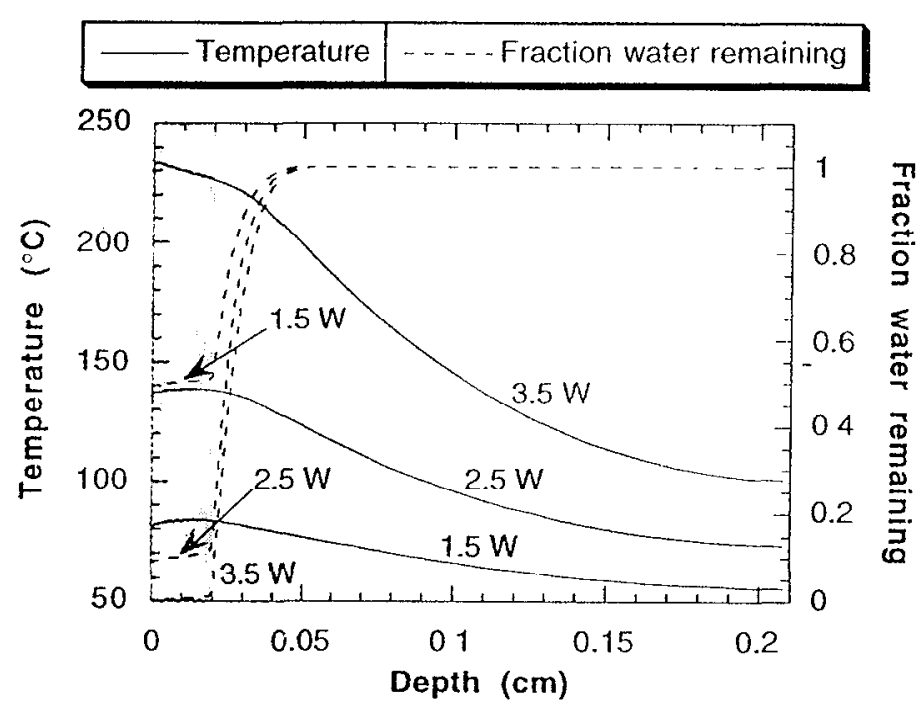

Fig. 5. Full solder/tissue thickness simulated temperature and water content profiles at the time of laser shutoff for laser powers of $1.5,2.5$, and $3.5 \mathrm{~W}$. The laser exposure time was 80 seconds. The solder layer thickness is $200 \mu \mathrm{m}$ (shaded region). The entire solder layer and top $200 \mu \mathrm{m}$ of the tissue experience water loss.

Trials in which the weld site was not desiccated were compared to trials in which desiccation occurred. The state of hydration was determined by temperature history data, and confirmed by observation. For both cases, approximately $150 \mathrm{~J}$ of energy was delivered. The desiccated samples received solder with twice the amount of ICG, allowing for more efficient absorption of the laser energy. The non-desiccated samples averaged a steady temperature of $78^{\circ} \mathrm{C}$, while those that 
desiccated averaged a peak temperature of $156^{\circ} \mathrm{C}^{\circ}$ before the laser was turned off. Figure 6 shows that non-desiccated welds yielded burst pressures that are slightly higher on average than those of desiccated welds. Both non-desiccated and desiccated welds achieved burst pressures in the area of $300 \mathrm{mmHg}$. These pressures exceed vascular physiologic pressures, which are generally below $200 \mathrm{mmHg}$.

\section{DISCUSSION}

Inclusion of water transport and evaporation in the model is important for accurately simulating the time-dependent temperature distributions in the laser-irradiated tissue: Various

\section{,}

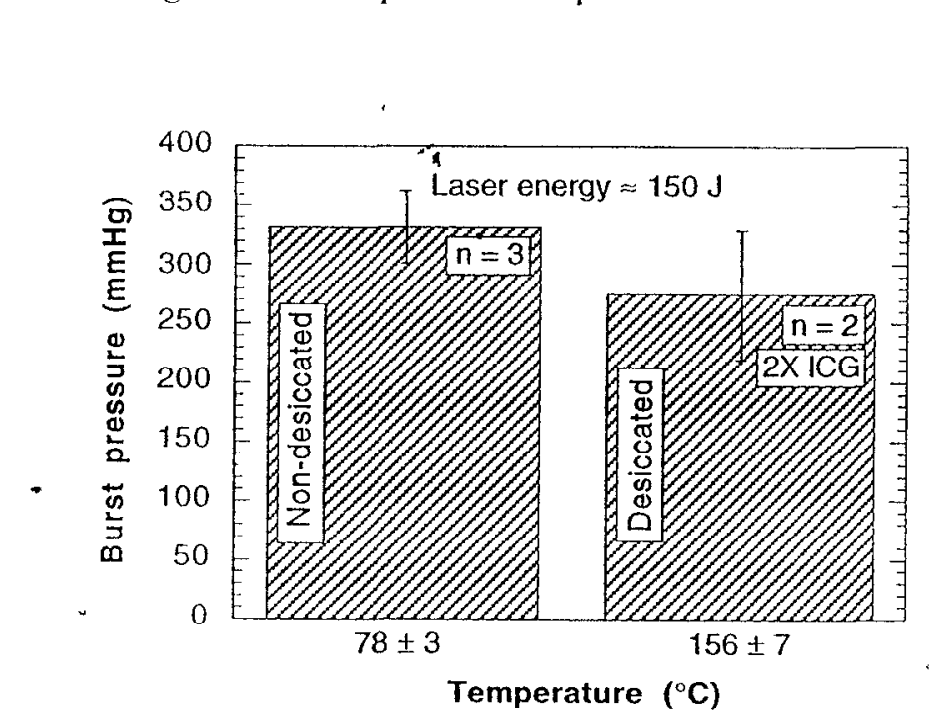

Fig. 6. Burst pressures for non-desiccated and desiccated welds. The desiccated welds were done using a solder with twice the ICG content of that used for the non-desiccated welds.

All samples were irradiated with a laser energy of $150 \mathrm{~J}$. The data suggests that non-desiccated welds may be slightly stronger than those in which desiccation occurred. laser powers are modeled that demonstrate the observed surface temperature behavior. Without evaporation, the model yields unrealistically high temperature distributions that contradict our experimental observations (data not shown in figures). This result is indicated indirectly in the simulations in which the water content is severely depleted, which prevents evaporative cooling. With evaporation, LATIS predicts temperature 
distributions that qualitatively agree with our observations The cooling effect of evaporation was also noted in a previous modeling study 147. Water diffusion from the cooler depths toward the hotter surface also results in cooling [3], though its contribution is more apparent after the laser is turned off and evaporation stops.

The simulated water content demonstrates the desiccation of the tissue and solder as the solder layer is depleted by evaporation, which occurs as long as the surface temperature is sufficiently elevated. It follows that excessive depletion of water will inhibit cooling of the surface via evaporation, allowing the temperature to increase well beyond $100^{\circ} \mathrm{C}$. Therefore, the experimentally measured sharp temperature rise following the period of evaporative cooling is attributed to solder/tissue desiccation. It is possible that different samples desiccated at different times for the same delivered power as a consequence of non-uniform thickness of the liquid solder layer. LATIS simulations using various solder layer thicknesses indicate that thinner solder layers desiccate sooner and yield higher temperatures for the same incident laser power (data not shown in figures).

Adequate hydration (provided by the water-based solder) inhibits desiccation, allowing for welding at controlled surface temperatures dependent on the laser power. Previous experiments by R.A. White et al have demonstrated that the use of a saline drip during the welding procedure can also be employed to cool the tissue in the absence of solder [5-8]. Both techniques exploit evaporation to limit the surface temperature by means of adequate hydration.

Similar weld strengths for non-desiccated and desiccated samples may shed some light on the bonding mechanism for laser tissue fusion. The bonding associated with desiccated samples is most likely electrostatic in nature [9], while a different mechanism may be responsible for the strength-bearing bonds formed when no desiccation occurs. When water is present, it will 
preferentially bond electrostatically to the available sites on the collagen molecule. When water is not present, those sites are available for electostatic bonding with other proteins (e.g. albumin and/or collagen). It has been demonstrated that such electrostatic proteinprotein bonds, though inherently strong, weaken when rehydrated [9]. The acute strength of non-desiccated welds (i.e. those in which water occupies the electrostatic bond sites) shown in this study and by White et al [5-8] implies that another, possible covalent, bonding mechanism may be responsible for the fusion. Furthermore, the burst pressure results indicate that the bonding mechanism associated with non-desiccated welds may be acutely stronger than that of desiccated welds. Additional work needs to be done to verify this result statistically. Because both hydration states yielded burst pressures above $200 \mathrm{mmHg}$, it is possible that multiple bonding mechanisms for tissue fusion exist.

\section{CONCLUSION AND SUMMARY}

The numerical simulations of LATIS show, and experimental results confirm, that evaporation serves to limit the surface temperature at the weld site. Through adequate hydration, in this case via the solder, the surface temperature can be clamped below $100^{\circ} \mathrm{C}$ during laser irradiation. The temperature at which the surface settles due to evaporative cooling is governed by the laser power. If the weld site becomes sufficiently desiccated, the surface temperature will no longer be limited by evaporation.

Welds of both non-desiccated and desiccated hydration states were able to withstand vascular physiologic pressures immediately following the welding procedure. The acute strength of the non-desiccated welds seems to be slightly greater than those in which desiccation occurred. 
The combination of experiment and modeling allow for the dynamic determination of the hydration state of the weld site Such volumetic information used in conjunction with weld strength assessment provides an interesting tool for investigating the mechanisms of laser tissue fusion.

\section{ACKNOWLEDGMENTS}

This work was performed under the auspices of the U.S. Department of Energy by Lawrence Livermore National Laboratory under Contract W-7405-ENG-48 as part of the Cooperative Research and Development Agreement TC-1085-95 with Conversion Energy Enterprises of Spring Valley, New York. The authors wish to thank L. Bass for his advice in the development of the protein solder. The authors also wish to thank J. Cox and K. Haney for their help in fabricating the experimental apparatus.

\section{REFERENCES}

1. Bass LS, Treat MR. Laser tissue welding: A comprehensive review of current and future clinical applications. Lasers Surg Med 1995; 17:315-349.

2. Poppas DP, Stewart RB, Massicotte JM, et al. Temperature-controlled laser photocoagulation of soft tissue: In vivo evaluation using a tissue welding model. Lasers Surg Med 1996; 18:335-344.

3. Maitland DJ, Eder DC, London RA, Glinsky ME, Soltz BA. Dynamic simulations of tissue welding. In: Lasers in Surgery: Advanced Characterization, Therapeutics, and Systems VI, Proc SPIE 1996; 2671:234-242.

4. Torres JH, Motamedi M, Pearce JA, Welch AJ. Experimental evaluation of mathematical models for predicting the thermal response of tissue to laser irradiation. Appl Opt 1993; 32:597-606.

5. White RA, Kopchok GE, Donayre C, et al. Comparison of laser-welded and sutured arteriotomies. Arch Surg 1986; 121:1133-1135.

6. Vlasak JW, Kopchok GE, Fujitani RM, White RA. Argon laser vascular fusion: Venous and arterial bursting pressures. Lasers Surg Med 1989; 9:478-481.

7. Murray LW, Su L, Kopchok GE, White RA. Crosslinking of extracellular matrix proteins: A preliminary report on a possible mechanism of argon laser welding. Lasers Surg Med 1989; 9:490-496.

8. Guthrie CR, Murray LW, Kopchok GE, Rosenbaum D, White RA. Biochemical mechanisms of laser vascular tissue fusion. J Invest Surg 1991; 4:3-12. 
9. Fenner J, Martin W, Moseley H, Wheatley DJ. Shear strength of tissue bonds as a function of bonding temperature: a proposed mechanism for laser-assisted tissue welding. I asers Med Sci 1992; 7:39-43. 


\title{
Chapter 2
}

Dye-Enhanced Protein Solders and Patches in I aser-Assisted Tissue Welding

\begin{abstract}
Objective: This study examines the use of dye-enhanced protein bonding agents in $805 \mathrm{~nm}$ diode laser-assisted tissue welding. A comparison of an albumin liquid solder and collagen solid-matrix patches used to repair arteriotomies in an in vitro porcine model is presented.

Summary Background Data: Extrinsic bonding media such as solders and patches have been used to enhance the practice of laser tissue welding. Preferential absorption of the laser wavelength has been achieved by the incorporation of chromophores.

Methods: Both the solder and the patch included indocyanine green dye (ICG) to absorb the $805 \mathrm{~nm}$ continuous-wave diode laser light used to perform the welds. Solder-mediated welds were divided into two groups (high power/short exposure and low power/long exposure), and the patches were divided into three thickness groups ranging from 0.1 to $1.3 \mathrm{~mm}$. The power used to activate the patches was constant, but the exposure time was increased with patch thickness.

Results: Burst pressure results indicated that solder-mediated and patched welds yielded similar average burst strengths in most cases, but the patches provided a higher success rate (i.e., more often exceeded $150 \mathrm{mmHg}$ ) and were more consistent (i.e., smaller standard deviation) than the solder. The strongest welds were obtained using $1.0-1.3 \mathrm{~mm}$ thick patches, while the high power/short exposure solder group was the weakest.

Conclusions: Though the solder and patches yielded similar acute weld strengths, the solidmatrix patches facilitated the welding process, and provided consistently strong welds. The material properties of the extrinsic agents influenced their performance.
\end{abstract}




\section{INTRODUCTION}

the advent of the indocyanine green dye (ICG)-enhanced protein solder opened a new door in the realm of laser tissue welding [1,2]. The use of protein as an extrinsic bonding medium offers potential improvements in weld strength and repeatability, while incorporation of the absorbing chromophore ICG creates a target with predictable absorption characteristics and invites the use of the less expensive, more compact low-power near-infrared diode laser as the welding source [3]. In addition to providing extra strength, the increased surface area over which the solder may bond to the tissue, which extends beyond the tissue edges to be joined, increases the probability of creating a successful weld. The preferential absorption of the laser energy by the topical solder helps reduce the extent of collateral thermal damage of the underlying tissue, which becomes important during the period of healing following the welding procedure.

Bass et al [3] initiated the incorporation ICG to selectively absorb near-infrared laser light into an albumin-based solder, the development and application of which was pioneered by Poppas et al [4]. In contrast to the more common liquid solders, Sawyer [5] championed the use of a solid-matrix collagen-based material for tissue welding. To elicit the similarities and differences associated with these formulations, in this study we compare the in vitro acute weld strengths and patency rates yielded by two different ICG-enhanced bonding agents activated by an $805 \mathrm{~nm}$ diode laser. One agent was an albumin liquid solder, and the other was a collagen solid-matrix patch. Qualitative observations based on the material properties of the agents as well as quantitative burst pressure measurements are presented. 


\section{MATERIALS AND METHODS}

\section{Tissue preparation}

Porcine aortas were freshly harvested and kept refrigerated $\left(5^{\circ} \mathrm{C}\right)$ in sealed containers prior to welding. Arterial wall thickness was approximately $2 \mathrm{~mm}$. The arteries were cut into $3 \times 3 \mathrm{~cm}$ slabs, and an incision $4 \mathrm{~mm}$ in length was made through the thickness of each slab. The slabs were soaked in phosphate-buffered saline (PBS) for several minutes to prevent desiccation prior to laser exposure. No stay sutures were used to appose the edges of the incision. The purpose of using slabs rather than the innate tubular structure of the arteries is associated with the burst/leak pressure chamber used for strength assessment.

\section{Welding protocols}

The tissue was placed on a glass substrate with the intima facing upward. Either $15 \mu \mathrm{l}$ of a water-based solder was applied to the region of the incision, or a water-based solid-matrix patch was placed over the incision. The solder consisted of $60 \%$ weight-by-volume (w/v) human albumin and $0.5 \% \mathrm{w} / \mathrm{v}$ ICG, resulting in a fairly low-viscosity liquid. The albumin comprised $38 \%$ of the total solder weight. The patches consisted of $60-70 \% \mathrm{w} / \mathrm{v}$ porcinederived gelatin (denatured collagen) and $0.25 \%$ w/v ICG. The gelatin comprised $38-41 \%$ of the total patch weight. The patches were made by dissolving the gelatin and ICG in water, sandwiching the mixture bewteen two glass slides, applying heat to melt and form the gelatin mixture into patches of various thicknessess $(10 \times 10 \times 0.1-1.3 \mathrm{~mm})$, and allowing them to cool and solidify. In their final form, the patches were solid, but soft and pliable.

Laser energy from an $805 \mathrm{~nm}$ continuous-wave diode laser was delivered to the weld site via a $1 \mathrm{~mm}$ diameter silica optical fiber. The fiber tip was positioned $13 \mathrm{~mm}$ above the 
solder/patch surface, yielding a spot size approximately $7 \mathrm{~mm}$ in diameter (FWHM). The solder-mediated welds were divided into two groups hased on laser power delivered within the $7 \mathrm{~mm}$ spot and exposure time: $1.6 \mathrm{~W}$ for $38 \mathrm{~s}$ (average fluence $\approx 160 \mathrm{~J} / \mathrm{cm}^{2}$ ) and $1.3 \mathrm{~W}$ for $70 \mathrm{~s}$ (average fluence $\approx 240 \mathrm{~J} / \mathrm{cm}^{2}$ ) The patched welds were divided into three groups based on patch thickness and exposure time (all patched welds received $0.6 \mathrm{~W}$ within the $7 \mathrm{~mm}$ spot): $0.1-0.2 \mathrm{~mm}$ thick, $90 \mathrm{~s}$ (average fluence $\approx 140 \mathrm{~J} / \mathrm{cm}^{2}$ ); $0.5 \mathrm{~mm}$ thick, $150 \mathrm{~s}$ (average fluence $\approx 230 \mathrm{~J} / \mathrm{cm}^{2}$ ); and $1.0-1.3 \mathrm{~mm}$ thick, $180 \mathrm{~s}$ (average fluence $\approx 280 \mathrm{~J} / \mathrm{cm}^{2}$ ).

\section{Strength assessment}

Burst pressure was used to quantify the integrity of each weld immediately following completion of the welding procedure. Each artery slab was positioned in a pressure chamber such that the intima faced the inside to simulate actual blood flow. PBS was pumped into the

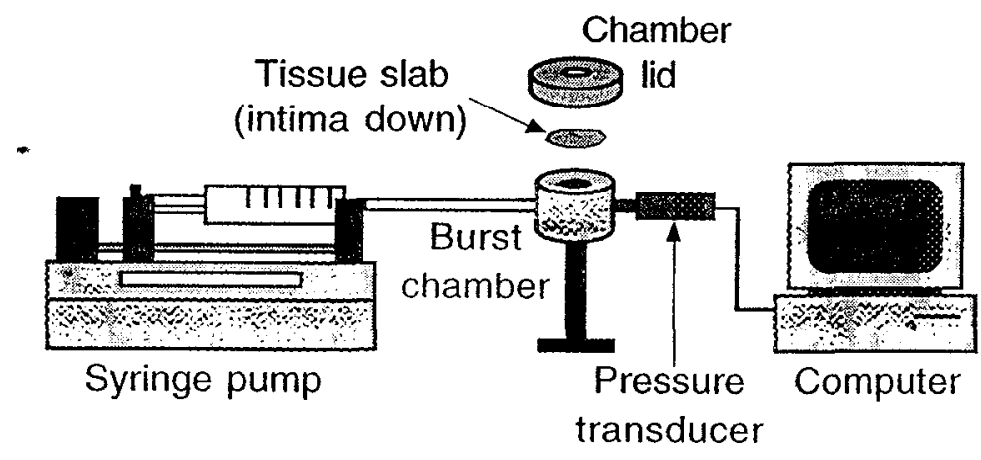

Fig. 1. Burst pressure measurement apparatus.

The patched tissue slab is clamped (intima down) between the lid and body of the chamber which is filled to the top with saline. Saline is infused into the chamber via a syringe pump at a rate of $3 \mathrm{ml} / \mathrm{min}$ until the weld bursts.

$\Lambda$ computer records the pressures measured by the pressure transducer as a function of time. chamber at a rate of 3 $\mathrm{ml} / \mathrm{min}$ using a Harvard syringe pump. The pressures indicated by a pressure transducer connected to the chamber were recorded by a computer as a function of time. The burst pressure was noted as the highest pressure reached, corresponding to the observed bursting of the weld. A diagram of the 
burst pressure measurement apparatus is shown in Figure 1. Because exposure to blood was shown to enhance the acute strength of in vivo vascular laser welds, the in vitro strength measured here may be significantly lower than would be realized in vivo after allowing blood flow to resume [6].

\section{Statistical analysis}

Analysis of variance was used to determine if mean burst pressures differed from group to group [7]. Significance was set at the $5 \%$ level.

\section{RESULTS}

Burst pressures of the solder-mediated and patched welds are shown in Figure 2 . The strongest welds $($ mean $=481 \mathrm{mmHg}$ ) were obtained using the $1.0-1.3 \mathrm{~mm}$ thick patches, while the higher power/shorter exposure solder group exhibited the weakest welds (mean $=194$ $\mathrm{mmHg}$ ). The other three groups (lower power/longer exposure solder and 0.1-0.2 $\mathrm{mm}$ and $0.5 \mathrm{~mm}$ thick patches) yielded weld strengths around $300 \mathrm{mmHg}$. The standard deviations of the three patch groups were lower than those of the two solder groups, suggesting that the patches reduced variation in weld strength.

Figure 3 shows the success rates of each group (welds that burst above $150 \mathrm{mmHg}$ were considered successful). The patches were more successful than the solder, never producing a weld that burst below $150 \mathrm{mmHg}$ (the weakest patched weld withstood a pressure of 217 $\mathrm{mmHg})$. 


\section{DISCUSSION}

\section{Solder performance}

The performance (both strength and success) of the solder-mediated welds was improved by decreasing the laser power and increasing the time of exposure. This result suggests that the optimization of solder-mediated welding depends on not only the peak temperature, but also

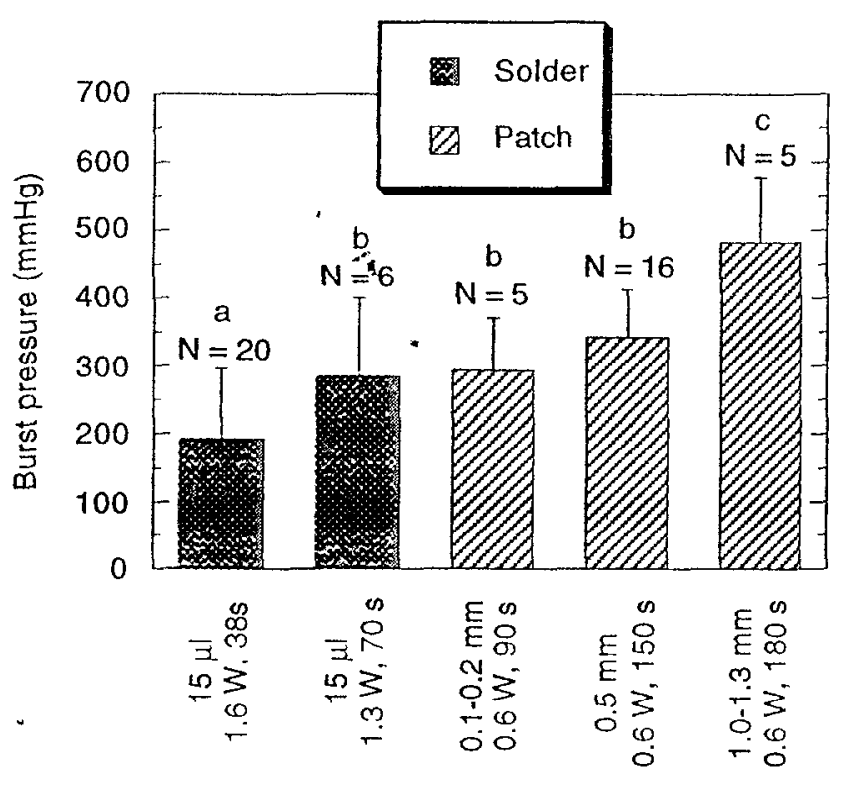

Fig. 2. Mean burst pressures for the soldermediated and patched welds. The volume of solder applied and the patch thickness are noted along with the laser delivery parameters for each group. The number of samples $(N)$ in each group is also noted. The error bars represent the standard deviation. Groups with different superscripts are significantly different ( $5 \%$ level of significance). on the temperature history at the weld site. In addition to the amount - of laser energy absorbed by the solder (dictated by the laser power and duration and the concentration of ICG), the physical deposition of the solder on the tissue surface also affects the temperature history. A previous soldermediated laser tissue welding temperature study indicated that the cooling effect of evaporation decreases as the amount of hydration decreases, which suggests that variations in the solder thickness will influence the temperature history $[8]$. In 
this light, the temperature history differences between the two solder groups is unclear due to inconsistent solder thicknesses among trials (the $15 \mu$ volume of solder distributed itself differently depending on the contours of the tissue surface). However, the fact that the energy delivered in the lower power/longer exposure group was $50 \%$ higher than that of the other group suggests that its water content was more severely depleted, and, therefore, may have reached higher temperatures.

Patch performance

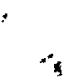

\section{The 1.0-1.3 $\mathrm{mm}$ thick} patches averaged stronger welds than the $0.1-0.2 \mathrm{~mm}$ and $0.5 \mathrm{~mm}$ thick patches. Though the different thicknesses were irradiated for different times in order to achieve thorough melting of the patch (visually determined), the apparent increase in strength associated with the 1.0 $1.3 \mathrm{~mm}$ thick patches is most likely due to the greater material strength of the thicker patches. Previous modeling results (obtained using the LATIS $[9,10]$ computer code) showed that evaporative cooling at the surface is strong until the water content drops to approximately $20 \%$ of its initial value [8]. Since water from the cooler depths of the patch 
and tissue diffuse toward the surface to replace the water that was lost via evaporation, the subsurface temperatmes are also tempered during evaporation Because the patches did not visually exhibit such severe desiccation, and the same laser power was used for all three groups, their temperature histories were probably quite similar. Though not as strong as the thicker patches, the thinner patches, which may be more appropriate in clinical applications (particularly if they are delivered endoscopically and applied in the blood vessel lumen [11]), also yielded burst pressures which comfortably exceed physiologic vascular pressures. However, the patches used in this study would not be viable under in vivo conditions due to their solubility and low melting temperature. Sawyer [5] noted a similar phenomenon when using gelatin-based solid-matrix materials for laser-assisted tissue welding. Whether- or not a physiologically compatible gelatin patch can be developed is unknown.

\section{Influence of material properties}

The material properties of the solder and patches influenced their effectiveness in vascular welding. Inconsistent solder application may have contributed to the increased variation and, hence, lower success rate of the solder-mediated welds compared to the patched welds. In addition to affecting the thermal dynamics, uneven solder deposition affected the physical properties of the soldered tissue junction. Because of the relatively low-viscosity of the solder, it tended to puddle in some places and run off in others, depending on the contours of the artery surface. As a result, the laser-heated solder appeared to form a "cast" over the incision in some instances and a "plug" in the incision in others. In either case, the soldertissue bond, as opposed to the joining of the tissue edges, seemed to be responsible for the weld strength, reducing need for precise apposition of tissue edges. Such behavior was noted by Poppas et al [12] and has been observed histologically [3]. 
Uniformity of thickness among patches within each group provided repeatably strong welds that consistently exceeded physiologic vascular pressures. As the patches were heated by the laser light, they gradually melted, completely sealing the incision as they bonded to the artery surface. Like the solder-mediated welds, the weld strength yielded by the patches derived from the patch-tissue fusion rather than tissue-tissue fusion, as the patch material had penetrated into the incision as it melted. Also, as the tissue bulged outward during the burst pressure measurements, the incisions were clearly open, illustrating the fact that the patchtissue bond was responsible for the strength--the tissue edges did not fuse together. The mechanism, therefore, is analogous to the solder "cast" described earlier, and has been observed in previous patch welding studies $[5,13]$. The high success rate can be attributed to the large patch-tissue fusion surface area combined with the inherent material strength of the uniform solid-matrix pateh.

\section{CONCLUSION}

Welds were performed using an albumin liquid solder and collagen solid-matrix patches, both of which were activated by a fiber-delivered near infrared diode laser. Both types of laserassisted welds are based on the fusion of the tissue to the extrinsic medium rather than the actual joining of apposed tissue edges. Though the solder-mediated welds using lower power for longer times provided similar strength to the thinner patches $(\approx 300 \mathrm{mmHg})$, their success rate was nearly $20 \%$ lower. This result may stem, at least partly, from the inconsistent application of the solder to the area of the incision, and the spatially nonuniform bonding of the solder to the tissue. The patches, on the other hand, provided a uniformly thick absorbing target for the laser, and completely sealed the incision. Although the gelatin-based patches used in this study would not be viable in vivo, they illustrate the potential of the "patch welding" concept, which may be better realized by chemically modifying these

patches or using a different protein constituent. Likewise, increasing the solder viscosity 
such that it becomes more manageable may improve its performance in terms of both strength and success rate Whether a liquid- or solid-form extrinsic agent is used, both its material properties and its ability to bond to tissue need to be factored into the optimization laser-assisted tissue welding.

\section{ACKNOWLEDGMENTS}

This work was performed under the auspices of the U.S. Department of Energy by Lawrence Livermore National Laboratory under Contract W-7405-ENG-48 as part of the Cooperative Research and Development Agreement TC-1085-95 with Conversion Energy Enterprises of Spring Valley, New York. The authors wish to thank L. Bass for his advice in the development of the albumin solder, and J. Cox and K. Haney for their help in fabricating the experimental apparatus.

\section{REFERENCES}

1. Oz MC, Johnson JP, Parangi S, Bass LS, Nowygrod R, Treat MR. Indocyanine green dye -enhanced vascular welding with the near infrared diode laser. Vasc Surg 1990; 24(8):564570 .

2. Oz MC, Johnson JP, Parangi S, Chuck RS, Marboe CC, Bass LS, Nowygrod R, Treat MR. Tissue soldering using indocyanine green dye enhanced fibrinogen with the near infrared diode laser. J Vasc Surg 1990; 11(5):718-725.

3. Bass LS, Treat MR. Laser tissue welding: A comprehensive review of current and future clinical applications. I asers Surg Med 1995; 17:315-349.

4. Poppas DP, Schlossberg SM, Richmond IL, Gilbert DA, Devine Jr DF. Laser welding in urethral surgery: Improved results with a protein solder. II Urol 1988; 139:415-417.

5. Sawyer PN. Collagen welding rod material for use in tissue welding. US Patent No $5156613,1992$.

6. Oz MC, Bass LS, Chuck RS, Johnson JP, Parangi S, Nowygrod R, Treat MR. Strength of laser vascular fusion: Preliminary observations on the role of thrombus, Lasers Surg Med 1990; 10:393-395.

7. Snedecor GW, Cochran WG. One-way classifications: Analysis of variance. In: Statistical Methods. Ames: lowa State University Press 1989:217-236.

8. Small IV W, Maitland DJ, Heredia NJ, Eder DJ, Celliers PM, Da Silva LB, London RA, Matthews DL. Investigation of laser tissue welding dynamics via experiment and modeling. Journal of Clinical Laser Medicine and Surgery 1997; 15(1):3-7.

9. London RA, Glinsky ME, Zimmerman GB, Bailey DS, Eder DC, Jacques SL. Laser-tissue interaction modeling with LATIS. Appl Opt, in press. 
10. Maitland DJ, Eder DC, London RA, Glinsky ME, Soltz BA. Dynamic simulations of tissue welding. In: Lasers in Surgery: Advanced Characterization, Therapeutics, and Systems VI. Proc SPIF, 1996; 2671:234-242.

1) Glinsky ME, London RA, Zimmerman GB. Computer modeling of endovascular patch welding using temperature feedback. In: Medical Applications of Lasers III. Proc SPIE $1996 ; 2623: 349-358$.

12. Poppas DP, Choma TJ, Rooke CT, Klioze SD, Schlossberg SM. Preparation of human albumin solder for laser tissue welding. Lasers Surg Med 1993; 13:577-580.

13. Sensaki K, Arai T, Tanaka S. Laser patch welding: Experimental study for application to endoscopic closure of brochopleural fistula, a preliminary report. Lasers Surg Med $1995 ; 16: 24-33$. 


\title{
Chapter 3
}

Experimental and Computational Laser Tissue Welding Using a Protein Patch

\begin{abstract}
An in vitro study of laser tissue welding mediated with a dye-enhanced protein patch was conducted. Fresh sections of porcine aorta were used for the experiments. Arteriotomies were treated using an indocyanine green dye-enhanced collagen patch activated by an $805 \mathrm{~nm}$ continuous-wave fiber-delivered diode laser. Temperature histories of the surface of the weld site were obtained using hollow glass optical fiber-based two-color infrared thermometer. The experimental effort was complemented by simulations with the LATIS (LAser-TISsue) computer code, which uses coupled Monte Carlo, thermal transport, and mass transport models. Comparison of simulated and experimental thermal data indicated that evaporative cooling clamped the surface temperature of the weld site below $100^{\circ} \mathrm{C}$. For fluences of approximately $200 \mathrm{~J} / \mathrm{cm}^{2}$, peak surface temperatures averaged $74^{\circ} \mathrm{C}$ and acute burst strengths consistently exceeded $0.14 \times 10^{6} \mathrm{dyn} / \mathrm{cm}$ (hoop tension). The combination of experimental and simulation results showed that the inclusion of water transport and evaporative losses in the computer code has a significant impact on the thermal distributions and hydration levels throughout the tissue volume. The solid-matrix protein patch provided a means of controllable energy delivery and yielded consistently strong welds.
\end{abstract}




\section{INTRODUCTION}

Laser tissue welding is a phrase used to describe the act of using laser light with or without extrinsic bonding materials such as protein solders or patches to join, seal, or appose biological tissues. Potential vascular applications include vessel anastomoses, aneurysm closure, and vessel wall reinforcement. Clinical experience has demonstrated the advantages of laser tissue welding over the conventional techniques of suturing and stapling: faster, reduced foreign body response (improved healing), and less susceptible to leakage [1]. However, these advantages are tempered by a lack of reproducibly strong welds.

Extrinsic bonding media such as glues or solders and feedback control have been employed to combat the strength and-fiepeatability issues currently affecting the developing practice of tissue welding [1]. The extrinsic agents provide a large surface area over which fusion with the tissue can occur, approximating tissue edges which eventually heal together in the days following laser treatment. In addition, incorporation of laser absorbing chromophores enables localized surface heating confined to the area of solder application, which reduces the extent of collateral thermal damage of the underlying tissue. Diagnostic feedback via surface temperature measurement has been used to control laser power delivery to achieve welldefined welding protocols en route to optimization [2-4].

Although a diagnostic such as surface temperature is important for primary control of the energy delivery, it does not reveal dynamic changes occuring below the tissue surface, where the weld actually occurs. This problem has been addressed by employing a numerical model of the laser-tissue interaction based on experimentally obtained surface temperature data [57]. The combination of experiment and simulation enables characterization of the status of the tissue and the progression of the weld. 
In this study, a laser-activated dye-enhanced collagen patch of uniform thickness was used to initiate repeatable repair of an arteriotomy in vitro, while a hollow glass optical fiber-based two-color infrared thermometer provided surface temperature data. The temperature histories were used in conjunction with the LATIS (LAser-TISsue) computer code to characterize the volumetric patch/tissue temperature distribution and hydration state. Consistent energy absorption of the uniform patch facilitated both the welding procedure and the subsequent computational analysis.

\section{MATERIALS AND METHODS}

\section{Tissue preparation}

Porcine hearts and the surrounding vasculature were freshly harvested (no rinsing during harvest) and kept refrigerated $\left(5^{\circ} \mathrm{C}\right)$ in sealed containers (not immersed in any fluid or wrapped in gauze) for 3 to 30 hours prior to use. The aortas were dissected out within one hour prior to welding. Arterial wall thickness was approximately $2 \mathrm{~mm}$. The arteries were cut into approximately $3 \times 3 \mathrm{~cm}$ slabs, and an incision $4 \mathrm{~mm}$ in length was made through the thickness of each slab. No gaps were observed between the edges of the incision. The slabs were soaked in phosphate buffered saline (PBS) for several minutes to remove any blood and inhibit desiccation prior to welding. No stay sutures were used to appose the edges of the incision. The purpose of using slabs rather than the innate tubular structure of the arteries is associated with the burst/leak pressure chamber used for strength assessment.

\section{Welding protocol}

PBS-based $0.5 \mathrm{~mm}$ thick patches consisting of $70 \%$ weight-by-volume (w/v) porcine-derived gelatin (denatured collagen) and $0.25 \% \mathrm{w} / \mathrm{v}$ indocyanine green dye (ICG) were made by 
dissolving the gelatin and ICG in the PBS, applying heat to melt and form the gelatin mixture into $10 \times 10 \times 0.5 \mathrm{~mm}$ patches, and allowing them to cool and solidify. The gelatin comprised $41 \%$ of the total patch weight. The ICG was included to absorb the laser energy. In their final form, the patches were solid, but soft and pliable.

The tissue was placed on a glass substrate with the intima facing upward. A patch was placed over the incision on the intima to simulate an endovascular procedure described by Glinsky et al [8] in which the patch surrounds a balloon at the end of a catheter. Laser energy from an $805 \mathrm{~nm}$ continuous-wave diode laser was delivered to the weld site via a $1 \mathrm{~mm}$ diameter fiber. The fiber tip was positioned $13 \mathrm{~mm}$ directly above the patch surface, yielding a gaussian laser spot with a full-width at half-maximum (FWHM) of approximately $7 \mathrm{~mm}$. The fiber was not moved during the irradiation. Though the center of the patch received a higher dose than the edges due to the gaussian beam shape, the entire patch was irradiated. The laser delivered 1 $\mathrm{W}$ of power for $150 \mathrm{~s}$, corresponding to an average fluence over the patch surface of approximately $200 \mathrm{~J} / \mathrm{cm}^{2}$ (power density $\approx 1.34 \mathrm{~W} / \mathrm{cm}^{2}$ ), which allowed the patch to melt slightly and bond to the tissue surface. As a result of the thermally-induced tissue shrinkage, the incision opened slightly, and some of the patch material melted into the incision during irradiation.

\section{Two-color temperature measurement}

The emissivity of a material may change as a function of temperature, chemical composition, and surface quality. Because the emissivity of the gelatin patch is unknown and may vary during the course of the welding procedure as a result of the water loss and melting caused by the temperature increase, a two-color method of temperature measurement was used. We assume the infrared emission of the protein patch is that of a graybody: 


$$
W=\varepsilon \frac{2 \pi h c^{2}}{\lambda^{5}} \frac{1}{e^{h / \lambda k T}-1} \quad\left[W \mathrm{~cm}^{-2} \mu m^{-1}\right\rfloor
$$

where $W$ is the spectral emittance, $\varepsilon$ is the emissivity (equal to 1 for a blackbody), $h$ is Planck's constant, $c$ is the speed of light, $\lambda$ is the wavelength in microns, $k$ is Boltzmann's constant, and $T$ is the temperature in degrees Kelvin. The spectral emittance of the target, and hence the signal yielded by a detector positioned to receive the emitted radiation, is dependent on two quantities: temperature and emissivity. If two detectors of different

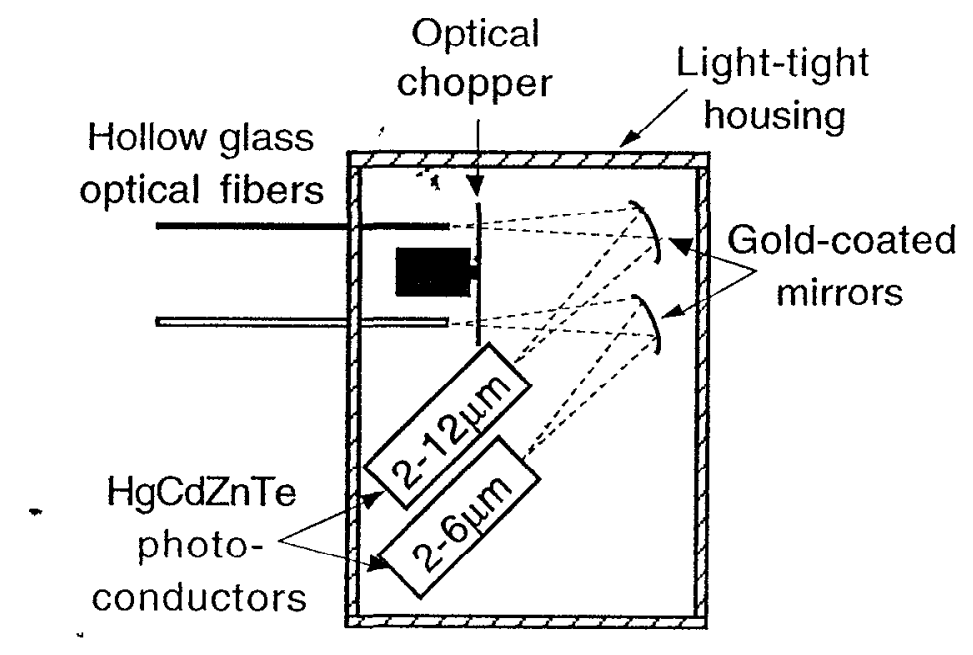

Fig. 1. The two-color infrared thermometry system in the laser tissue welding experiment. Radiation from the center of the laser spot is collected via two hollow glass fibers, modulated by a chopper, and transported to two detectors of different spectral bandpass. The modulated signals are recovered using lock-in amplification and sent to a computer for realtime temperature calculation. spectral bandpass are used to collect the emitted radiation, the ratio of the two signals can be calibrated using a blackbody of known temperature. Assuming that the emissivity of the sample is constant over the spectral bandpass of the system, the emissivity will cancel out of the ratio, making the calibration valid for any graybody target [9]. Assuming the two signals originate from the same geometric region on the target, the ratio is also independent of the fiber-to- 
target distance in the case of a fiber-based system. It should be noted that the detected radiation actually contains ambient (room temperature) blackbody radiation and laser radiation reflected from the target (patch) surface in addition to the radiation emitted by the target itself. The intensity of the reflected blackbody radiation is scaled down by the surface reflectance, 1- $\varepsilon$. Because the target in this study is water-based, its reflectance is low, and, therefore, the portion of the signals corresponding to reflected ambient radiation was negligible compared to the emittance of the much hotter target. Because the laser wavelength was not within the spectral bandpass of the fibers or detectors, any laser light reflected from the target surface was not detected.

An optical fiber-based two-color infrared thermometer was constructed to acquire patch surface temperatures during the course of the welding procedure. Radiation within a $1 \mathrm{~mm}$ diameter spot at the center of the laser spot was collected via two $700 \mu \mathrm{m}$ bore hollow glass fibers $[10,11]$ directed to a common point on the patch surface, modulated by an optical chopper, and detected by two thermoelectrically cooled $\mathrm{HgCdZnTe}$ photoconductors of different spectral response (2-6 $\mu \mathrm{m}$ and 2-12 $\mu \mathrm{m}$, respectively). Lock-in amplifiers were used to recover the two modulated detector signals. The ratio of the signals was calibrated using a blackbody target (emissivity equal to 1) of known temperature varied from $20^{\circ} \mathrm{C}$ to $125^{\circ} \mathrm{C}$. The calibration formula was encoded into a computer for real-time temperature data acquisition. The configuration of the optical components is shown in Figure 1.

\section{Strength assessment}

Burst pressure was used to quantify the integrity of each weld immediately following completion of the welding procedure. Each artery slab was positioned in a pressure chamber such that the patched intima faced the inside to simulate actual blood flow. PBS was pumped into the chamber at a rate of $3 \mathrm{ml} / \mathrm{min}$ using a Harvard syringe pump. The pressures 
indicated by a pressure transducer connected to the chamber were recorded by a computer as a function of time $A$ diagram of the burst pressure measurement apparatus is shown in Figure 2. The burst pressure was noted as the highest (gauge) pressure reached, corresponding to the observed bursting of the weld. From the measured burst pressures, the hoop tension in the vessel wall was estimated using the law of Laplace which assumes a thin-walled membrane and spherical symmetry (the tissue bulged outward dưing the burst test, forming a hemisphere).

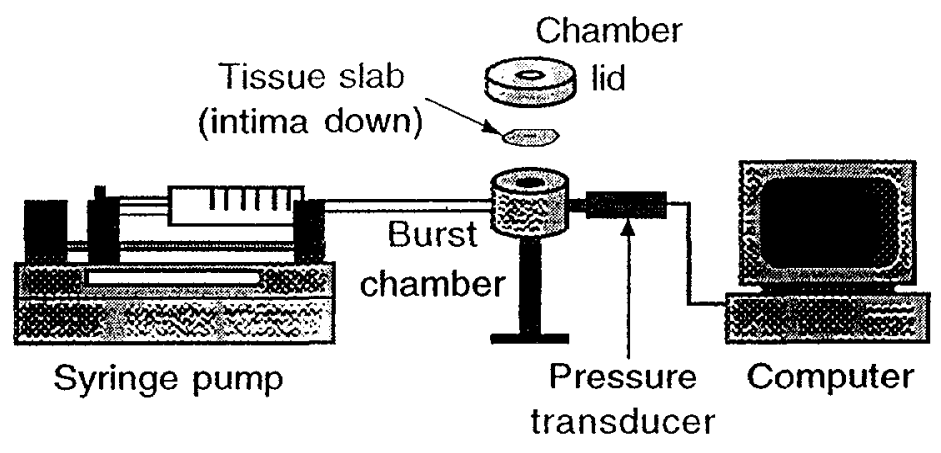

Fig. 2. Burst pressure measurement apparatus. The patched tissue slab is clamped (intima down) between the lid and body of the chamber which is filled to the top with saline. Saline is infused into the chamber via a syringe pump at a rate of $3 \mathrm{ml} / \mathrm{min}$ until the weld bursts. A computer records the pressures Modeling measured by the pressure transducer as a function of time.

The LATIS computer code simulated the exposure of the patched artery to near-infrared radiation using coupled Monte Carlo, thermal transport, and mass transport numerical models [6,7]. LATIS was applied in a two-dimensional (2-D) geometry with an experimentally measured gaussian laser spot of 7 $\mathrm{mm}$ (FWHM) and an ICG-enhanced patch thickness of $0.5 \mathrm{~mm}$, using the same laser power (1 W) and duration (150 s) as the experiment. The initial temperature was set to $25^{\circ} \mathrm{C}$ (room temperature) prior to laser exposure. The results of the simulations were compared with the temperature histories obtained in the laboratory to characterize the dynamic volumetric changes associated with laser irradiation. 


\section{RESULTS}

\section{Thermal dynamics}

Peak surface temperatures of the patched artery at the center of the laser spot measured

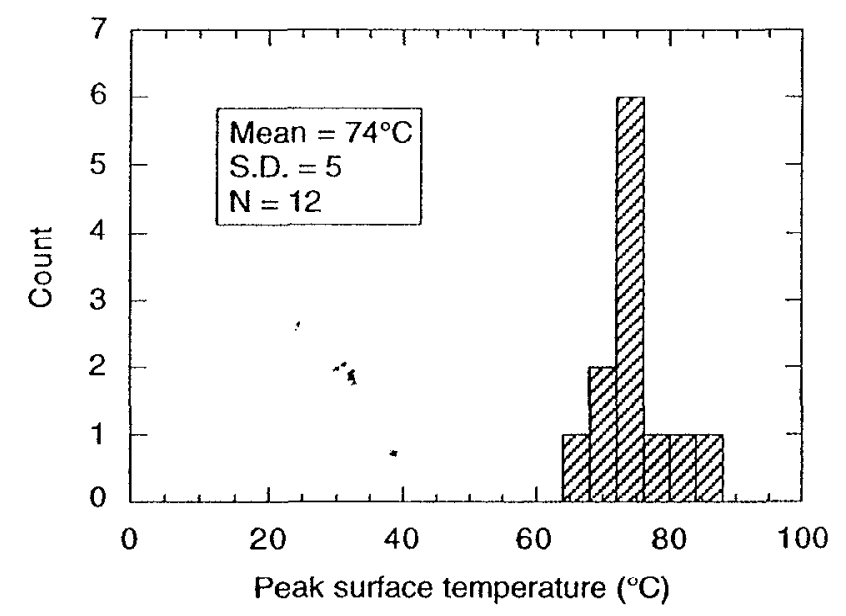

- Fig. 3. Histogram of peak surface temperatures. The laser delivered $1 \mathrm{~W}(7 \mathrm{~mm}$ spot) for $150 \mathrm{~s}$. The small variation in peak surface temperatures indicates that the absorption of laser energy was consistent among all trials. Part of the variation may have been due to error in the temperature measurement of $\pm 3^{\circ} \mathrm{C}$. using the two-color infrared thermometer are shown in Figure 3. The peak surface temperatures of all trials were tightly clustered around $74^{\circ} \mathrm{C}$. Figure 4 shows a typical experimentally measured temperature history of the patch surface at the center of the laser spot during the welding process and a corresponding simulation generated by LATIS. In both cases, after the laser is turned on the temperature quickly rises

then begins to settle, eventually peaking in the neighborhood of $80^{\circ} \mathrm{C}$. A sharp decrease in temperature occurs when the laser is turned off. Simulations generated for patched artery with evaporation turned off resulted in a peak surface temperature of about $160^{\circ} \mathrm{C}$ (data not shown in figures), which is contradictory to experiment. 
LATIS was used to determine the energy-based effects beneath the patch surface. The simulated 2-D sub-surface patch/tissue temperature distribution is shown in Figure 5 . The highest temperature occurs beneath the patch surface, in the patch itself. Figurc 6 shows the sub-surface material density, which is related to the water content, plotted in two dimensions. Areas experiencing more water loss have lower material densities. After the laser is turned off, the center of the patch has lost

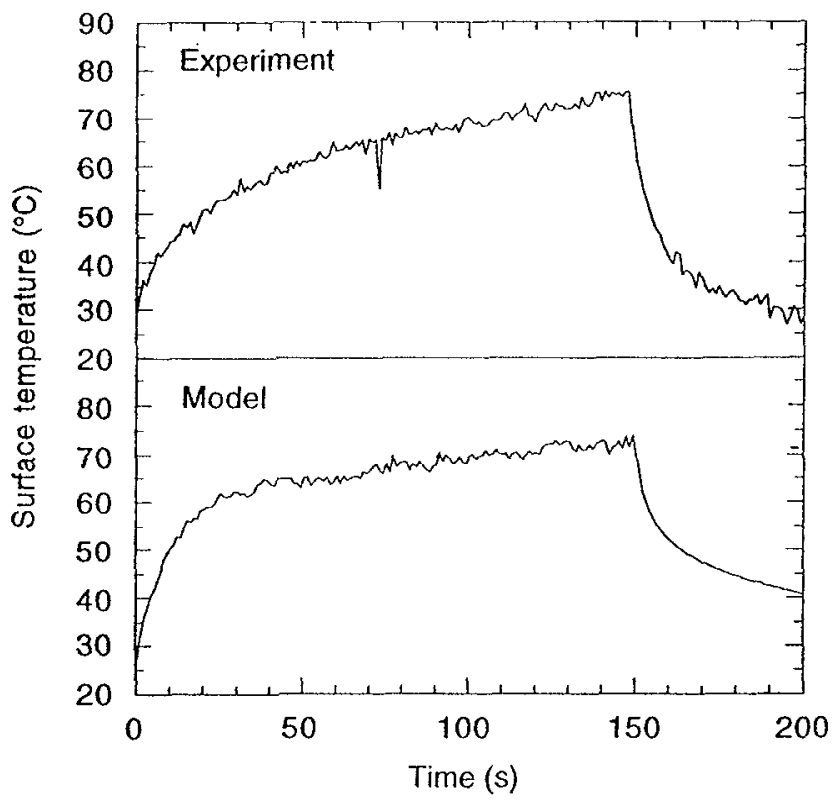
approximately half of its water via evaporation, while the tissue is only slightly less hydrated than normal.

Fig. 4. Experimental and simulated temperature histories of the patch surface for 1 W of delivered laser power $(7 \mathrm{~mm}$ spot). The laser is turned on at $0 \mathrm{~s}$ and turned off at $150 \mathrm{~s}$. The noise in the simulation is due to the Monte Carlo Weld strength laser transport model.

The acute hoop tension and corresponding burst pressure of the patched incisions is shown in Figure 7. For comparison the hoop tension for the aorta in its natural cylindrical shape (importabnt for an arteriotomy) was estimated to be $0.18 \times 10^{6} \mathrm{dyn} / \mathrm{cm}$ under physiologic conditions (120 $\mathrm{mmHg}$ blood pressure). The corresponding longitudinal tension (important for an end-to-end anastomosis) was estimated to be $0.09 \times 10^{6} \mathrm{dyn} / \mathrm{cm}$. There appears to be 
two distinct groups around $017 \times 10^{6} \mathrm{dyn} / \mathrm{cm}$ and $0.25 \times 10^{6} \mathrm{dyn} / \mathrm{cm}$, though no correlations were determined.

\section{DISCUSSION}

\section{Temperature accuracy}

The two-color infrared thermometer used in this study provided surface temperature data free from significant emissivity bias. The method of using the ratio of the signals automatically corrected for any emissivity effects, allowing recovery of more accurate surface temperatures. The accuracy of the technique in this study is slightly reduced due to error in the alignment of the two. fibers to a common spot. This factor is important because the laser heats the surface nonuniformly, which could result in slightly different detected emittances for the two bands. According to the LATIS simulation in Figure 5 , the surface temperature is

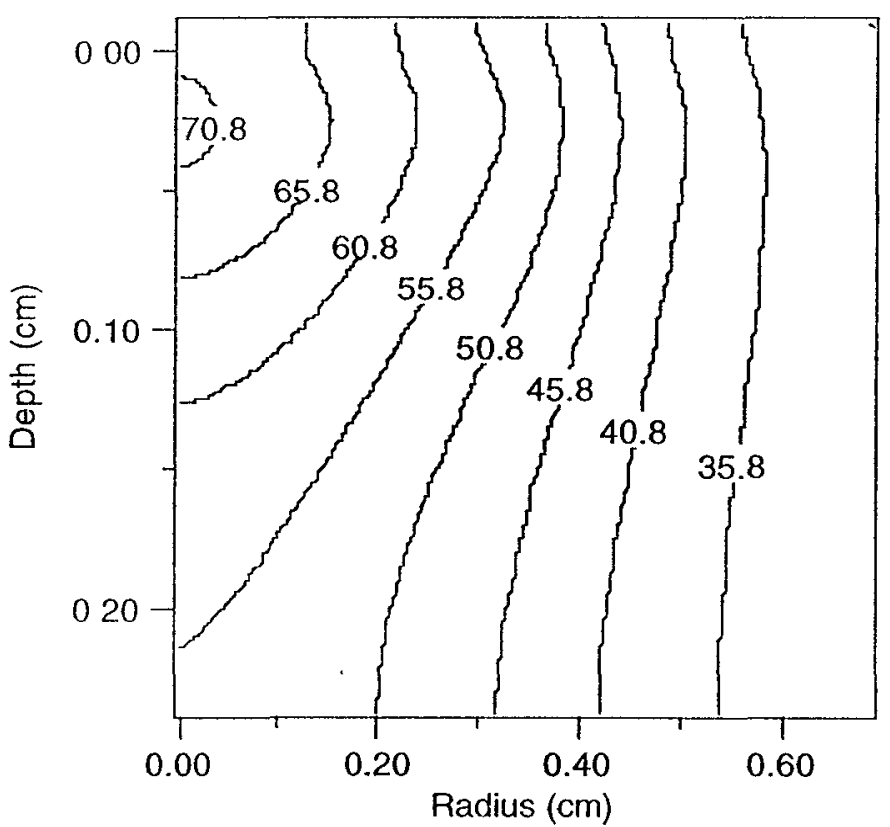

Fig. 5. Simulated sub-surface temperature distribution of the patched artery at the time of laser shutoff. The contours are labeled in degrees Celsius. $1 \mathrm{~W}$ of power ( $7 \mathrm{~mm}$ spot $)$ was delivered for $150 \mathrm{~s}$. The patch occupies the top $0.05 \mathrm{~cm}$ of the graph. nearly constant within a $2 \mathrm{~mm}$ diameter circle at the center of the laser spot. Because the 
two fibers were aligned within this area of constant temperature, the accuracy of the measurement in this study was not significantly affected. Worst case error is estimated to be within $\pm 3^{\circ} \mathrm{C}$.

\section{Patch welding dynamics}

Experimental and simulated temperature histories indicated that evaporative cooling clamped the surface temperature of the patched tissue. This result agrees with previous studies

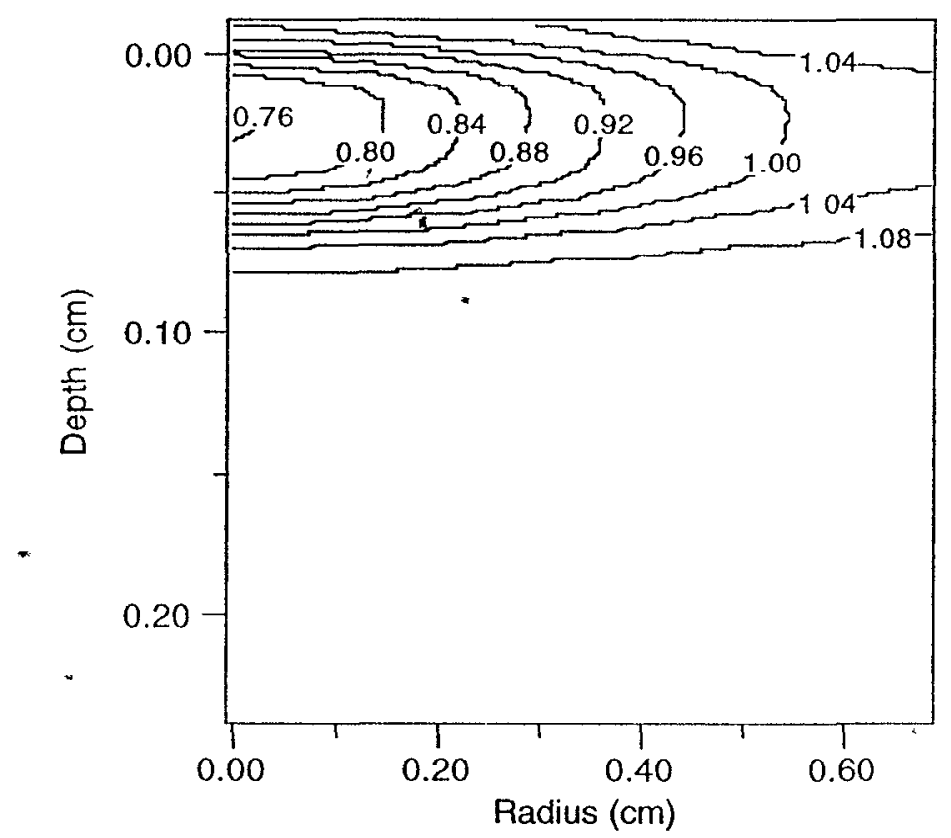

Fig. 6. Simulated sub-surface density of the patched artery at the time of laser shutoff. The decrease in density corresponds to water loss. The contours are labeled in $\mathrm{g} / \mathrm{cc} .1 \mathrm{~W}$ of power $(7 \mathrm{~mm}$ spot) was delivered for $150 \mathrm{~s}$. The patch occupies the top $0.05 \mathrm{~cm}$ of the graph. The initial density of the patch was $1.15 \mathrm{~g} / \mathrm{cc}$, and that of the tissue was $1.05 \mathrm{~g} / \mathrm{cc}$.
$[5,6,12]$. The patches provided suffcient hydration to allow evaporation to occur and prevent desiccation. The uniform thickness and composition of the patches resulted in consistent absorption of the laser energy, yielding only small variation in peak surface temperatures for a given laser fluence. It is possible that the shape of the surface temperature history could be controlled by changing the ICG and/or water concentrations in the patch and/or altering the laser power. Elimination of 
the problem of solder thickness variability [5] enabled repeatable energy delivery, which played an important role in coupling the experiment with the computes model, and may prove to be csscntial in detcrmining welding protocols.

Agreement between the experimental and simulated surface temperatures allowed LATIS to predict sub-surface energy-based changes. Temperature and hydration information beneath the tissue surface illustrate "the volumetric effects caused by

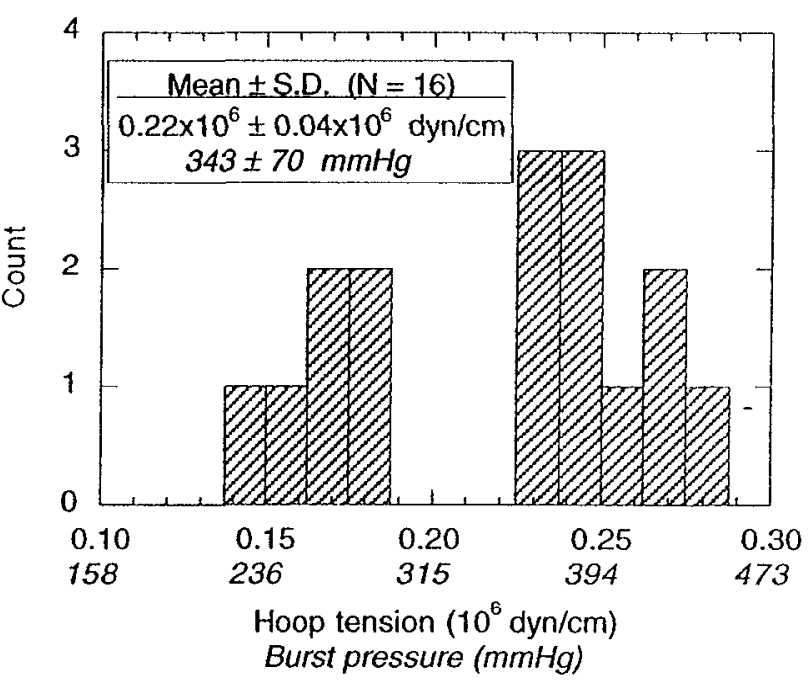
the laser irradiation. The immediate area of the patchtissue interface experienced significant $(\approx 25 \%)$ water loss due to evaporation. This

Fig. 7. Histogram of acute hoop tension and burst pressure (italics) for the patched incisions. The laser delivered $1 \mathrm{~W}$ (7 $\mathrm{mm}$ spot) for $150 \mathrm{~s}$.

water loss may have resulted in the formation of electrostatic bonds, which, although acutely strong, will weaken when sufficiently rehydrated [12]. Exposure to the saline in the burst chamber did not immediately cause the patches to detach from the tissue surface, though it may have contributed to the eventual bursting of the weld.

\section{Weld strength}

The relatively high burst strength of the welds can be attributed to the strength of the collagen patch material as well as the patch-tissue bond. Observation of the patched incisions 
revealed that some of the patch matcrial melted into the incision during laser irradiation, indicating that the strengh lies in the patch rissue fusion, as direct lissue-to-tissue apposition between the edges of the incision was not achieved. This mechanism was realized in previous patch welding studies $[14,15]$ However, the patches used in this study would not be viable in vivo due to their solubility and low melting temperature. Sawyer [14] noted a similar phenomenon when using gelatin-based solid-matrix materials for laser-assisted tissue welding. Whether or not the gelatin-based patches used in this study can be modified to compensate for these inadequecies is unknown.

\section{Patches in practice}

The use of patches facilitated the usually ambiguous tissue welding procedure, removing the commonly incurred need for a "trained eye." The end point for the procedure was marked by the slight, but thorough, melting of the patch; no subjective visual cues such as tissue blanching or desiccation were necessary to achieve repeatable welds. Consistent laser energy absorption among the uniform patches resulted in reproducibly strong welds.

The clinical drawbacks of solubility and low melting temperature of these gelatin-based patches require further investigation. Incorporating additional constituents or increasing the laser power and/or duration to reach higher temperatures to alter the chemistry of the patches and redefine the final molecular and conformational state of the protein may help remedy these problems. At this time, the prospect of developing a physiologically compatible gelatin-based patch is unknown. In addition, the clinical possibilities of residual blood in the welding field (particularly in the case os endovascular deployment) may influence the overall strength of the patch-tissue bond. Given the current clinical deficiencies of these patches, the concept of patch-mediated welding was demonstrated to address and overcome the ease-of-use and repeatability issues commonly associated with laser tissue welding. 


\section{ACKNOWLEDGMENTS}

This work was performed under the auspices of the U.S. Department of Energy by Lawrence I.ivermore National Laboratory under Contract W-7405-ENG-48 as part of the Cooperative Research and Development Agreement TC-1085-95 with Conversion Energy Enterprises of Spring Valley, New York. The authors wish to thank J. Harrington for providing the hollow glass fiber, and J. Cox and K. Haney for their help in fabricating the experimental apparatus.

\section{REFERENCES}

1. Bass LS, Treat MR. Laser tissue welding: A comprehensive review of current and future clinical applications. Lasers Surg Med 1995; 17:315-349.

2. Klioze SD, Poppas DP, Rooke CT, Choma TJ, Schlossberg SM. Development and initial application of a real time thermal control system for laser tissue welding. J Urol 1994; 152:744-748.

3. Poppas DP, Stewart RB, Massicotte JM, Wolga AE, Kung RTV, Retik AB, Freeman MR. Temperature-controlled laser photocoagulation of soft tissue: In vivo evaluation using a tissue welding model. Lasers Surg Med 1996; 18:335-344.

4. Stewart RB, Benbrahim A, LaMuraglia GM, Rosenberg M, L'Italien GJ, Abbot WM, Kung RTV. Laser assisted vascular welding with real time temperature control. Lasers Surg

- Med 1996; 19:9-16.

5. Small IV W, Maitland DJ, Heredia NJ, Eder DC, Celliers PM, Da Silva LB, London RA, Matthews DL. Investigation of laser tissue welding dynamics via experiment and modeling. Journal or Clinical Laser Medicine and Surgery 1997; 15:3-7.

6. Maitland DJ, Eder DC, London RA, Glinsky ME, Soltz BA. Dynamic simulations of tissue welding. In: Lasers in Surgery: Advanced Characterization, Therapeutics, and Systems VI, Proc SPIE 1996; 2671:234-242.

7. London RA, Glinsky ME, Zimmerman GB, Bailey DS, Eder DC, Jacques SL. Laser-tissue interaction modeling with LATIS. Appl Opt, in press.

8. Glinsky ME, London RA, Zimmerman GB. Computer modeling of endovascular patch welding using temperature feedback. In: Medical Applications of Lasers III, Proc SPIE $1996 ; 2623: 349-358$.

9. Tenney AS. Radiation ratio thermometry. In: Theory and Practice of Radiation Thermometry, DeWitt DP and Nutter GD (eds), pp. 459-494, John Wiley and Sons, Inc., New York (1988).

10. Abel $T$, Hirsch J, Jarrington JA. Hollow glass waveguides for broadband infrared transmission. Proc SPIE 1994; 2131:11-17.

11. Abcl T, Hirsch J, Harrington JA. Hollow glass waveguides for broadband infrared transmission. Opt Lett 1994; 19:1034-1036.

12. Torres JH, Motamedi M, Pearce JA, Welch AJ. Experimental evaluation of mathematical models for predicting the thermal response of tissue to laser irradiation. Appl Opt 1993; 32:597-606. 
13. Fenner I, Martin W, Moseley H, Wheatley DJ. Sheal strength of tissue bonds as a function of bonding temperature: a proposed mechanism for laset-assisted tissue welding I Lasers Med Sci 1992; 7:39-43.

14. Sawyer PN Collagen welding rod material for use in issue welding us Paten No 5156613 (1992).

15. Sensaki K, Arai T, Tanaka S. Laser patch welding: Experimental study for application to endoscopic closure of bronchopleural fistula, a preliminary report. Lasers Surg Med $1995 ; 16: 24-33$. 


\title{
Chapter 4
}

Indocyanine Green Dye Mediated Laser Tissue Welding and Collagen Crosslinks

\begin{abstract}
Indocyanine green dye (ICG) is a common radiation absorbing chromophore used in laser tissue welding. Because the strength and stability of laser-welded tissue may be affected by collagen crosslinks already present, created during the welding procedure, or formed ${ }^{-}$after the procedure, the influence of ICG alone and with subsequent laser exposure $(805 \mathrm{~nm}, 1-8 \mathrm{~W}, 30$ s) on collagen crosslinking was investigated using a calf tail tendon model. The monohydroxylated crosslink HLNL, its dihydroxylated analogue DHLNL, and the maturational product of DHLNL, OHP, were quantified. As a point of interest, the effects of high pressure $(\approx 1000 \mathrm{psi})$ with and without previous ICG exposure were also studied. Tissue treated with ICG alone had significantly increased DHLNL and OHP, but not HLNL. Laser exposure after ICG application reduced elevated DHLNL and OHP crosslink concentrations down to their native levels. Laser powers greater than $2 \mathrm{~W}$ destroyed normally occuring HLNL crosslinks; HLNL was inversely correlated with laser output $(p<0.01$ by linear regression analysis). Pressure alone resulted in a significant increase in HLNL, but not DHLNL or OHP. The combination of pressure and ICG served to reduce the crosslink increase associated with either pressure or ICG alone. DHLNL content was highly correlated with content of its maturational product, OHP, suggesting that precursor-product relationships are maintained.
\end{abstract}




\section{INTRODUCTION}

Although laser welding offers many potential advantages over conventional tissue closure methods, there is little consensus as to how best to use the rapidly proliferating array of available laser systems. There is even less consensus as to how to develop successful welding protocols. Some of these difficulties result from our ignorance of the molecular mechanisms responsible for laser-mediated tissue bonding, and of the interplay between laser-induced changes in tissue structure and the course of wound healing. In addition, evolution of laser welding techniques has been largely an empirical process, driven more by technological advancement than by theoretical insights. As there is little consensus as to the most appropriate parameters for assessing "goodness of weld," it is difficult to compare results from different groups, or to interpret discrepant results. However, as underlying mechanisms are elucidated, the gap between technology and theory may lessen. Eventually, as laser welding is increasingly viewed as a component of wound healing rather than an isolated event, "goodness of weld" will come to have a commonly accepted meaning.

In the present study, we address basic questions concerning effects of indocyanine green dye (ICG)-mediated diode laser welding on collagen structure' at the molecular level, specifically, the effects on lysine-derived crosslinks. These crosslinks comprise a family of covalent bonds that not only link two or more collagen molecules together, but also stabilize the spatial relationships among the molecules, so that they form a highly ordered array. The number and type of the collagen crosslinks present in a given tissue are the major determinants of the functional properties of that tissue. Thus, immediate post-weld strength as well as long-term stability of laser welded tissue may depend, in large part, on the effects of laser welding on collagen crosslinks already present in tissue, as well as on crosslinking synthesized as part of the wound healing process. If a laser welding procedure generates widespread perturbations in the crosslinking process, either acutely or chronically, there may be long-term adverse 
effects, which could range from failure to heal and inadequate wound strength on the one hand, to hypertrophic scarring and fibrosis on the other. To address this issue systematically, we have developed an in vitro system for exposing tissue to a defined ICG-mediated diode laser welding protocol. In addition, we investigated the influence of high pressures on lissues both with and without ICG exposure. We report herein on the effects on specific crosslinks, and the implications of these findings for refinement of laser welding protocols.

\section{MATERIALS AND METHODS}

\section{Tissue source}

Tail tendons were obtained from calves aged 3-5 months. Tendon fascicles $5-8 \mathrm{~cm}$ in length were dissected out and stored frozen in normal saline prior to treatment.

\section{Experimental protocol}

The tendons were cut into $25 \mathrm{~mm}$ fascicles, and soaked in either a phosphate buffered saline (PBS) solution of $0.25 \%$ weight-by-volume ICG or PBS alone (control group) for $40 \mathrm{~min}$. Of the tendons exposed to ICG, one set was simultaneously exposed to room light, and another set was kept in the dark. A group of ICG-exposed tendons left in the room light were irradiated with an $805 \mathrm{~nm}$ diode laser at 1,2, 4, or $8 \mathrm{~W}$ of power. The laser spot $(2 \mathrm{~mm}$ diameter) was scanned at constant velocity along the entire length of the tendon; average duration of exposure was $30 \mathrm{~s}$ from end-to-end. Another group of ICG-exposed (no laser) and a group of control tendons were subjected to approximately 1000 psi for $20 \mathrm{~min}$. All samples were immediately frozen following treatment until biochemical analysis. 


\section{Crosslink analyses}

For biochemical analysis, each tendon fascicle was sliced into segments $2-3 \mathrm{~mm}$ long. The number of segments per fascicle ranged from 3 to 5. Each segment was analyzed individually for collagen crosslink content, using previously described techniques [1]. First, the samples were washed overnight in $5 \mathrm{mM}$ phosphate buffer containing $0.9 \%$ sodium chloride $(\mathrm{NaCl})$, pH 7.4. The next day, the wash fluid was removed with a Pasteur pipette, and the tissue was

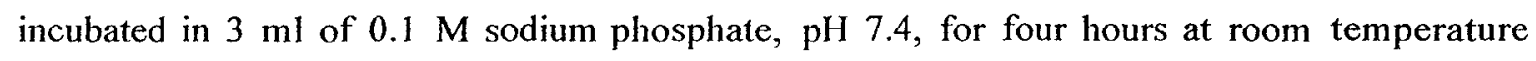
(about $25^{\circ} \mathrm{C}$ ). Tritiated sodium borohydride $(142 \mathrm{Ci} / \mathrm{Mol})$ was then added at a ratio of one part per 30 parts (dry weight) of the sample. After one hour the reduction was stopped by the addition of about, $1 \mathrm{ml}$ of glacial acetic acid (to $\mathrm{pH} 3$ to 4). The tissues were then thoroughly rinsed with distilled water, hydrolyzed in $6 \mathrm{~N}$ hydrochloric acid (HCl) for 18 hours at $110^{\circ} \mathrm{C}$, rotary evaporated to remove $\mathrm{HCl}$, and filtered using a Rainin microfiltration apparatus. Hydroxyproline content of the hydrolysates was determined by a colorimetric assay [2].

Crosslinks were analyzed using high performance liquid chromatography methods described by us in detail previously [1]. For DHLNL and HLNL analysis, aliquots of the hydrolysate containing $50 \mathrm{mg}$ of hydroxyproline were chromatographed on a C18 reverse-phase column (Ultrasphere $0.4 \times 25 \mathrm{~cm}$ ). An isocratic elution system was used; the buffer consists of $22.5 \%$ $\mathrm{n}$-propanol in $0.1 \mathrm{M}$ phosphate buffer, $\mathrm{pH} 2.83$, containing $0.3 \%$ sodium dodecylsulfate. The flow rate was $0.8 \mathrm{ml} / \mathrm{min}$. Amino acids and difunctional crosslinks in the effluent were visualized by their fluorescence (excitation filter cutoff $=360 \mathrm{~nm}$, emission filter cutoff $=$ $155 \mathrm{~nm}$ ), using a Gilson Spectra-Glo Photometer, after postcolumn derivatization with $\underline{\text { o- }}$ pthalaldehyde (OPA). In this system the difunctional crosslinks were completely separated from each other and were eluted well after arginine so they can bc directly visualized even in an unfractionated hydrolysatc. Fractions $(1.3 \mathrm{ml})$ were collected from the fluorometer 
effluent every minute for determination of radioactivity by liquid scintillation counting. Samples were counted in $8 \mathrm{ml}$ of scintillation fluid at an efficiency of about $33 \%$. Every hydrolysate was run in duplicate; variance between runs was $5 \%$ or less.

Samples were analyzed for the nonreducible trifunctional fluorescent crosslink hydroxypyridinium OHP; its deoxy analogue, lysyl pyridinium, was not detectable. Samples containing $5 \mathrm{ug}$ of hydroxyproline were chromatographed on a $0.4 \times 25 \mathrm{~cm}$ C18 reverse phase column (Ultrasphere, Altex, Berkeley, CA), with an elution solvent of $18 \%$ acetonitrile in $0.01 \mathrm{M}$ heptafluorobutyric acid. A Hitachi 2000 fluorometer was used for detection (excitation $=295 \mathrm{~nm}$, emission $=395 \mathrm{~nm}$ ). Duplicate runs were performed for each hydrolysate; again, variance was less than $5 \%$.

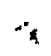

RESULTS

\section{Effects of ICG and diode laser exposure on crosslinks}

In normal calf tail tendon $\mathrm{HI}$,NI, is the predominant difunctional crosslink; the mean HLNL content was $0.25 \mathrm{~mol}$ per mol of collagen, consistent with other literature reports. DHLNL was detectable, but at much lower concentrations, with mean concentration approximately $0.01 \mathrm{~mol}$ per mol of collagen. This finding is consistent with the literature: in most fibrillar tissues DHLNL decreases rapidly during the postnatal period relative to HLNL. The maturation product of DHLNL, the trifunctional crosslink OHP, was similarly low, with content also approximately $0.01 \mathrm{~mol}$ per mol of collagen.

Because ICG potentially could react with collagen, we investigated the effects of applying dye to tendon without subsequent laser exposure. ICG-treated tissue (in room light) had significantly elevated values for DHLNL and OHP relative to control tissue. Values for 
HLNL, however, were not significantly different from control values (Fig. 1). To confirm that the apparen increase in $\mathrm{OHP}$ was in fact due to OHP, and not th a spurious fluorophore generated by dyc exposure, the sample was placed in an ultra-violet (UV) lightbox overnight; rechromatography showed absence of fluorescence at the OHP elution position, indicating that the increased size was

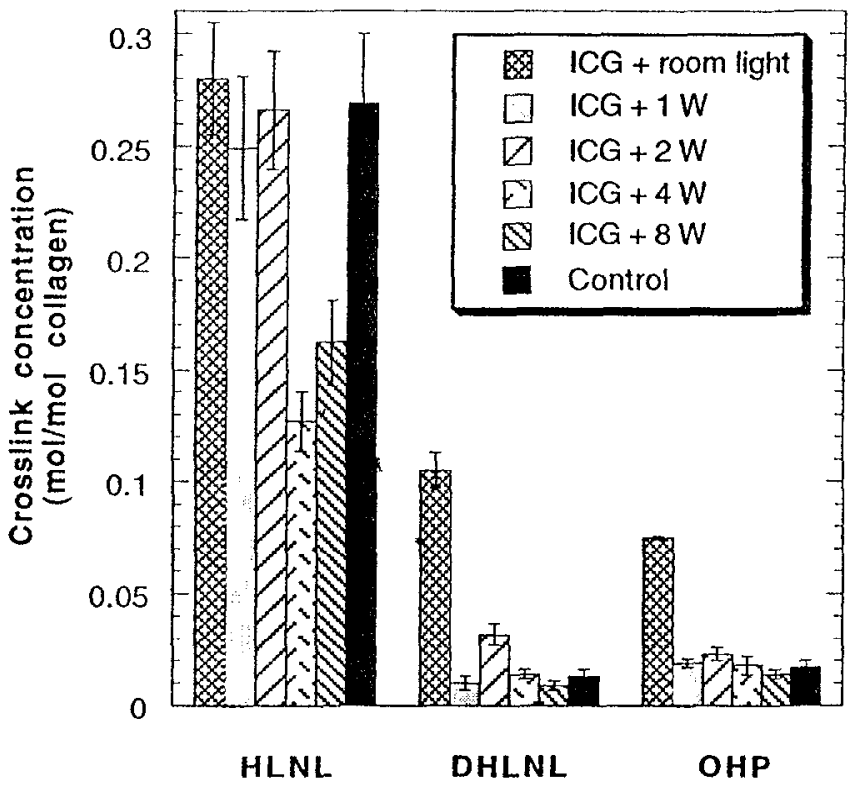

Fig. 1. Effect of ICG and subsequent diode laser exposure on collagen crosslinks. Diode laser powers of $1,2,4$, and $8 \mathrm{~W}$ were used. The tendon was exposed to room light during laser irradiation. completely attributable to OHP (since it was degraded by UV exposure).

Laser exposure was associated with variable effects on crosslink content, depending on power applied and specific crosslink. DHLNL and OHP were reduced from their ICGinduced elevated values down to native levels for all laser powers tested. HLNL content was decreased with respect to native levels in tendons exposed to laser at 4 or 8 watts. These data are summarized in Fig. 1. We found that there was a significant inverse relationship between HLNL content and laser power output. Linear regression analysis showed a slope of -0.46 , with $p<0.01$. 
Cffects of ICG and room light on crosslinks

A comparison of the effects of ICG in room light and in dark is shown in Fig. 2. In the dark, ICG still induced formation of DHLNL and OHP. However, exposure to room lights enhanced the crosslinkinducing effect of ICG.

Effects of ICG and pressure on crosslinks

Figure 3 shows the effects of pressure with and without prior ICG exposure relative to ICG alone and controls. Pressure alone induced

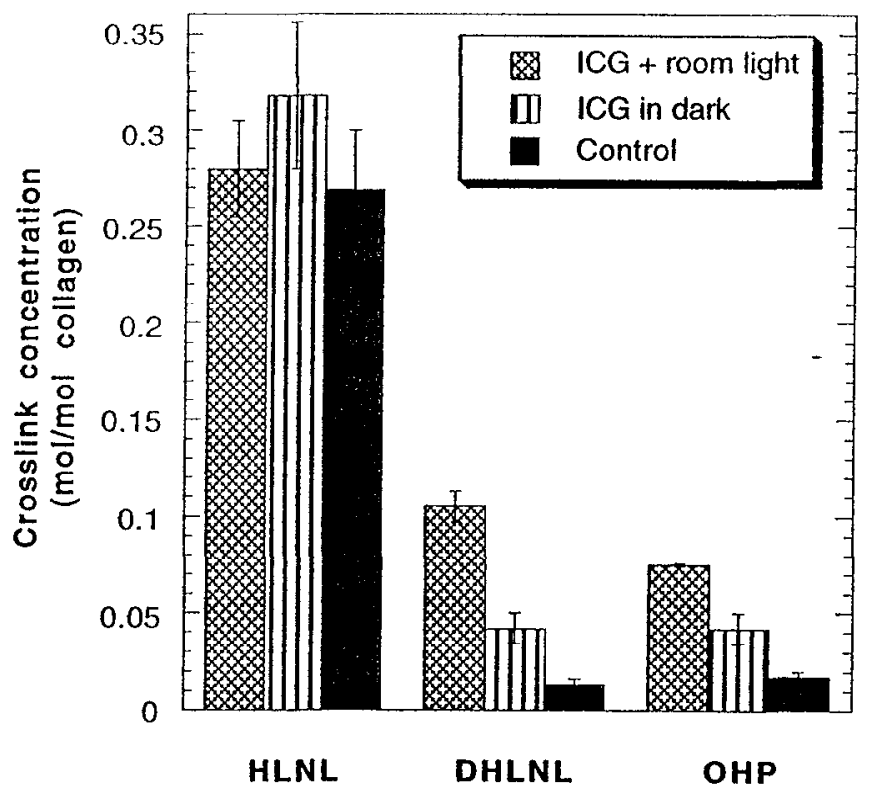

HLNL formation; however, prior ICG exposure reduced Fig. 2. Effect of ICG exposed to room light and in dark on collagen crosslinks.

this effect. DHLNL and

OHP were not influenced by pressure alone. DHLNL and OHP formation caused by ICG exposure was reduced by subsequent application of pressure.

\section{Intrasample variability}

The experimental design was aimed at determining if tissue response to laser exposure and pressure was uniform over the length of the treated tissue with respect to crosslink content. Fascicles were therefore sliced cross-sectionally into lengths of 2-3 mm, and each section was analyzed individually. Thus, by averaging results from all the sections, the mean effect on 
the tendon as a whole was determined. Variance among values for crosslinks in individual sections was not appreciably greater in treated tissues as compared with controls.

\section{DHLNL and OHP correlation}

The relationship between the precursor DHLNI, and its product OHP was investigated for treated and control tendons. The results are shown in Fig. 4. The percent change of OHP with respect to its native value was roughty half that of DHLNL (e.g., a $50 \%$ increase (decrease) in DHLNL corresponded to a $25 \%$ increase (decrease) in OHP). The data also suggests that approximately $40 \%$ of the newly formed DHLNL matured into OHP.

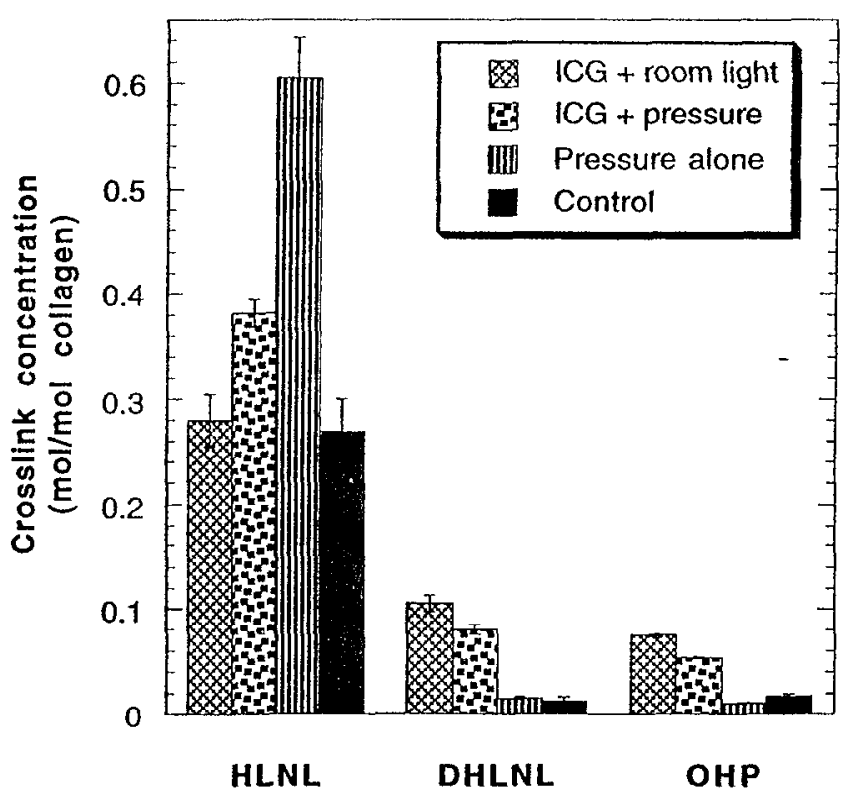

Fig. 3. Effect of pressure with and without prior ICG exposure on collagen crosslinks. The tendon was exposed to room light during the application of pressure.

\section{DISCUSSION}

ICG and laser heating have an impact on collagen crosslink content. The initial application of ICG caused significant formation of DHLNL and OHP crosslinks within the tendon prior to laser exposure, possibly reducing the strength and/or likelihood of subsequent laser-induced 
tissue-to-tissue fusion. However, lascr hcating following ICG cxposure returned the elevated DHLNL and OHP concentrations back down to their native levels. Jxcessive heating destroyed approximately half of the normally occurring HLNL crosslinks. Our results difier from those reported by Bass et al. [3], who also looked at the effect of diode laser + ICG exposure on type I collagen.

They inferred from their structural data that all covalent crosslinking is destroyed by laser exposure. This study demonstrated that relatively high laser powers do not completely destroy all crosslinks.

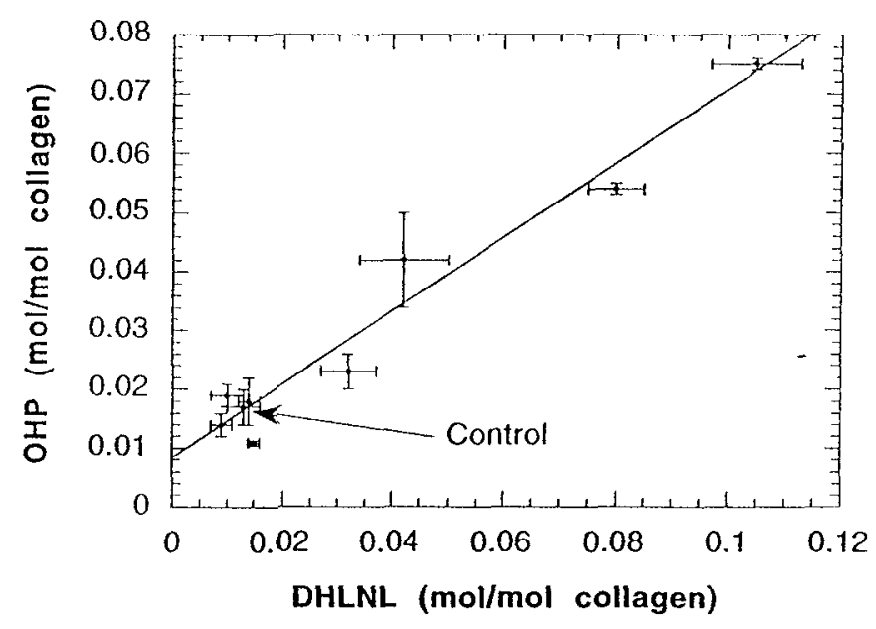

Fig. 4. Relationship between DHLNL content

In addition, pressure had and OHP content. Linear regression analysis was both positive and negative used to investigate the relationship between the affects on collagen precursor DHLNL and its product OHP in treated and crosslinking. In fact, the control tendons. There was a highly significant most pronounced effect (i.e., correlation between DHLNL content and OHP the formation of HLNL) was content. due to pressure alone.

Pressure was also shown to partially destroy the ICG-induced DHLNL and OHP crosslinks, but did not reduce their content below native levels for tendons not previously exposed to ICG. 
The relationship between the precursor DHLNL and its product OHP is maintained in treated tissues This result indicates that ICG, laser heating, and pressure, while affecting the overall concentration of specific crosslinks, do not disturb the normal crosslink maturation process.

\section{ACKNOWLEDGMENTS}

This work was performed under the auspices of the U.S. Department of Energy by Lawrence Livermore National Laboratory under Contract W-7405-ENG-48 as part of the Cooperative Research and Development Agreement TC-1085-95 with Conversion Energy Enterprises of Spring Valley, New York, and the Intra-university Memorandum Agreement -B291526 between Lawrence Livermore National Laboratory and the University of California, Davis.

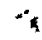

REFERENCES

1. Buckingham B, Reiser KM. Relationship between the content of lysyl oxidase-dependent crosslinks in skin collagen, nonenzymatic glycosylation and long-term complications in - type I diabetes mellitus. J Clin Invest 1990; 86:1046-1054.

2. Woessner JF. The determination of hydroxyproline in tissue and protein samples containing small proportions of this imino acid. Arch Biochem Biophys 1961; 93:440447.

3. Bass LS, Moazami N, Pocsidio J, Oz MC, LoGerfo P, Treat MR. Changes in type I collagen following laser welding. Lasers Surg Med 1992; 12:500-505. 


\title{
Chapter 5
}

Temperature Feedback and Collagen Crosslinking in Argon Laser Vascular Welding

\begin{abstract}
A preliminary single-animal study of in vivo argon laser vascular welding was conducted using a canine model. The effects of temperature feedback control and saline drip cooling on patency and collagen crosslinking were investigated. The surface temperature at the center of the laser spot was monitored using a two-color infrared thermometer. The surface temperature was limited by either a saline drip or feedback control of the laser. Acute patency was evaluated and collagen crosslink assays were performed. Though both protocols yielded successful tissue fusion, welds maintained at a surface temperature of $50^{\circ} \mathrm{C}$ using feedback control had an elevated crosslink count compared to controls, while tissues irradiated without feedback control experienced a crosslink decrease. Simulations using the LATIS (LAser-TISsue) computer code suggest that drip cooled procedures achieve significantly higher temperatures beneath the tissue surface than temperature feedback controlled procedures. Differences between the volumetric heating associated with drip cooled and feedback controlled protocols may account for the different effects on collagen crosslinks. Covalent mechanisms may play a role in argon laser vascular fusion.
\end{abstract}




\section{INTRODUCTION}

Various laser wavelengths with and without the use of extrinsic bonding media and feedback control have been employed in the developing practice of laser tissue welding [1]. The argon laser accompanied by a cooling saline drip has yielded successful results in both animal and human in vivo models without feedback control [2-4]. Recent studies have demonstrated that temperature-controlled laser tissue welding yields increased consistency and strength compared to uncontrolled procedures [5]. However, the mechanisms responsible for the creation of a viable weld remain unknown.

This preliminary single-animal study investigated the influence of argon laser irradiation on the collagen crosslink content, comparing the effects of temperature feedback control on argon laser vascular tissue welding to procedures done using a cooling saline drip without feedback control. A hollow glass optical fiber-based two-color infrared thermometer was used to monitor the surface temperature, and a feedback control loop was employed to maintain a preset temperature by intermittently blocking the laser beam with a mechanical shutter. Biochemical assays were performed to quantify the concentrations of three specific covalent crosslinks between collagen molecules. The LATIS (LAser-TISsue) computer code, which uses coupled Monte Carlo, thermal transport, and mass transport models [6,7], was used to

investigate the volumetric laser heating associated with both open (saline drip) and closed $\left(50^{\circ} \mathrm{C}\right.$ setpoint) feedback loop protocols.

\section{MATERIALS AND METHODS}

The animal used in this study received humane care in compliance with the "Principles of Laboratory Animal Care" formulated by the National Society for Medical Research and the "Guide for the Care and Use of Laboratory Animals" prepared by the National Academy of 
Sciences and published by the National Institutes of Health (N1H Publication No. 86-23, revised 1985).

\section{Welding procedures}

A $30 \mathrm{~kg}$ mongrel dog was intubated and placed under general anesthesia. Both femoral veins and the right femoral artery were isolated for welding. Once proximal and distal control of the vessels was attained, a longitudinal incision $1 \mathrm{~cm}$ in length were made with a scalpel. Clips were placed at the proximal and distal ends of the incision, and a stay suture was placed at the center. The proximal and distal segments, each $5 \mathrm{~mm}$ in length, were welded separately.

Argon laser energy was delivered via a $400 \mu \mathrm{m}$ optical fiber held $5 \mathrm{~mm}$ above the tissue, yielding a gaussian spot with a full-width half-maximum of about $3 \mathrm{~mm}$ at the tissue surface. The surgeon moved the handpiece containing the laser fiber back and forth along the incision at a rate of approximately $1 \mathrm{~mm} / \mathrm{s}$. The open loop procedures were done at $0.7 \mathrm{~W}$ using 5 second-long on pulses alternated with 0.5 -second-long off pulses. Laser exposure times varied from $50 \mathrm{~s}$ to $105 \mathrm{~s}$ for each $5 \mathrm{~mm}$ segment depending on the surgeon's visual determination of the endpoint. The corresponding delivered energies ranged from $35 \mathrm{~J}$ for a $50 \mathrm{~s}$ exposure to $75 \mathrm{~J}$ for a $105 \mathrm{~s}$ exposure; the average fluence was $22 \mathrm{~J} / \mathrm{cm}^{2}$. A continuous drip of room-temperature saline was applied to the tissue surface at a rate of approximately 1 drop/s for cooling during the irradiation.

Based on the open loop temperature histories and the corresponding visual endpoint, a setpoint of $50^{\circ} \mathrm{C}$ was chosen for the closed loop procedures. The closed loop procedures were done in continuous-wave (CW) mode using laser powers of $0.36 \mathrm{~W}$ for $30 \mathrm{~s}$ or $0.7 \mathrm{~W}$ for $60 \mathrm{~s}$ for each segment. Though the laser was operated in CW mode, the mechanical shutter 
effectively pulsed the delivery at a rate of about $1 \mathrm{~Hz}$, yielding laser exposure times of approximately $15 \mathrm{~s}$ at $0.36 \mathrm{~W}$ and $30 \mathrm{~s}$ at $0.7 \mathrm{~W}$ (total energy delivered was $5.4 \mathrm{~J}$ and $21 \mathrm{~J}$, respectively). Average fluences were $10 \mathrm{~J} / \mathrm{cm}^{2}$ at $0.36 \mathrm{~W}$ and $22 \mathrm{~J} / \mathrm{cm}^{2}$ at $0.7 \mathrm{~W}$. No saline was applied in the closed loop trials.

\section{Temperature}

\section{feedback}

A diagram of the tissue welding feedback system is shown in Figure $1 . A$

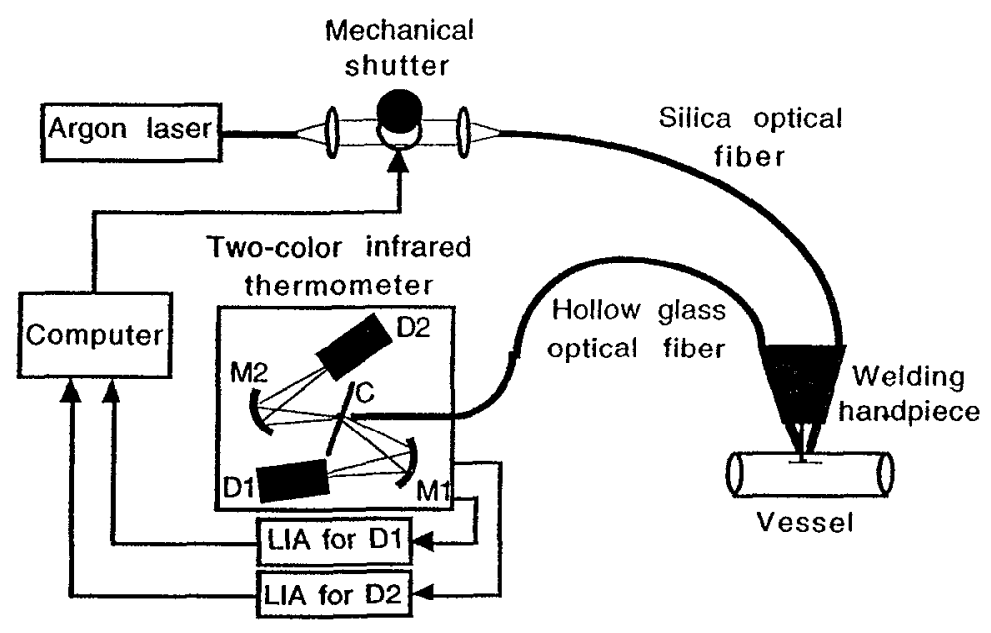

The surface temperature within a $1 \mathrm{~mm}$ diameter circle centered on the laser spot was monitored in real time during the laser procedures using a hollow glass optical fiber-based two-color infrared thermometer. This system provided true surface temperature measurements free from emissivity bias [8]. A $700 \mu \mathrm{m}$ bore hollow

Fig. 1. Surface temperature feedback system used to control the argon laser vascular tissue welding procedures. The temperature monitoring system consists of a gold-coated reflective optical chopper (C) which simultaneously modulates and splits the radiation collected by the hollow glass fiber, two gold-coated spherical mirrors (M1 and M2) to focus the radiation onto two different photoconductors with bandpasses of 2-6 $\mu \mathrm{m}$ (D1) and 2-12 $\mu \mathrm{m}$ (D2), two lock-in amplifiers (LIA) to recover the modulated detector signals, and a computer to calculate the temperature. For closed loop procedures, the shutter alternately passes and blocks the laser to maintain a preset temperature. The shutter is kept open for open loop procedures. 
glass optical fiber [9] collected the radiation from the tissue surface, and a reflective chopper modulated and split the incident radiation into two paths, each of which contained a thermoelectrically cooled infrared photoconductor. Lock-in amplifiers were used to recover the signals from the two photoconductors, which had spectral bandpasses of 2-6 $\mu \mathrm{m}$ and 2-12 $\mu \mathrm{m}$, respectively. A computer calculated the surface temperature (corrected for any emissivity changes) based on a previous blackbody calibration. A handpiece containing both the laser and sensing fibers and a guide wire allowed the surgeon to maintain a preset fiber-totissue distance of $5 \mathrm{~mm}$. The two fibers subtended an angle of $25^{\circ}$, and the guide wire extended to the point where the two fibers would intersect. A mechanical shutter was used in the feedback loop to control the laser delivery in a binary fashion (on/off) and maintain the surface temperature at $50^{\circ} \mathrm{C}$ for closed loop procedures. No audio or video prompts were provided to the operator'sto indicate arrival at the temperature setpoint. The shutter was kept in the open position during open loop procedures.

\section{Weld integrity assessment}

Patency of each weld was determined immediately following completion of both proximal and distal segments either by qualitative observation or in vivo burst pressure measurement. Visual evaluation consisted of allowing the blood to resume flowing through the vessel and identifying the presence of any leak. Quantitative evaluation was done by infusing anticoagulated blood via a syringe pump at $30 \mathrm{cc} / \mathrm{min}$ while the pressure was monitored by a physiologic transducer connected to a bioamplifier and chart recorder. In either case, the segment (i.e., proximal or distal) in which any leak occurred was noted. 
Collagen crosslink measurement

The inadiated femoral vein tissues from the $1 \mathrm{~cm}$ venotomy repairs were harvested for biochemical analysis to quantify the concentrations of three specific enzymatic covalent crosslinks between tropocollagen molecules: the intermediate difunctional crosslink dehydrohydroxylysinonorleucine (HLNL); the intermediate difunctional crosslink dehydrodihydroxylysinonorleucine (DHLNL); and the mature trifunctional product of DHLNL, hydroxypyridinium (OHP). Enzymatic crosslinks confer strength and stability to

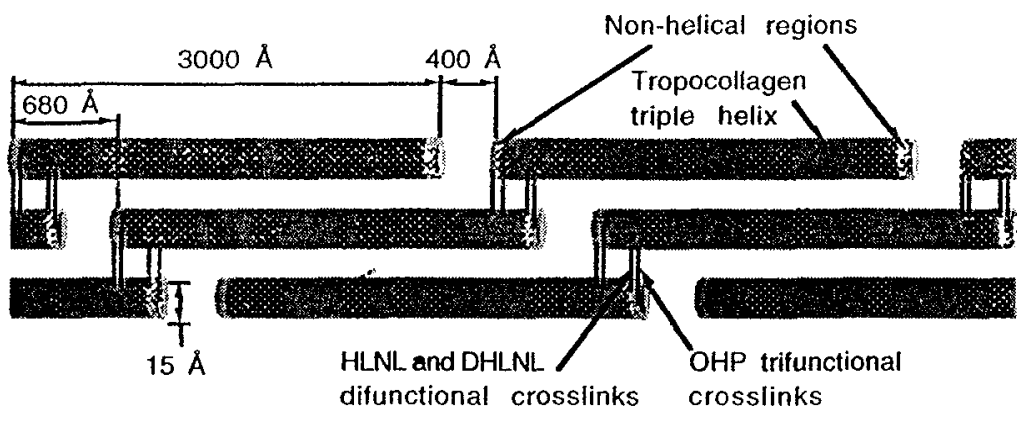

Fig. 2. Location of HLNL, DHLNL, and OHP

The crosslinks may form between the helical and non-helical portions of adjacent tropocollagen molecules. The

trifunctional crosslinks are shown as extending further into the non-helical region to illustrate the additional intramolecular bond bewteen the two polypeptide chains. The vertical dimension is shown exaggerated with respect to the horizontal, which is to scale. Normal collagen fibrils contain fewer than one crosslink per tropocollagen molecule.

the collagen matrix, and HLNL, - DHLNL, and $\mathrm{OHP}, \quad$ in particular, are found in granulation tissue during wound healing [10], making them prime targets for investigation of the tissue fusion mechanism. Each sample was divided into several smaller samples prior to analysis. Highperformance liquid chromatography

(HPLC) was used to analyze the samples. HLNL and DHLNL were analyzed by HPLC using an isocratic solvent $[11,12]$, and OHP was analyzed using a modification of the method of 
Eyre et al $[13,14]$ The relative locations of these crosslinks within the Type I collagen matrix are shown in 1 igne $2|15|$

\section{Computer modeling}

The LATIS computer code [6,7] was used to investigate relative differences between the surface and sub-surface temperatures associated with simulated open and closed loop argon laser energy delivery. These initial simulations did not account for the "paint brush" technique used in the actual welding procedures--a single spot initially at $25^{\circ} \mathrm{C}$ was heated for $80 \mathrm{~s}$. The open loop simulations included the $0.5 \mathrm{~s}$ interval between $5 \mathrm{~s}$ laser pulses, and maintained a thin layer of water on the tissue surface for the entire duration of the laser exposure to simulate the"saline drip, which enhanced evaporative cooling. The closed loop simulations included a laser" power switch to mimic shutter-based temperature control. In both cases, approximately $100 \mathrm{~J}$ of energy was delivered. To account for the actual $1 \mathrm{~mm}$ thick vessel wall which collapsed upon itself prior to welding, a $2 \mathrm{~mm}$ thick tissue slab was modeled. The absorption coefficient was set to $6 \mathrm{~cm}^{-1}$, and the scattering coeffcient was set to $414 \mathrm{~cm}^{-1}[16]$.

\section{RESULTS}

\section{Surface temperature}

A sample of the surface temperature data for both open and closed loop $1 \mathrm{~cm}$ incision procedures is shown in Figure 3. The open loop temperatures never exceeded approximately $60^{\circ} \mathrm{C}$, while the closed loop temperatures averaged $50^{\circ} \mathrm{C}$ for the duration of every weld. Figure 4 shows a portion of the data from Figure 3, along with the laser/shutter operation. 


\section{Weld patency}

Table 1 shows the open and closed loop patency results for the femoral vein welding procedures. For the relatively small number of trials, the success rate for the closed loop welds was similar compared to the open loop welds. Table 2 shows the closed loop patency and burst pressure results for femoral artery welding procedures.

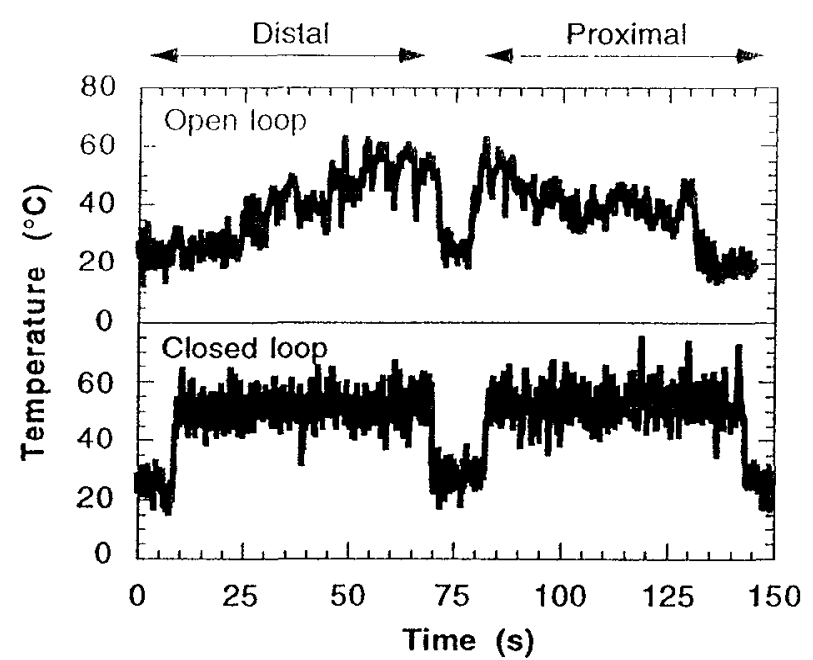

Fig. 3. Open and closed loop surface temperature histories during argon laser femoral vein repair. The laser was turned off following completion of the $5 \mathrm{~mm}$ distal segment, and then turned on again several seconds later to begin welding the $5 \mathrm{~mm}$ proximal segment.

TABLE 1. Acute Patency for Open and Closed Loop Argon Laser Femoral Vein Weläling of $1 \mathrm{~cm}$ Incisions

Acute segment patency (proximal / distal)

\begin{tabular}{llll} 
& \multicolumn{1}{c}{ Trial 1 } & Trial 2 & Trial 3 \\
\cline { 2 - 4 } Open loop & no leak / leak & no leak / leak & no leak / no leak \\
Closed loop $\left(50^{\circ} \mathrm{C}\right)$ & no leak / no leak & no leak / no leak & - \\
\hline
\end{tabular}

\section{Collagen crosslink assays}

Figure 5 shows the results of the HLNL, DHLNL, and OHP collagen crosslink assays for open and closed loop femoral vein procedures. Laser irradiation time during the welding procedure was approximately $1 \mathrm{~min}$ for completion of the $5 \mathrm{~mm}$ segment for open loop trials and $30 \mathrm{~s}$ 
for closed loop trials. Tissues maintained at $50^{\circ} \mathrm{C}$ using feedback control contained significantly greater concentrations of DHLNL and OHP compared to controls, the HLNI, concentration did not change. Tissues treated in the open loop format contained significantly lower concentrations of all three analyzed crosslinks compared to controls. Though arterial tissues from open loop procedures were not analyzed, closed loop welded femoral arteries dið not differ in terms of

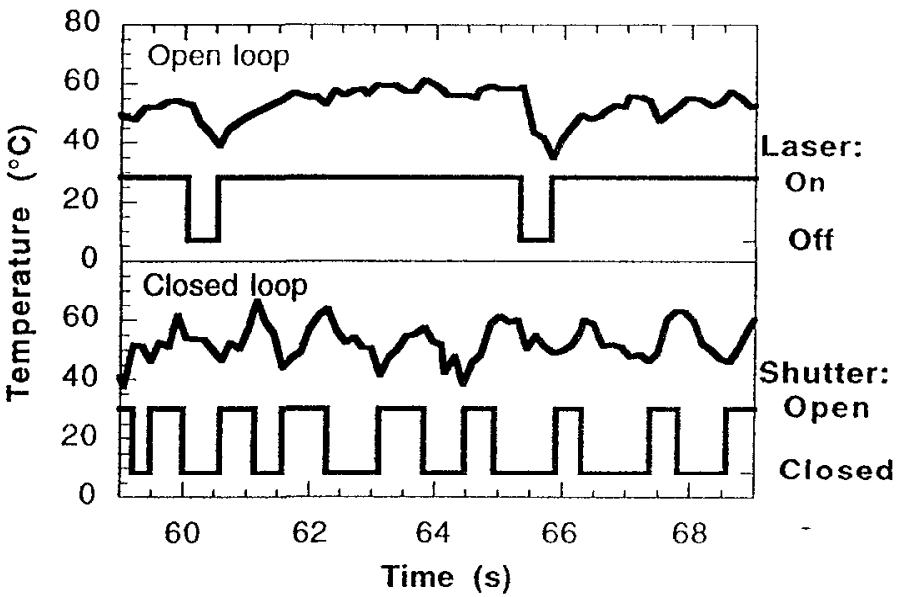
crosslink concentrations from closed loop welded femoral veins (data not procedures. shown in figures).

\section{Computer simulations}

The results of the LATIS temperature simulations are shown in Figure 6. For nearly equivalent surface temperatures in the open and closed loop formats, the sub-surface temperatures achieved using the open loop format with a saline drip are approximately $12^{\circ} \mathrm{C}$ greater than those in the closed loop at a depth of $0.1 \mathrm{~mm}$ after $80 \mathrm{~s}$, and $6^{\circ} \mathrm{C}$ greater at a depth of $1.0 \mathrm{~mm}$. The peak temperature $(\approx 0.1 \mathrm{~mm}$ deep $)$ is over $10^{\circ} \mathrm{C}$ greater than the 
surface temperature after $80 \mathrm{~s}$ for the open loop case, there is almost no difference between the surface and peak sub-surface temperatures in the closed loop case.

TABLE 2. Acute Patency and Burst Pressure for Closed Loop Argon Laser Femoral Artery Welding of $1 \mathrm{~cm}$ Incisions at $50^{\circ} \mathrm{C}$

Acute segment patency (proximal / distal)

Burst pressure ( $\mathrm{mmHg}$ )

\begin{tabular}{ccc}
\hline Trial 1 & Trial 2 & Trial 3 \\
\hline leak / leak & no leak / no leak & no leak / no leak \\
& 140 & 140 \\
\hline
\end{tabular}

\section{DISCUSSION}

\section{Experimental temperatúre data}

The fluctuations in the surface temperature histories obtained using the two-color infrared thermometer originates from two sources: the sampling rate and the mechanical shutter. The fast sampling rate required a fast detection time constant, which elevated the noise level. Though it was not done here, most of this noise can be removed using a low-pass filtering technique at an intermediate temperature calculation stage. For the closed loop data, the binary on/off operation of the mechanical shutter also contributes to the fluctuations. However, unlike the noise due to the sampling rate, these fluctuations are real (i.e., the temperature slightly exceeded the setpoint before the shutter responded).

\section{Open versus closed loop protocols}

Though the open loop femoral vein procedures resulted in more erratic temperature histories compared to the closed loop procedures, visual cues alone provided sufficient feedback. This result indicates that a somewhat broad temperature range for tissue fusion exists, which is 
consistent with previous studies $[5,17]$. However, the open loop surface temperatures never exceeded $60{ }^{\circ} \mathrm{C}$ due to the saline drip and pulsed energy format, as well as the surgeon's trained eye. This protocol has been employed successfully in several earlier in vivo experiments [247 , and is effectively a surface temperature-limiting method. The surgeon relies on visual cues such as tissue blanching or the onset of shrinkage to traverse the incision, while an upper limit on the surface temperature set by the saline drip "and

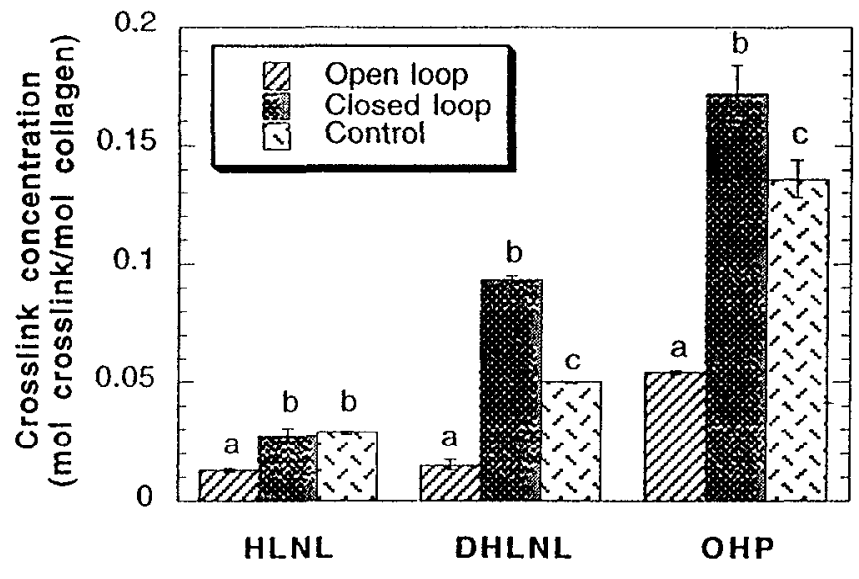
pulsed energy delivery assists in preventing severe damage.

Though the small number of trials cannot justify a definitive comparison between open and closed loop patency, modeling results allow a comparison of the sub-surface temperatures associated with the open and closed loop methods, which Fig. 5. ILNL, DHLNL, and OMP collagen crosslink concentrations for open and closed loop femoral vein procedures. The open loop $5 \mathrm{~mm}$ segments were done using eleven $5 \mathrm{~s}$ laser pulses at 0.7 $\mathrm{W}$ (total irradiation time $=55 \mathrm{~s}$ ) with a saline drip. The closed loop procedures maintained the surface near $50^{\circ} \mathrm{C}$ using a laser power setting of $0.7 \mathrm{~W}$ for $60 \mathrm{~s}$ (total irradiation lime $\approx 30 \mathrm{~s}$ ). Controls were not exposed to the laser. Bars with different superscripts differ significantly within each crosslink category. The error bars represent the standard error.

may impact their overall success. The peak tissue temperature actually occurs beneath the surface as a result of scattering of the argon laser radiation, and can be significantly higher than the surface temperature [18]. The LATIS simulations predicted the peak temperature 
to occur approximately $100 \mu \mathrm{m}$ beneath the tissue surface for open and closed loop laser delivery for the closed loop procedures employing the mechanical shutter to generate relatively short, frequent laser pulses, the peak temperature was probably on the order of only a few degrees higher than the measured surface temperature as suggested by LATIS. However, for the open loop procedures, saline was applied to cool the surface as the tissue was exposed to relatively long laser pulses. This may have resulted in a much larger difference between the surface and sub-surface peak temperatures (i.e., significantly higher sub-surface temperatures). The LATIS simulations predicted a difference of approximately $10^{\circ} \mathrm{C}$ between the temperature at the surface and at a depth of $100 \mu \mathrm{m}$.
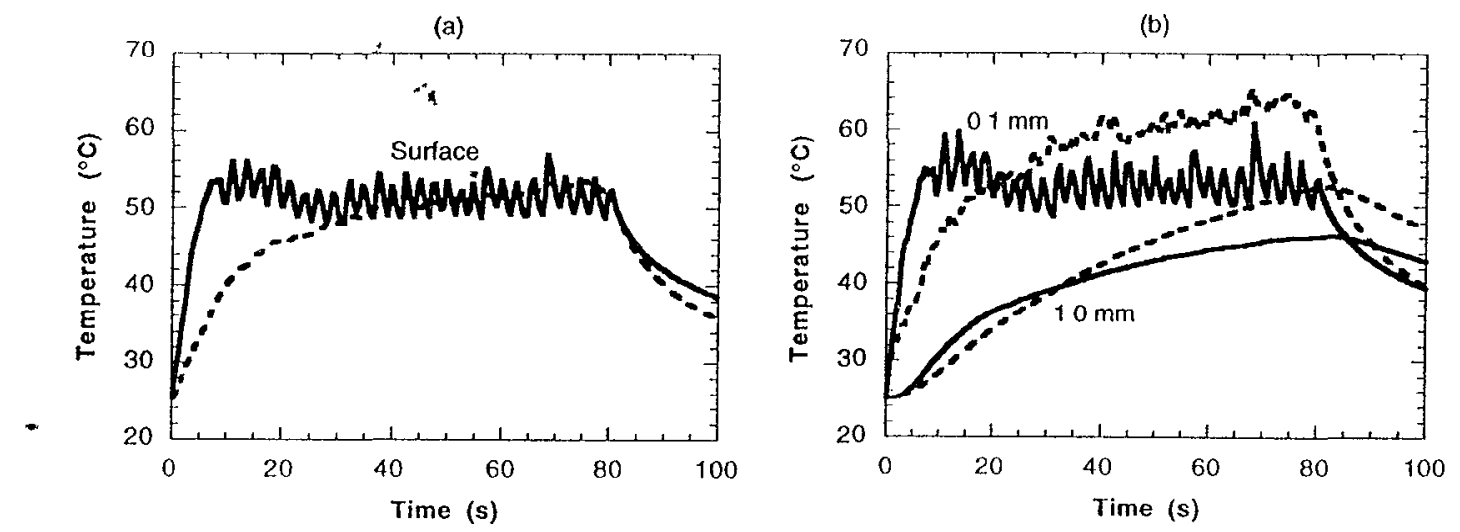

Fig. 6. Simulated temperature histories for, open and closed loop laser welding protocols at (a) the surface and (b) $0.1 \mathrm{~mm}$ and $1.0 \mathrm{~mm}$ beneath the surface. The solid lines represent closed loop (shutter-based temperature control) simulations and the dashed lines represent open loop (water drip) simulations. The noise in the open loop curves at the surface and $0.1 \mathrm{~mm}$ deep is due to the Monte Carlo laser transport model.

Previous open loop repairs of $0.5 \mathrm{~cm}$ arteriotomies by Vlasak et al [3] using the same protocol as this study reported a mean burst pressure of $114 \mathrm{mmHg}$ with a standard deviation of 66 Vlasak et al also reported a threefold decrease in mean burst pressure between $0.25 \mathrm{~cm}$ 
and $0.5 \mathrm{~cm}$ open loop welded arieriotomies, which suggests that the burst pressure of a $1 \mathrm{~cm}$ incision would be lower than that of a $05 \mathrm{~cm}$ However, the $1 \mathrm{~cm}$ arteriotomies repaired in this study using the closed loop protocol burst at $140 \mathrm{mmHg}$, which is comparable to the 0.5 $\mathrm{cm}$ strength.

\section{Biochemistry}

Argon laser irradiation was shown to have an effect on the femoral vein crosslink content. The increase of DHLNL and OHP associated with $50^{\circ} \mathrm{C}$ temperature-controlled procedures combined with the decrease of HLNL, DHLNL, and OHP associated with open loop procedures suggests that crosslink formation and destruction depend on the temperature history throughout the tissue volume. It is possible that the deposited laser energy enhanced the crosslinking process at any of several stages (e.g., rate of lysyl oxidase mediated deamination of lys and hyl, reactions between aldehydes and unmodified lys and hyl residues, change in either the number or location of lysyl oxidase targets, increase in the rate of condensation between DHLNL and unmodified hyl residues), inducing the formation of new crosslinks in the case of the closed loop procedures. Because collagen denatures at $62-67^{\circ} \mathrm{C}$ in physiologically buffered solution [19], the newly formed and existing (native) crosslinks were probably not interrupted by denaturation using the short pulses of the closed loop method based on the LATIS simulations. However, for the case of open loop procedures, the collagen denaturation threshold may have been reached due to the elevated subsurface temperature, causing the breakdown of any crosslinks. Further work needs to be done to thoroughly identify the effects of temperature history and laser pulse format on collagen crosslinks.

Modeling studies have revealed that, as tissue is heated by laser radiation, evaporation occurs, depleting the water content of the tissue [6,20,21]. However, the room-temperature saline 
drip employed during the open loop procedures not only cooled the tissue surface, but also served to hydrate the tissue. The hydration provided by the saline drip in this study inhibits electrostatic bonding, which is most likely associated with excessive water depletion $[21,22]$. Therefore, patency of the open loop welds is probably not primarily a consequence of electrostatic bonding (at least in the region near the tissue surface where the water content is not depleted), but rather involves covalent bonding. This view agrees with previous studies, which indicate that vascular tissues fused using an argon laser with a saline drip undergo biochemical extracellular matrix protein alterations, which may correspond to collagen crosslinking [23,24].

Because new DHLNL and OHP crosslinks were created in the femoral vein tissue irradiated in the closed loop format, these two types of crosslinks may be at least partly responsible for the tissue fusion achieved with temperature feedback control. It is likely that the crosslinks were dispersed throughout the tissue, some of which may have bridged the incision. However, it should be noted that there is no definitive evidence that crosslinks formed between the cơpted tissue edges. Nonetheless, it is interesting to know that existing covalent bonds were not destroyed and that new covalent bonds were created upon argon laser irradiation. The relatively deep penetration of the argon laser radiation $(1 / \mathrm{e}$ depth $\approx 200 \mu \mathrm{m})$ suggests that the elastin and collagen constituents of the medial layer of the vein, as well as the highly collagenous adventitia, contribute to the tissue fusion. This view is supported by histologic examination of argon laser welded vessels [25]. Because the collagenous adventitial layer is proportionately larger than the medial layer in veins [26] it is likely that the adventitial collagen is a key player in venous tissue fusion. The fact that collagen is responsible for over $50 \%$ of the dry weight of veins $[27,28]$ further supports its potential involvement.

The fact that the open loop procedures yielded successful welds in spite of a decreased collagen crosslink concentration suggests that additional mechanisms, including other 
collagen- and/or elastin-mediated bonds or other covalent bonds not investigated in this study, may also play a role in argon laser tissue fusion. The elastin in the media, believed to be an important factor in the fusion process $[5,25,26]$, may form bonds with collagen and/or elastin in areas of tissue apposition. Such bonds may help provide the acute strength observed experimentally. Because the denaturation threshold of elastin is above $100^{\circ} \mathrm{C}[19]$, any involvement of the elastin probably occurs while in its native state, supporting the view that tissue fusion incorporates covalent bonds which may be broken when protein denaturation occurs.

\section{ACKNOWLEDGMENTS}

This work was performed sunder the auspices of the U.S. Department of Energy by Lawrence Livermore National Laboratory under Contract W-7405-ENG-48 as part of the Cooperative Research and Development Agreement TC-1085-95 with Conversion Energy Enterprises of

Spring Valley, New York. The authors wish to thank J. Harrington for providing the hollow gtass fiber and J. Cox and K. Haney for their help in fabricating the infrared thermometer.

\section{REFERENCES}

1. Bass LS, Treat MR. Laser tissue welding: A comprehensive review of current and future clinical applications. I asers Surg Med 1995; 17(4):315-349.

2. White RA, Kopchok G, Donayre C, Abergel RP, Lyons R, Klein SR, Dwyer RM, Uitto J. Comparison of laser-welded and sutured arteriotomies. Arch Surg 1986; 121(10):11331135.

3. Vlasak JW, Kopchok GE, Fujitani RM, White RA. Argon laser vascular fusion: Venous and arterial bursting pressures. Lasers Surg Med 1989; 9(5):478-481.

4. White RA, White GH, Fujitani RM, Vlasak JW, Donayre CE, Kopchok GE, Peng SK. Initial human evaluation of argon laser-assisted vascular anastomoses. J Vasc Surg 1989; $9(4): 542-547$.

5. Stewart RB, Aziz B, LaMuraglia GM, Rosenberg M, L'Italien GJ, Abbott WM, Kung RTV. Laser assisted vascular welding with real time temperature control. Lasers Surg Med 1996; 19(1):9-16.

6. Maitland DJ, Eder DC, London RA, Glinsky ME, Soltz BA. Dynamic simulations of tissue welding. In: Lasers in Surgery. Advanced Characterization, Therapewics, and Systems VI, Proc SPIE 1996, 2671·234-242. 
7. London RA, Glinsky ME, Zimmerman GB, Bailey DS, Eder DC, Jacques SL. Laser-tissue interaction modeling with J.ATIS Appl Opt, in press

8 Small IV W, Celliers PM, Da Silva L,B, Matthews DL, and Soltz BA. Two-color infrared themometer for low-temperature measurement using a hollow glass optical fiber. In: Specialty Fiber Optics for Biomedical and Industrial Applications, Proc. SPIE 1996; 2977:115-20.

9 Abel T, Hirsch J, Harrington JA. Hollow glass waveguides for broadband infrared transmission. Opt Lett 1994; 19.1034-1036.

10. Reiser KM. Nonenzymatic glycation and enzymatic crosslinking in a model of wound healing: The effects of aging, diet, and modulating agents. J Ger Derm 1993; 1(2):9099.

11. Reiser KM, Hennessy SM, Last JA. Analysis of age-associated changes in collagen crosslinking in the skin and lung in monkeys and rats. Biochim Biophys Acta 1987; 926(3):339-348.

12. Reiser KM, Tyler WS, Hennessy SM, Dominguez JJ, Last JA. Long-term consequences of exposure to ozone II: Structural alterations in lung collagen of monkeys. Tox Appl Pharm 1987; 89(3):314-322.

13. Eyre DR, Koob TJ, Van Ness KP. Quantitation of hydroxypyridinium crosslinks in collagen by high-performance liquid chromatography. Analyt Biochem 1984; -137:380388 .

14. Buckingham B, Reiser KM. Relationship between the content of lysyl oxidasedependent cross-links in skin collagen, nomenzymatic glycosylation, and long-term complications in type I diabetes mellitus. J Clin Invest 1990; 86(4):1046-1054.

15. Reiser K, McCormick RJ, Rucker RB. Enzymatic and nonenzymatic cross-linking of collagen and elastin. FASEB J 1992; 6:2439-2449.

16. Keijzer M, Jacques SL, Prahl SA, Welch AJ. Light distributions in artery tissue: Monte carlo simulations for finite-diameter laser beams. Lasers Surg Med 1989; 9:148-154.

17. Poppas D, Klioze S, Rooke C, Choma T, Schlossberg S. Optimal temperature values for laser welding of rat urethral tissues: Time zero studies. Lasers Surg Med 1992; Suppl 4:77.

18. Motamedi M, Rastegar S, LeCarpentier G, Welch AJ. Light and temperature distribution in laser irradiated tissue: the influence of anisotropic scattering and refractive index. Appl Opt 1989; 28(12):2230-2237.

19. Florkin M, Stotz EH, eds. Extracellular and supporting structure. In: Comprehcnsive Biochemistry, Vol. 26c. Amsterdam: Elsevier 1971.

20. Torres JH, Motamedi M, Pearce JA, Welch AJ. Experimental evaluation of mathematical models for predicting the thermal response of tissue to laser irradiation. Appl Opt 1993; 32(4):597-606.

21. Small IV W, Maitland DJ, Heredia NJ, Eder DC, Celliers PM, Da Silva LB, London RA, Matthews DL, Soltz BA. Investigation of laser tissue welding dynamics via experiment and modeling. J Clin Laser Med Surg 1997; 15(1):3-7.

22. Fenner I, Martin W, Moseley H, Wheatley DJ. Shear strength of tissue bonds as a function of bonding temperature: a proposed mechanism for laser-assisted tissue welding. Lasers Med Sci 1992; 7:39-43.

23. Murray LW, Su L, Kopchok GE, White RA. Crosslinking of extracellular matrix proteins: A preliminary report on a possible mechanism of argon laser welding. Lasers Surg Med 1989; 9(5):490-496.

24. Guthrie CR, Murray LW, Kopchok GE, Rosenbaum D, White RA. Biochemical mechanisms of laser vascular tissue fusion. J Invest Surg 1991;4(1):3-12.

25. White RA, Kopchok GE, Peng SK. Laser vascular welding--how does it work? Ann Vasc Surg 1986; 1:461-464.

26. Springer TA, Welch AJ. Temperature control during laser vessel welding. Appl Opt $1993 ; 32(4): 517-525$. 
27. Lowry OH, Gilligan DR, Katersky EM. The determination of collagen and elastin in tissues, with results obtained in various normal tissues from different species. J Biol Chem 1941; 139:795-804.

28. Svejcar I, Prerovsky 1, Linhart J, Kruml J. Content of collagen, elastin, and water in walls of the internal saphenous vein in man. Circ Res 1962;11:296-300. 


\title{
Chapter 6
}

Two-Color Mid-Infrared Thermometer Using a Hollow Glass Optical Fiber

\begin{abstract}
A low-temperature optical fiber-based two-color infrared thermometer has been developed. Radiation from a target is collected via a single $700 \mu \mathrm{m}$-bore hollow glass optical fiber, simultaneously split into two paths and modulated by a reflective optical chopper, and detected by two, different thermoelectrically-cooled mid-infrared $\mathrm{HgCdZnTe}$ photoconductors. The modulated detector signals are recovered using lock-in amplification. Using the two previously obtained blackbody calibration equations, a computer algorithm calculates the true temperature and emissivity of a target in real time, taking into account reflection of the ambient radiation field from the target surface. The small numerical aperture of the hollow glass fiber and the fast response of the detectors, together with the two-color principle, permit high spatial and temporal resolution while allowing the user to dynamically alter the fiber-to-target distance.
\end{abstract}

\section{INTRODUCTION}

Radiation thermometry is a common non-contact method of measuring temperature. In particular, the technique of two-color pyrometry compensates for the effect of unknown emissivity, which can vary with temperature and surface quality. Two-color pyrometers sample the target radiance in two different spectral regions, and infer the true temperature and/or emissivity using various algorithms. Many methods of separating the incident radiation into two spectral bands have been used, including using a beamsplitter with two 
detectors [1], a rotating filter wheel composed of two different filters with a single detector [2], and a single detector consisting of two different active regions [3]. Once the radiation is divided into two distinct spectral bands, the temperature may be determined from the ratio of the two signals [4] which is independent of the emissivity (assuming the emissivity is independent of the wavelength) if the background is negligible, or by solving the two detector response equations simultaneously for the temperature and emissivity [5]. The spectral characteristics of the optical components and the sensitivity of the system determine the useful temperature range of any radiation thermometer.

We have constructed a two-color mid-infrared thermometer incorporating a single hollow glass optical fiber and lock-in amplification for fast, high spatial resolution, low-temperature measurement. The use of a single fiber eliminates the problem of aligning two fibers to a common spot on the target, while the small numerical aperture of the hollow glass fiber provides high spatial resolution. The radiation collected by the hollow glass optical fiber is simultaneously split into two paths and modulated by a reflective optical chopper. Each path contains a detector whose signal is recovered using lock-in amplification. The temperature and emissivity are calculated in real time from the two detector response calibration equations, taking into account reflection of the background radiation field from the target surface. The mid-infrared spectral bandpass of the system, together with lock-in amplification, enables measurement of the small signals emitted from low-temperature targets. 


\section{THEORY}

\section{Blackbody radiation}

The spectral radiant emittance [power per unit area per unit wavelength] of a blackbody (emissivity equal to 1) is given by Planck's Law,

$$
W_{\mathrm{bb}}(\lambda, T)=\frac{2 \pi h c^{2}}{\lambda^{5}} \frac{1}{e^{h c / \lambda k T}-1}
$$

where $h$ is Planck's constant, $c$ is the speed of light, $\lambda$ is the wavelength, $k$ is Boltzmann's constant, and $T$ is the blackbody temperature [K]. The emission peaks of room temperature-regime $(300-500 \mathrm{~K})$ radiation fields are situated in the mid-infrared around $8 \mu \mathrm{m}$ (higher temperatures peak ar shorter wavelengths). Because the spectral distribution is a function of the temperature, the signal produced by a detector that is sensitive to all or part of the radiated thermal spectrum of the blackbody will be related to its temperature.

Assuming Lambertian emission, the signal yielded by a detector using an optical fiber to collect the blackbody radiation is given by

$$
V_{\mathrm{bb}}(T)=\iint d A_{\mathrm{f}} d A_{\mathrm{t}} \frac{\cos ^{2} \theta}{R^{2}} \int_{\lambda_{\min }}^{\lambda_{\operatorname{mix}}} d \lambda \frac{W_{\mathrm{bb}}(\lambda, T)}{\pi} F(\lambda) S(\lambda)
$$

where $F(\lambda)$ is the fiber transmittance, $S(\lambda)$ is the detector response [V/W], $\lambda_{\max }-\lambda_{\min }$ is the spectral bandpass of the system, $d A_{\mathrm{f}}$ is an infinitesimal element of area on the surface of the fiber tip, $d A_{t}$ is an infinitesimal element of area on the surface of the target sensed by the fiber, $R$ is the distance from $d A_{\mathrm{f}}$ to $d A_{1}$, and $\theta$ is the angle between the ray joining $d A_{\mathrm{f}}$ and 
$d A_{t}$ and the normal to either of the surfaces (the fiber tip and target surfaces are parallel). In the case of the hollow glass fiber which has no "surface" at the tip, $d A_{t}$ is in the hollow region in the plane of the fiber tip. The double integral containing the geometric dependence can be calculated in polar coordinates using the radii and azimuthal angles of the fiber tip and sensed area as described by Eyal et al [6]. Using simple trigonometric relationships, Equation 2 can be rewritten in terms of the new variables as

$$
\begin{aligned}
& V_{\mathrm{bb}}(T)=\frac{D^{2}}{\pi} \int_{0}^{a_{\mathrm{f}}} d R_{1} \int_{0}^{a_{\mathrm{f}}} d R_{\mathrm{f}} \int_{0}^{2 \pi} d \phi_{\mathrm{f}} \int_{0}^{2 \pi} d \phi_{\mathrm{t}} \frac{R_{\mathrm{f}} R_{\mathrm{f}}}{\left(R_{\mathrm{f}}^{2}+\right.}\left.R_{\mathrm{t}}^{2}-2 R_{\mathrm{f}} R_{\mathrm{f}} \cos \phi_{\mathrm{f}}+D^{2}\right)^{2} \\
& \times \int_{\lambda_{\min }}^{\lambda_{\max }} d \lambda W_{\mathrm{bb}}(\lambda, T) F(\lambda) S(\lambda)
\end{aligned}
$$

where $D$ is the distance between the fiber tip and target surfaces, $R_{t}$ and $\phi_{t}$ are the polar coordinates on the target surface, $R_{\mathrm{f}}$ and $\phi_{\mathrm{f}}$ are the polar coordinates on the fiber tip surface (the origin of $\phi_{\mathrm{f}}$ is $\phi_{\mathrm{t}}$ ), $a_{\mathrm{t}}$ is the radius of the sensed area on the target surface (governed by the numerical aperture of the sensing fiber), and $a_{\mathrm{f}}$ is the fiber radius (bore radius, in the case of the hollow glass fiber). When $D$ is large compared to the target and fiber radii, the portion of Equation 3 to the left of the spectral integral reduces to a constant independent of $D$, and Equation 3 simplifies to

$$
V_{\mathrm{bb}}(T)=\pi a_{\mathrm{f}}^{2} \mathrm{NA}^{2} \int_{\lambda_{\min }}^{\lambda_{\max }} d \lambda W_{\mathrm{bb}}(\lambda, T) F(\lambda) S(\lambda)
$$

where NA is the numerical aperture of the sensing fiber, given by $a_{t} / D$. Hence, when the fiber-to-target distance is sufficiently largc, and assuming a spatially uniform target temperature, the geometric dependence of the signal is governed only by the fiber (bore) 
radius and the numerical aperture of the fiber, the fiber-to-target distance has no effect. When the heated region is finite in extent, Equation 4 will not hold unless the numerical aperture of the fiber is sufficiently small that the sensed area is contained within the heated target region. For applications requiring some degree of spatial resolution there is an advantage to using fibers with relatively small numerical apertures.

\section{Graybody radiation}

In the case of a graybody, the emissivity is less than 1 and is independent of wavelength. The spectral radiant emittance of a graybody is related to that of a blackbody (Equation 1) by

$$
W(\lambda, \varepsilon, T)=\varepsilon W_{\mathrm{bb}}(\lambda, T)
$$

where $\varepsilon$ is the emissivity. When the emissivity is less than 1 , the ambient radiation field will be reflected from the target surface and contribute to the detected signal. The detected signal is then given by

$$
V\left(\varepsilon, T_{\mathrm{targ}}\right)=\varepsilon V_{\mathrm{bb}}\left(T_{\mathrm{targ}}\right)+(1-\varepsilon) V_{\mathrm{bb}}\left(T_{\mathrm{bg}}\right)
$$

where $T_{\text {targ }}$ is the target temperature and $T_{\mathrm{bg}}$ is the ambient background temperature near the target. The first term represents the contribution from the target and the second term represents the contribution from the reflected ambient (blackbody) radiation ficld.

Because there are two unknowns in Equation 6, $T_{\operatorname{targ}}$ and $\varepsilon$, a second equation is needed to calculate their values. Addition of a detector with a different spectral bandpass will yield the necessary equation. It should be noted that the geometric dependence is the same for both 
detector equations (assuming that the two detcctors receive radiation from the same spot on the target), and so does not affect the temperature and emissivity calculation

\section{DEVICE SETUP}

A $2 \mathrm{~m}$-long $700 \mu \mathrm{m}$-bore hollow glass optical fiber coated with a metallic/dielectric layer on its inner surface $[7,8]$ is used to collect the infrared radiation emitted by the target. A goldcoated planar chopper modulates the incident radiation while simultaneously splitting it into

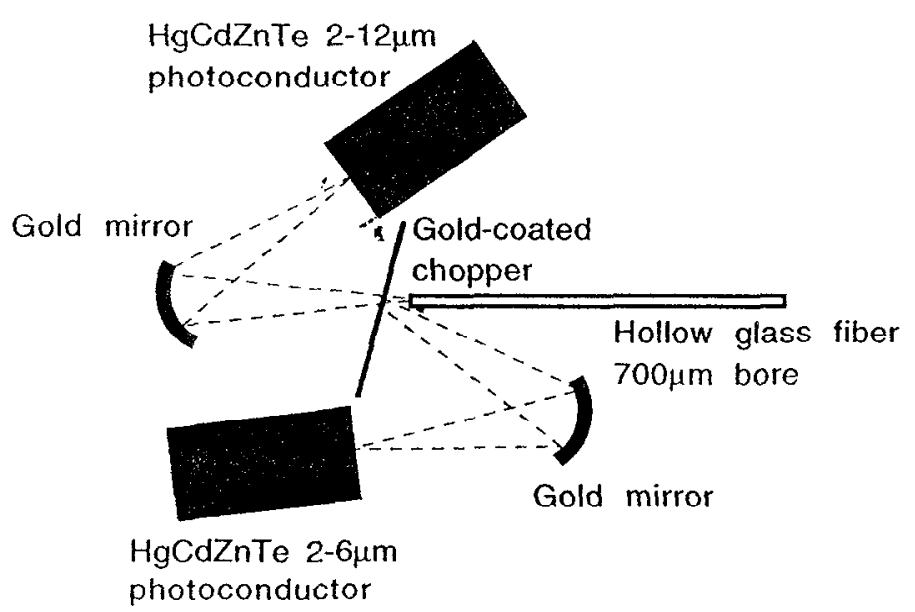

Fig. 1. Configuration of the two-color infrared

thermometer. The radiation transmitted by the fiber is either passed or reflected by the chopper, simultaneously modulating the radiation for lock-in amplification and splitting the radiation into two detection paths. two paths. Two gold-coated spherical mirrors focus the radiation onto their corresponding thermoelectrically-cooled $\mathrm{HgCdZnTe}$ photoconductors $(1 \times 1 \mathrm{~mm}$ active area). The spectral bandpasses of the photoconductors are 2-6 $\mu \mathrm{m}$ and $2-12 \mu \mathrm{m}$ and their response times are $<100$ ns and $<10$ ns, respectively. The two modulated signals are recovered using lock-in amplification.

The

configuration of the optical components is shown in Figure 1. The components are contained within a light-tight housing which contains a port through which the hollow glass fiber extends. Also contained within the housing is a silicon sensor to monitor the temperature inside the housing. This reading is used to dynamically adjust the two lock-in 
signals to account for changes in the ambient radiance at the detectors. A computer receives the detector and silicon sensor signals and calculates the temperature and emissivity using previously obtained blackbody calibration equations.

\section{SYSTEM CALIBRATION}

\section{Lock-in signals}

Our two-color system measures the radiation intensity in each of the spectral bands using lock-in amplification. The lock-in signals are proportional to the difference between the signals originating from the chopper in the open position and closed position, resulting in a signal that is comprised of target and background contributions. The background produces a constant offset independent of the target radiance which must be subtracted from the measured signal. It should be noted that the offset dominates the measured when the target is sufficiently cold.

\section{Calibration procedure}

The system was calibrated by measuring the lock-in signal of each spectral band as a function of the target temperature using a blackbody target. The blackbody was a $10 \times 10 \times 10 \mathrm{~cm}$ aluminum block with a $4 \times 4 \times 4 \mathrm{~cm}$ hollow cavity in the center. A silicon sensor was placed within the aluminum wall to measure the actual blackbody temperature. The hollow glass fiber was inserted through a bore in the aluminum wall such that the fiber tip was flush with the cavity edge. The two calibration curves were fit using an exponential of the form,

$$
V_{\text {lock-in }}(T)=V_{o}+\exp \left(a+\frac{b}{T}+c T\right)
$$


where $V_{\text {lock-in }}(T)$ is the lock-in signal $|V|$ and $V_{o}, a, b$, and $c$ are fit parameters. The calibration curves and their fits are shown in Figure 2.

As described above, $V_{0}$ is related to the background radiation field in the system housing, and is governed mainly by the temperature within the housing. It follows that the signal originating from the blackbody only is given by

$$
V_{\mathrm{bb}}(T)=V_{\text {lock-in }}(T)-V_{o}=\exp \left(a+\frac{b}{T}+c T\right)
$$

Fiber transmittance (which is essentially independent of the wavelength within the measurement band) and system alignment govern $a$, which is a scaling factor. The parameters $b$ and $c$ depend on the temperature (spectral) response of the detectors.

To compensate for fluctuations in the temperature within the housing and possible changes

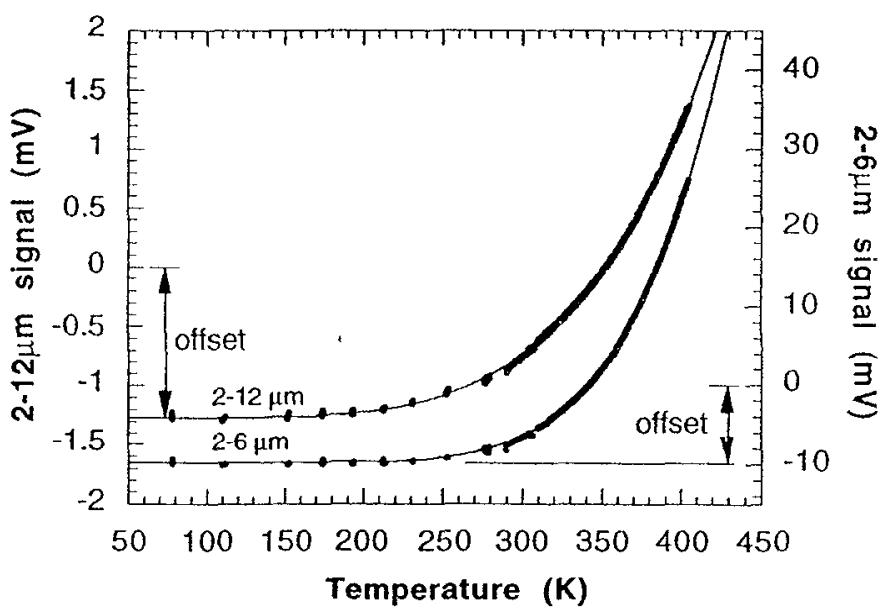
in coupling mechanisms such as the alignment of the optics and fiber transmission, the system calibration is designed to allow for slight Fig. 2. Detector calibration curves. The lock-in signals from the two detectors were measured as a function of the temperature of a blackbody and were fit with the exponential function (solid line) in Equation 7. 
shifting and rescaling of the calibration curves which results in adjustments to $V_{o}$ and $a$. This task is accomplished accurately by measuring the signals from a cool blackbody $\left(\mathrm{T} \leq 25^{\circ} \mathrm{C}\right)$ and a warm blackbody $\left(\mathrm{T} \geq 80^{\circ} \mathrm{C}\right)$, providing two realizations of Equation 8 which can be solved simutanelously for $V_{o}$ and $a$.

Variations in the background signal arising from temperature drifts within the housing (i.e., $V_{o}$ ) during use are compensated by independently measuring the temperature within the housing (with a silicon sensor) and applying temperature dependent corrections to the measured signals. To determine the appropriate corrections, the signals from a blackbody at constant temperature were measured as a function of the temperature in the housing.

The theoretical blackbody temperature response of each of the two detectors is approximated using Equation 2 with the fiber acceptance function (Equation 13) in placc of the two cosines (the function accounts for the

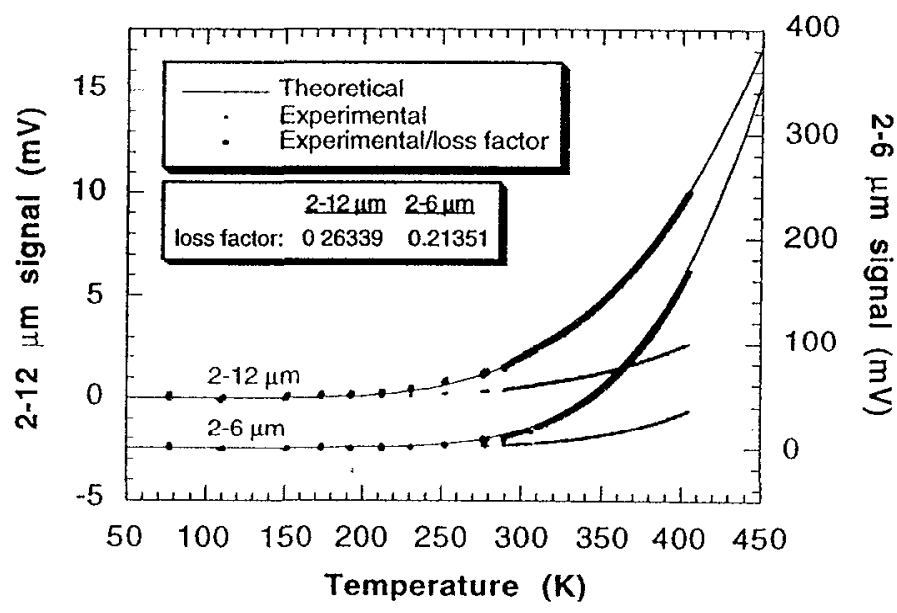

Fig. 3. Theoretical and experimental tempcrature response of the detectors. The effect of the projected offset is subtracted from the experimental curves. areas). Figure 3 shows the Division of each experimental curve by a constant theoretical blackbody representing system losses shows that the temperature response for each of the two detectors experimentally determined calibration equations agree with those derived theoretically 
compared to the corresponding expcrimentally determined calibration $\left(V_{\mathrm{l}(\mathrm{k}, \mathrm{k}-\mathrm{in}}(T)-V_{0}\right)$. Division of each experimental curve by a particular constant resulted in excellent agrecment with theory. This constant represents coupling losses introduced by the real system, which were not included in the theoretical calculation.

\section{DETERMUNATION OT TEMOERATURE AND EMISSIVITY}

Substituting the experimentally determined blackbody temperature response (Equation 8) and the offset-corrected detected signal in Equation 6, the resulting equation for a non-blackbody target is

$$
V_{\text {lock }- \text { in }}\left(\varepsilon, T_{\text {targ }}\right)-V_{o}=\varepsilon \exp \left(a+\frac{b}{T_{\text {targ }}}+c T_{\text {targ }}\right)+(1-\varepsilon) \exp \left(a+\frac{b}{T_{\text {bg }}}+c T_{\text {bg }}\right) \text {. }
$$

These two equations, one for each spectral band, can be solved simultaneously for target temperature and emissivity (the background temperature is measured with a silicon sensor). However, when the target temperature is equal to the ambient background (i.e., when it is in thermal equilibrium with its surroundings), no emissivity information is available.

System time response is detcrmined by the lock-in time constant. Longcr time constants increase the signal-to-noise, providing greater accuracy, but increase the rise time. Shorter time constants, on the other hand, reduce the rise time at the expense of the signal-to-noise. Fast system response combined with high signal-to-noise detection can be obtained through a scheme that takes advantage of two circumstances: (i) emissivity variations are usually small and take place on a longer time scale than temperature variations and (ii) the signal-to-noise or detectivity of the shorter wavelength detector is approximately 10 times larger in this case. Initially a noisy temperature and emissivity are computed by solving Equations 9 using 
fast time constant lock-in signals. The resulting emissivity is filtered at a much smaller cutoff fiequency implemented in a real time digital filter. This emissivity value is then substituted into the 2-6 $\mu \mathrm{m}$ detector equation along with the corresponding unfiltered (fast) lock-in signal 10 calculate a "fast" temperature (the 2-6 $\mu \mathrm{m}$ detector is used because it has a higher signal-to-noise ratio than the $2-12 \mu \mathrm{m}$ detector). One can also filter the temperature signal obtained from the two-color calculation to reduce nöise,

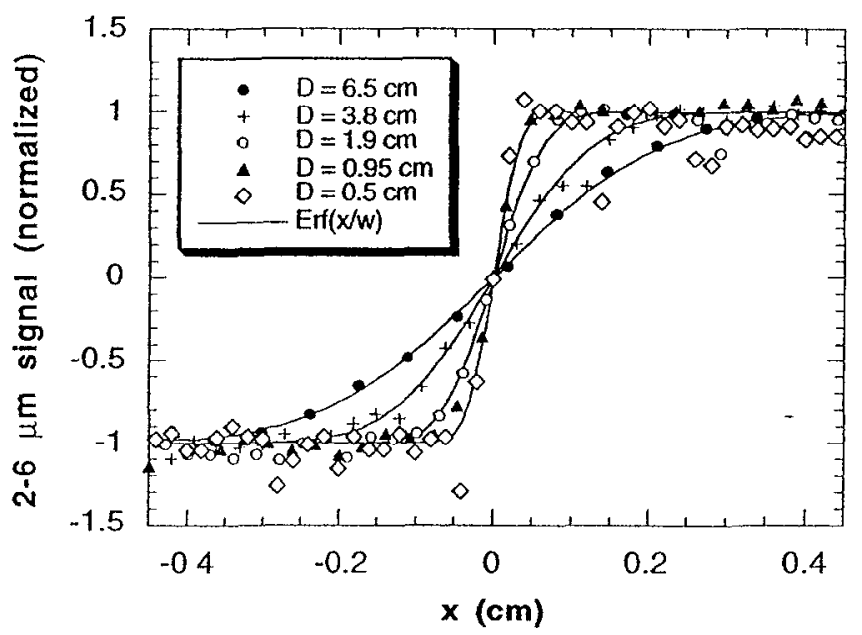
but at a cost of a significant reduction of speed (this procedure would be equivalent to using slow lock-in time constants without any filtering). A single equation is all that is Fig 4. Normalized detector voltages as a function of scan distance across an interface between black anodized and white spray painted aluminum for various fiber heights. The interface is located at $x=0$, with the black surface on the left and the white surface on the right. necessary to compute the true temperature after the two-color principle is used to determine the emissivity using the slow, filtered signals. This method relies on the assumption that variations of the target emissivity will occur over a relatively long time scale.

\section{NUMERICAL APERTURE AND SPATIAL RESOLUTION}

The function describing the radial acceptance of the hollow glass optical fiber was determined experimentally by scanning the fiber across an interface between black anodized and white 
spray painted aluminum and recording the voltage signal from the $2-6 \mu \mathrm{m}$ detector. As a result of the insulation provided by the spray paint, when the aluminum was heated the two surfaces yielded two different signals. Scans at five fiber heights were done, and the resulting normalized signal versus scan distance curves were fit using the error function

$$
\operatorname{Erf}\left(\frac{x}{w}\right)=\frac{2}{\sqrt{\pi}} \int_{0}^{2 / w} \exp \left(-t^{2}\right) d t
$$

where $x$ is the scan distance and $w$ is the fit parameter. The scans and their fits are shown in Figure 4.

The radial acceptance function of the optical fiber $H\left(R_{1}\right)$ was defined by the equation

$$
V(x)=V_{\text {white }} \int_{\text {white }} H\left(R_{1}\right) d A+V_{\text {black }} \int_{\text {black }} H\left(R_{t}\right) d A
$$

where $V(x)$ is the detector voltage during the scan, $V_{\text {white }}$ is the detector voltage when the detector receives radiation from the white surface only, $V_{\text {black }}$ is the detector voltage when the detector receives radiation from the black surface only, the first integral is over the sensed area occupied by the white surface, the second integral is over the sensed area occupied by black surface, and $R_{t}$ is the radial distance on the target surface. The normalized solution of this equation is the gaussian function

$$
H\left(R_{1}\right)=\exp \left[-\left(\frac{R_{t}}{w}\right)^{2}\right],
$$


where the fit parameter $w$ is the $1 / e$ half-width of the gaussian.

Plotting the gaussian $1 / e$ half-width parameter $w$ versus the fiber height and fitting a line originating at the origin to the far field data points (Figure 5) yields the general far field fiber acceptance function

$$
H\left(R_{\mathrm{l}}\right)=\exp \left[-\left(\frac{R_{1}}{0.0375 D}\right)^{2}\right]
$$

where $D$ is the fiber height above the target. The numerical aperture of the hollow glass fiber, giveñ by the sine of the acceptance cone half-angle, is then approximately 0.04 , (the aeceptance cone half-angle is about $\left.2^{\circ}\right)$.

The rather small numerical aperture of the fiber means that collected signals are much smaller than obtained, for example, with silver halide fibers (numerical aperture $\approx 0.5$ ). However, this disadvantage is

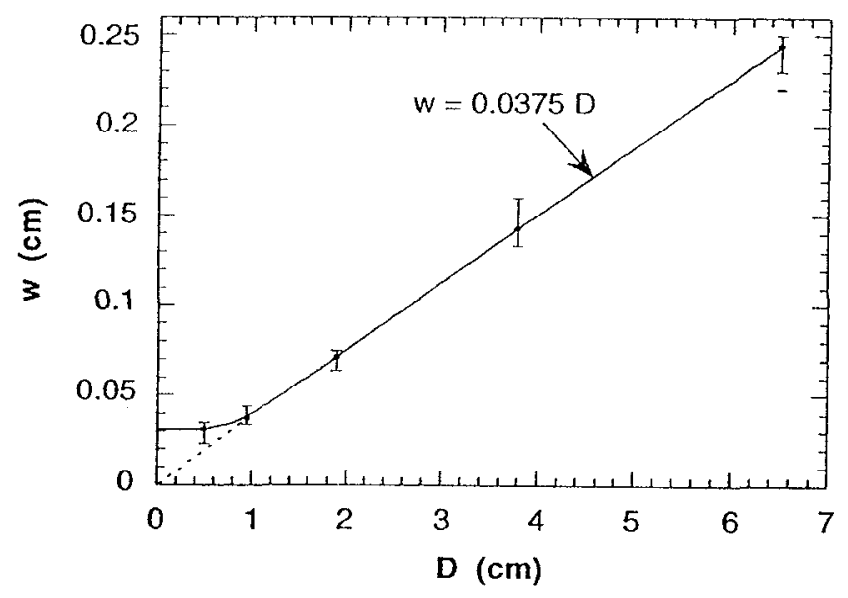

Fig. 5. Gaussian $1 / e$ half-width fit parameter as a function of fiber height above the target surface. As $D$ approaches zero, $w$ approaches the bore radius $(\approx 0.031 \mathrm{~cm})$, and the linear fit is no longer valid. The effective bore $(\approx 620 \mu \mathrm{m})$ is slightly smaller than the $700 \mu \mathrm{m}$ hollow glass bore due to the metallic/dielectric layer on the glass surface. The error bars represent the upper and lower bounds on the values for $w$ that could fit the scans in Figure 4. 
compensated by high spatial resolution. From figure 5 it is evident that the hollow glass fiber will accurately monitor the surface temperature of heated spots as small as $2 \mathrm{~mm}$ at a working distance of $2 \mathrm{~cm}$. This spatial resolution is relatively insensitive to small variations in working distance since no focusing system is used to collect the radiation.

\section{MEASUREMENTS}

The temperature of a blackbody (same as those used in the calibration procedure) was measured with the two-color system and the calculated temperature was compared with the

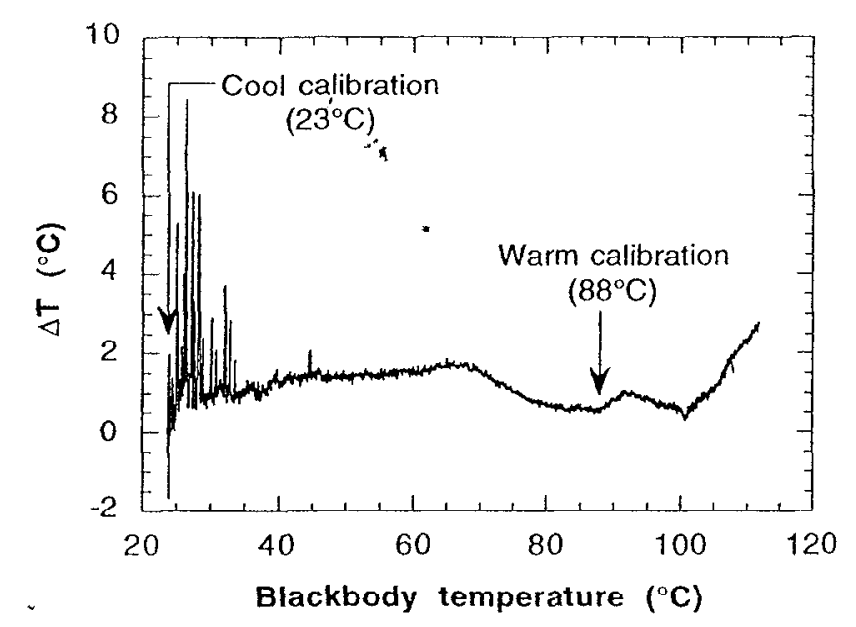

Fig. 6. Difference between the two-color temperature and the actual (silicon sensor) temperature versus the actual temperature for a blackbody target. The two temperatures agree to within the accuracy of the silicon sensor at all temperatures between the cool and warm blackbosy calibration points. The noise at lower temperatures is a result of lower signal-to-noise in the detectors. actual blackbody temperature measured by the silicon sensor (Figure 6). The two-color measurement agrees with the silicon sensor reading to within $\pm 2^{\circ} \mathrm{C}$, although the data in Figure 6 indicate a systematic bias in the two-color measurement of approximately $+1^{\circ} \mathrm{C}$. This discrepancy might result from approximate $\quad \pm 1^{\circ} \mathrm{C}$ absolute uncertainty of the various silicon sensors used to perform the initial calibrations and subsequent tests. When the systematic bias is removed, the two-color temperature monitor produces systematic variations within 
$\pm 1^{\circ} \mathrm{C}$ relative to the silicon sensor over a temperature range of $20-100^{\circ} \mathrm{C}$. This degree of accuracy is adequate for many applications. This systematic variation might be improved by refining the calibration fits. Figure 6 also demonstrates that the accuracy of the system is greatly diminished as the target approaches the ambient background temperature $\left(T_{\mathrm{bg}} \approx 20^{\circ} \mathrm{C}\right.$ in this case), owing to the singularity when $T_{\text {targ }}=T_{\mathrm{bg}}$ (see Equation 9). For this reason the system cannot accurately measure target temperatures much below $35^{\circ} \mathrm{C}$ in a room temperature environment.

Figure 7 shows the twocolor temperature and emissivity versus the fiberto-target distance for "a uniformly heated target. A black anodized aluminum block was maintained at constant temperature and the two-color temperature and emissivity were measured as a function of the fiber height above the

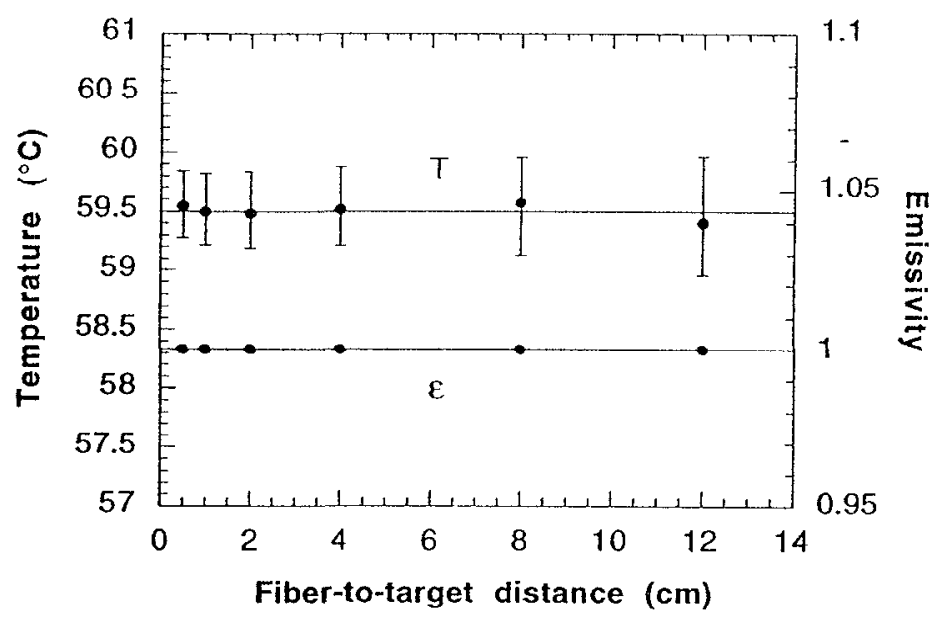

Fig. 7. Two-color temperature and emissivity versus fiber height above a uniformly heated target. The data points represent average values and the error bars represent minimum and maximum values over the $10 \mathrm{~s}$ measurement interval surface of the block. Measurements were taken for $10 \mathrm{~s}$ at each of several fiber heights from 0.5 to $12 \mathrm{~cm}$. As expected, the calculated values are independent of the fiber-to-target distance.

To demonstrate the utility of two-color thermometry for measurements of objects with moderate albedos, the temperature and emissivity of two materials with different emissivities at the same temperature were measured (Figure 8). A thin layer of a silicone thermal 
conductive compound was applied to part of a heated stainless steel surface and allowed to reach thermal equilibrium. Both the twocolor and brightness (single detector) temperatures were calculated. In the case of the silicone compound the two calculated temperatures agree since the emissivity was 1 . However, the brightness temperature of the low emissivity stainless steel is significantly lower than the emissivity-corrected twocolor temperature. Though the two-color algorithm

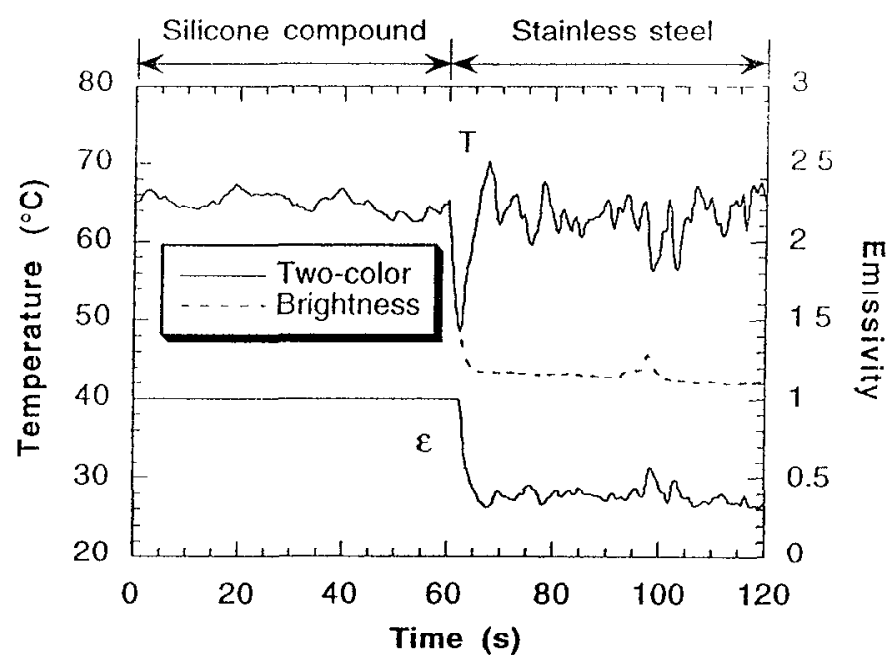

Fig. 8. Comparison of two-color and brightness (single detector: $2-6 \mu \mathrm{m}$ ) calculated temperatures for two materials of different emissivity at the same temperature. Measurements were acquired for $1 \mathrm{~min}$ for each material. Unlike the two-color temperature, the brightness temperature obtained from the 2-6 $\mu \mathrm{m}$ photoconductor is inaccurate for the low-emissivity target.

returns quite noisy data for the stainless steel and other low-emissivity targets, it does provide a much improved temperature measurement compared to the single detector calculation.

\section{SUMMARY AND CONCLUSION}

The hollow glass optical fiber-based two-color mid-infrared thermometer enables dynamic non-contact, fast, high spatial resolution temperature and emissivity measurement. The midinfrared bandpasses of the hollow glass fiber and $\mathrm{HgCdZnTe}$ photoconductors, coupled with lock-in amplification, permit low-temperature measurement. As a result of the two-color 
principle, the true temperature and emissivity of a target are determined (assuming the emissivity is independent of wavelengh within the measurement band). Failure to meet the graybody requirement as a result of a large measurement band, as is the case for this device, will increase the uncertainty associated with the calculated values; nevertheless, the two-color method results in improved temperature values compared to the brightness temperature.

The single fiber eliminates the problem of aligning two fibers to a common spot on the target. In order to obtain true values for the temperature and emissivity, the radiation observed through both bands must originate from the same geometric region on the target (which may not be true when a separate fiber is used to collect radiation for each band. As a result of the small numerical aperture of the hollow glass fiber, the calculated temperature and emissivity are effectivelya independent of the fiber-to-target distance (for a target of uniform temperature over the observed surface area). This feature allows the user to dynamically adjust the distance between the fiber tip and the target. The small numerical aperture of the hollow glass optical fiber also provides high spatial resolution, and the hollow bore eliminates reflective losses. In addition, the hollow glass fiber is flexible, robust, and stable.

The combination of the single fiber, multiplexing chopper, and separate detectors enables the realization of a variety of configuration schemes, which may involve simply rearranging the optical components or extending the system to multiple wavelength bands. For example, the two-color configuration described here may be improved by using aspherical mirrors or altering the beam paths to decrease the angle of incidence as a means of reducing astigmatism. Further, incorporation of one or more additional detectors can be accomplished by inserting a beamsplitter in either or both paths. The basic single fiber/multiplexing chopper concept provides a high degree of flexibility in the design and construction of a multi-color infrared thermometer. 


\section{ACKNOWLEDGMENTS}

This work was performed under the auspices of the U.S. Department of Energy by Lawrence Livermore National Laboratory under Contract W-7405-ENG-48 as part of the Cooperative Research and Development Agreement TC-1085-95 with Conversion Energy Enterprises of Spring Valley, New York The authors wish to thank J. Harrington for providing the hollow glass fiber, and J. Cox and K. Haney for their help in fabricating the device.

\section{REFERENCES}

1. Maldague $X$, Dufour $M$. Dual imager and its applications to active vision robot welding, surface inspection, and two-color pyromctry. Opt Eng 1989; 28(8):872-880.

2. K. Crane, et al. I.R:sradiation pyrometer. US Patent No 4470710 (1984).

3. Eyal $O$, Katzir A. Temperature measurements utilizing two-bandpass fiber optic radiometry. Opt Eng 1995; 34(2):470-473.

4. Tenney AS. Radiation ratio thermometry. In: Theory and Practice of Radiation Thermometry, Dewitt DP and Nutter GD (eds), pp. 459-494, John Wiley and Sons, Inc., New York (1988).

5. Brownson J, Gronokowski K, Meade E. Two-color imaging radiometry for pyrotechnic diagnostics. In: Selected Papers on Temperature Sensing: Optical Methods, Lucier RD

- (ed), SPIE Milestone Series 1987; 116:525-532.

6. Eyal O, Zur A, Shenfeld O, Gilo M, Katzir A. Infrared radiometry using silver halide fibers and a cooled photonic detector. Opt Eng 1994; 33(2):502-509.

7. Abel $T$, Hirsch J, Harrington JA. Hollow glass waveguides for broadband infrared transmission. Proc SPIE 1994; 2131:11-17.

8. Abel T, Hirsch J, Harrington JA. Hollow glass waveguides for broadband infrared transmission. Opt Lett 1994; 19:1034-1036. 


\title{
Chapter 7
}

Effect of $527 \mathrm{~nm}$ Laser Light on Collagen Crosslinks: Implications for Tissue Welding

\begin{abstract}
Laser-induced changes in native collagen crosslinking may impact the success of laser tissue fusion. To investigate the influence of laser exposure on crosslinking, a systematic in vitro study was performed using a porcine carotid artery model. Tissues were irradiated using a 527 $\mathrm{nm}$ solid state laser at various powers $(0.5,1.0,3.0,5.0,8.0 \mathrm{~W})$ for different durations $(5$, $10,15,30 \mathrm{~s}$ ); no absorbifing chromophores or solders were used. The difunctional crosslink HLNL, its dihydroxylated analogue DHLNL, and the trifunctional product of DHLNL, OHP, were quantified for treated and native tissues. Laser power and duration had variable effects on HLNL, which generally increased or remained unchanged. DHLNL was significantly elevated above native levels for laser exposed tissue; both power and duration were independently correlated with the increase. OHP was significantly decreased compared to native controls; the effect was strongly correlated with duration, but not power. Examination of the precursor-product relationship suggests that under some conditions OHP was degraded to the precursor stage which may account for the increase in DHLNL, while under other conditions it may have degraded beyond this stage. Though mature crosslinks may be reduced, optimal laser exposure conditions may exist which do not destroy the precursors for a given tissue. Laser-induced formation and destruction of covalent crosslinks may impact the strength and stability of laser welded tissues.
\end{abstract}




\section{INTRODUCTION}

The phrase "laser tissue welding" suggests a futuristic procedure for instantaneous healing such as one might see on the television series Star Trek. In reality, laser tissue welding cannot properly be considered an isolated event that stops when the laser is turned off. The acute bond formed between adjacent tissues (or between tissue and an extrinsic agent such as solder) is only the first step in the realization of a successful weld. Though the foundation of the weld is established by the initial laser-activated bonding, the strength and stability of the welded tissue is ultimately determined in the months following the laser treatment, after the body's healing response has run its course. Essentially, the function of laser tissue welding is to provide a temporary bond to be enhanced and finalized by the deposition of new collagen and other wound healing mechanisms. In spite of the futuristic connotations of laser tissue welding, the importance of the natural physiology of healing has not diminished.

Covalent collagen crosslinks, which stabilize the spatial relationships among the tropocollagen molecules, govern the functional properties of a given tissue [1] and are present in new collagen formed during wound healing [2]. In fact, disturbance of the crosslinking process can negatively affect the healing response [1]. Therefore, crosslinks already present, created or destroyed during the welding procedure, or synthesized after the procedure may influence the acute weld strength and long-term stability of the laser irradiated tissue. Because previous laser tissue welding studies have suggested that crosslinking is modified as a result of argon laser irradiation [3-6], a systematic study of the effects of green $(527 \mathrm{~nm})$ laser light on covalent crosslinking was performed. The implications for laser tissue welding are discussed. 


\section{MATERIALS AND METHODS}

\section{Tissue preparation}

Porcine carotid arteries were freshly harvested and refrigerated $\left(5^{\circ} \mathrm{C}\right)$ for several hours prior to the experiment. The arteries were cut into $5 \times 5 \mathrm{~mm}$ slabs and soaked in phosphatebuffered saline (PBS) for several minutes to prevent desiccation. Each tissue slab was placed on a glass substrate with the intima facing up immediately before laser exposure.

\section{Laser exposure protocol}

A $527 \mathrm{~nm}$ frequency doübled Nd:YLF laser (beam diameter $=6 \mathrm{~mm}$ ) operating at $50 \mathrm{kHz}$ (pulse width $=250 \mathrm{~ns}$ ) was used to irradiate the intima surface of each artery slab at average

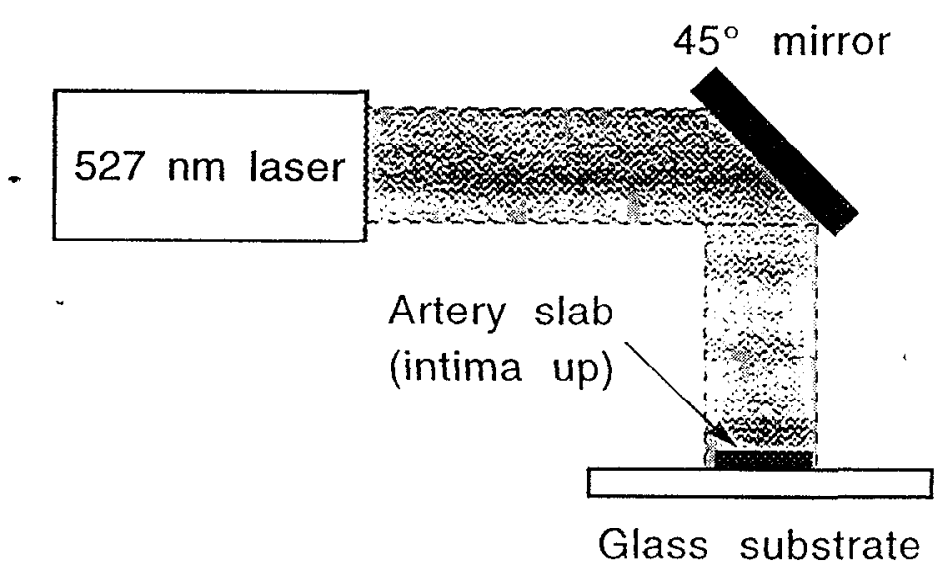

Fig. 1. Laser irradiation of porcine carotid artery. The entire tissue slab was exposed to the unfocused laser beam. powers of 0.5 or $1.0 \mathrm{~W}$ for 5 , 10,15 , or $30 \mathrm{~s}(8$ separate protocols), 3.0 or $5.0 \mathrm{~W}$ for 10,15 , or $30 \mathrm{~s}$ (6 separate protocols), or $8.0 \mathrm{~W}$ for $30 \mathrm{~s}$ (1 protocol). Delivered energies (power $\times$ duration) ranged from 2.5 to $240 \mathrm{~J}$. The beam was directed onto the tissue by a single flat mirror such that the entire

surface of the tissue was irradiated (Figure 1); the beam was not focused onto the tissue surface. Following laser exposure, the tissue slabs, including 3 native control slabs which were 
not exposed to laser light, were flash frozen in PBS until biochemical crosslink analysis was performed.

\section{Crosslink}

measurement

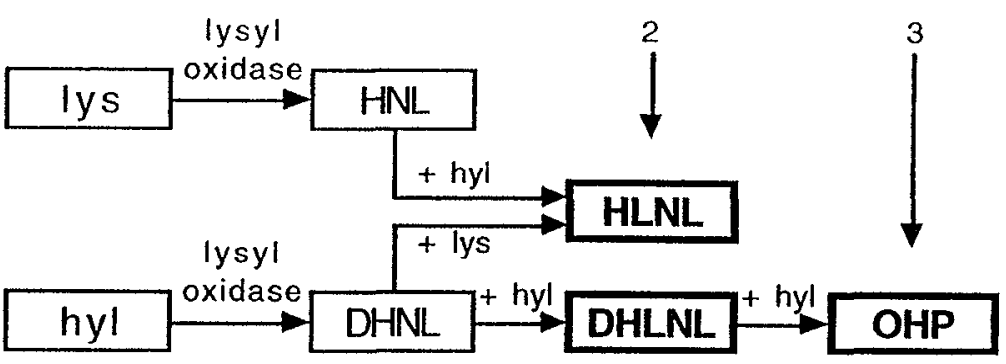

slab was cut into

several smaller pieces.

Fig. 2. Biosynthesis of HLNL, DHLNL, and OHP

Each piece was

collagen crosslinks. Lysine (lys) and hydroxylysine (hyl)

analyzed individually is

for collagen crosslink

.DHNL) by the enzyme lysyl oxidase, which further react to content, using high-

form covalent bonds with other lysine and hydroxylysine performance liquid residues. The number of residues participating in each

chromatography crosslink is indicated by the arrows $(2=$ difunctional, $3=$ techniques previously trifunctional). The difunctional crosslinks HLNL and described in detail [7]. DHLNL link two separate tropocollagen molecules The difunctional together, connecting a residue on one molecule to a residue crosslink on an adjacent molecule. In addition to a connection hydroxylysinonorleuci between residues on two separate molecules, the ne (HLNL) and its trifunctional crosslink OHP also links one of the dihydroxylated participating residues to a third residue; this residue may analogue either be on one of the two linked molecues (two molecules dihydroxylysinonorleu are linked) or on a third distinct molecule (three molecules cine (DHLNL) were are linked), depending on the molecular stagger in the analyzed using an collagen matrix [8] 


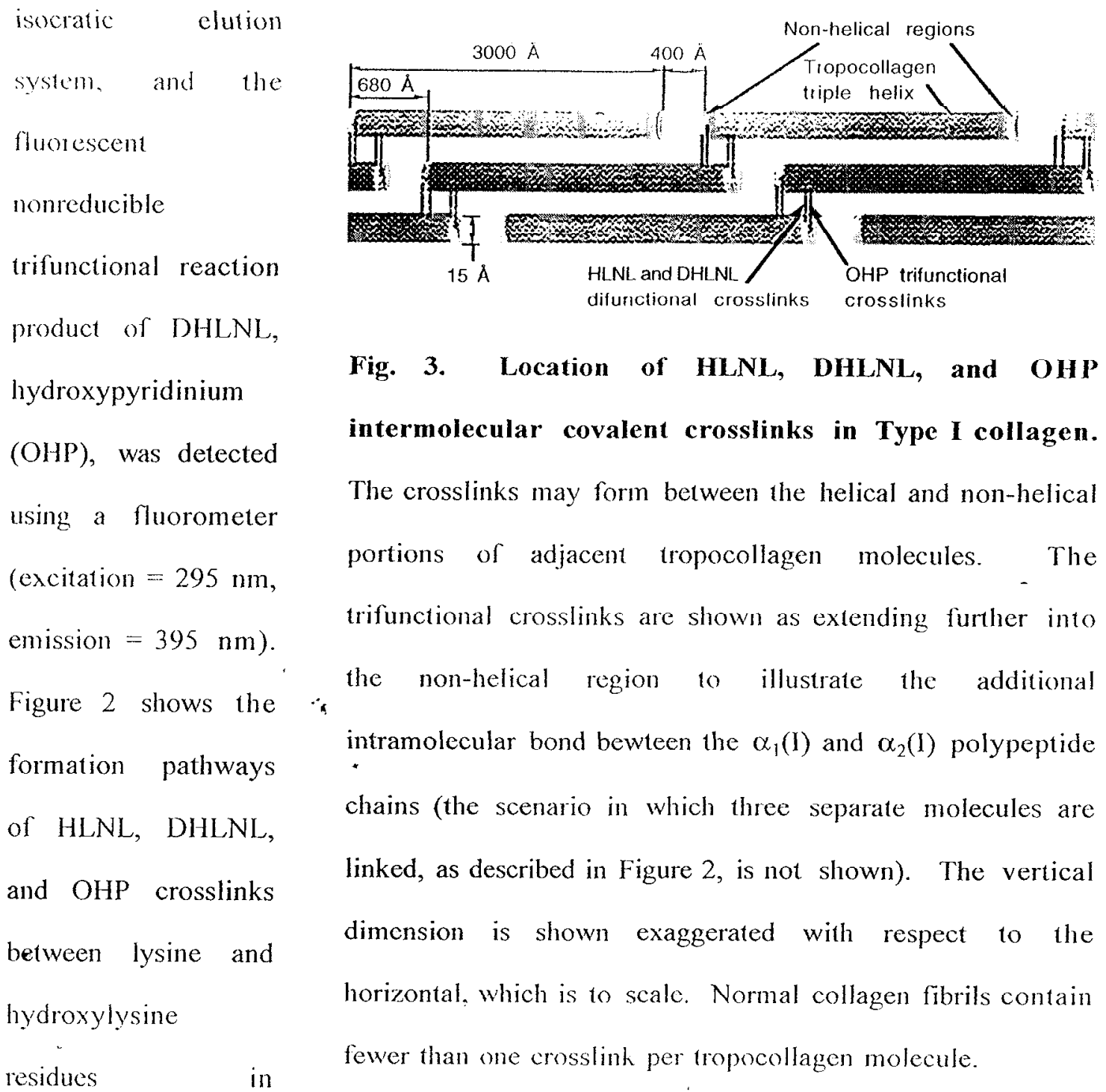

tropocollagen molecules in Type I collagen [1]. The relative locations of these crosslinks in the Type I collagen matrix are shown in Figure $3[1,9]$.

\section{Statistical analysis}

Correlations between two quantities were investigated using the nonparametric measure Kendall's Tau [10]. The null hypothesis (i.e., the two quantities are mutually independent) was accepted if the critical significance level of the Kendall test statistic was greater than 
0.20 (one-sided test); otherwise, the possibility of either positive or negative correlation of the two quantities was considered I incar lits were obtained using the method of least squares.

\section{RESULTS}

\section{Effects of energy}

The crosslink concentrations of all trials are shown in Figure 4 as a function of delivered energy. For delivered energies below $75 \mathrm{~J}$, HLNL increased or remained unchanged with respect to its native level under laser exposure; no significant destruction occurred. At or above $75 \mathrm{~J}$, HLNL increased, decreased, or remained unchanged. DHLNL, which is strongly correlated with energy, generally experienced an increase or no change regardless of the delivered energy (one outlier at $75 \mathrm{~J}$ ). In all cases, OHP was reduced below its native
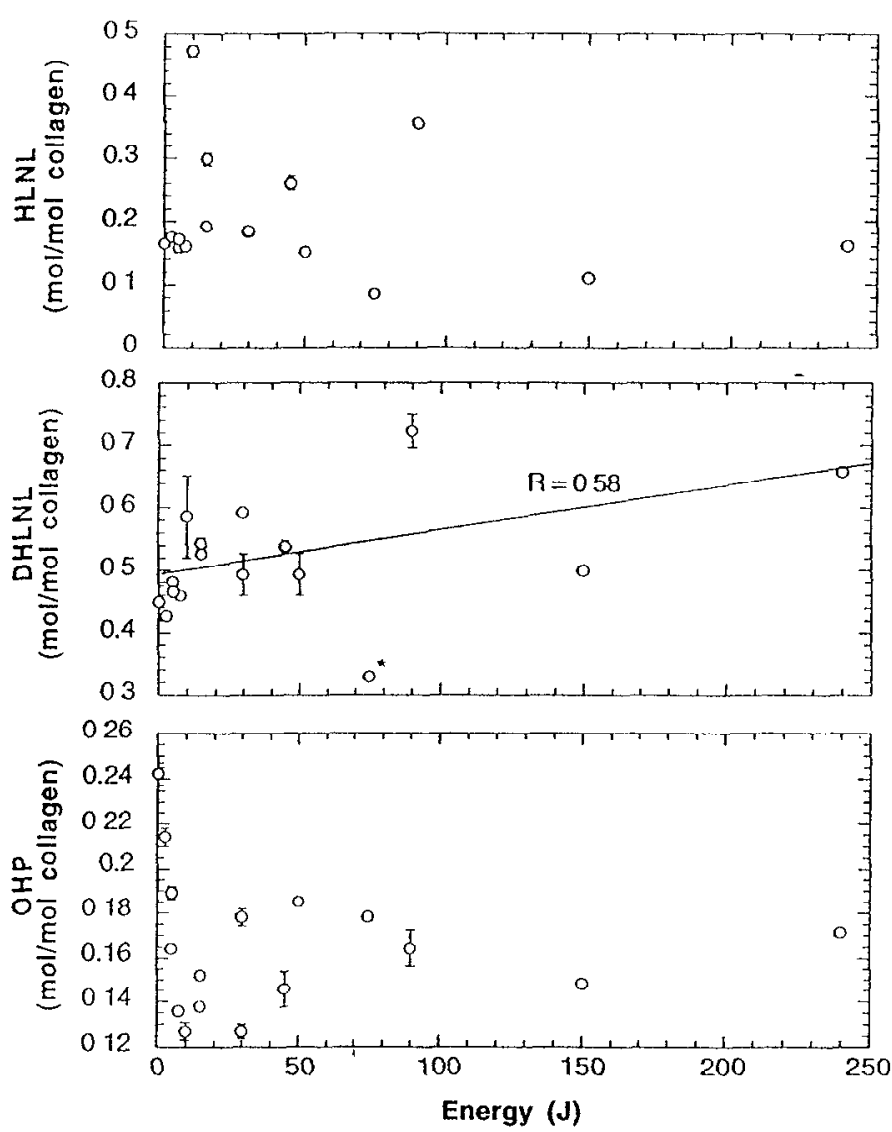

Fig. 4. Concentration of HLNL, DHLNL, and OHP as a function of energy delivered by the laser. A correlation exists between DHINI, and energy delivered (0.025 significance level). The DHLNL outlier at $75 \mathrm{~J}(5.0 \mathrm{~W}, 15 \mathrm{~s})$ marked by the asterisk $\left(^{*}\right)$ was not included in the linear fit. Native levels are indicated at Energy $=0 . \quad$ The error bars represent the standard error. 
level following laser

exposure.

Effects of power and duration

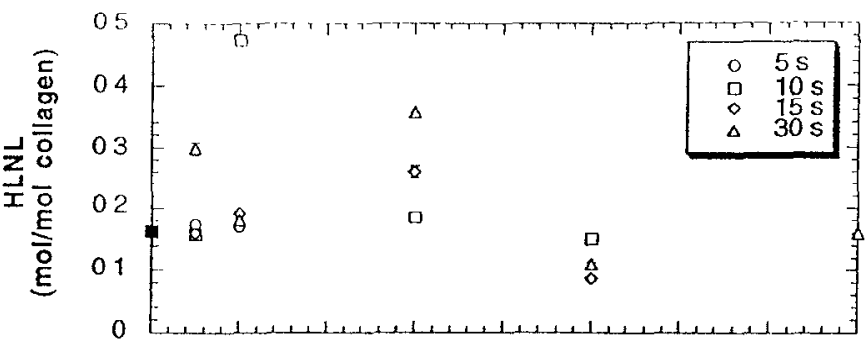

The individual effects of laser power and exposure duration were investigated. The results are shown in Figures 5 and 6, respectively. Laser power and duration had variable effects on HLNL: Both power and duration were independently cerrelated with the increase in DHLNL. The decrease in OHP was strongly correlated with duration, but not power.

The ratio of DHLNL to
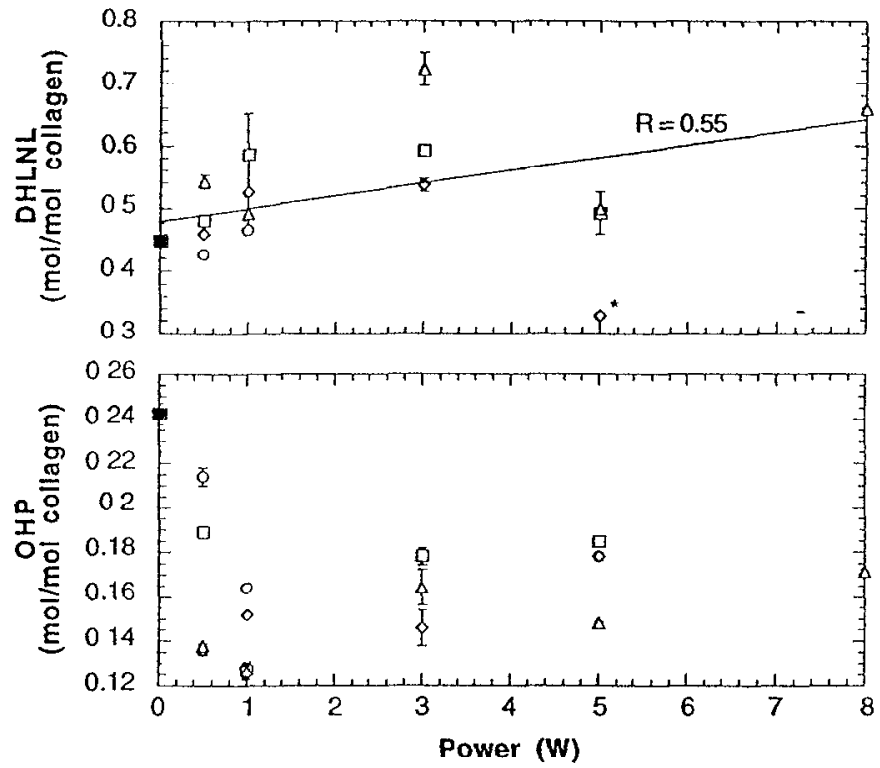

Fig. 5. Concentration of HLNL, DHLNL, and OHP as a function of laser power for various exposure durations. Only DHLNL is correlated with laser power (0.05 significance level). The DHLNL outlier $(5.0 \mathrm{~W}, 15 \mathrm{~s})$ marked by the asterisk HLNL was elevated for laser powers of $5.0-8.0 \mathrm{~W}$ (mean $=3.9)$ compared to the ratio $\left(^{*}\right)$ was not included in the linear fit. Native levels are indicated by the black square at Power $=0$. The error bars represent the standard error.

for $0.5-3.0 \mathrm{~W}$ (mean $=2.4$ ) and the ratio of 2.7 for the native control (data not shown in figures). The ratio was not correlated to either power or duration. 


\section{Precursor-product relationship}

The correlation between the difunctional precursor DHLNL and its trifunctional maturation product OHP is shown in Figure 7. With the exception of a single trial (power $=5 \mathrm{~W}$, duration $=15 \mathrm{~s}$ ) in which a reduction of both OHP and DHLNL occurred, the laser-induced decrease in OHP was accompanied by either no change or an increase in DHLNI.

\section{DISCUSSION}

Under some conditions, laser exposure in the green region of the spectrum can affect the normal distribution of collagen crosslinks. Though the effects of laser power and duration on the concentration of HLNL were variable, changes in DHLNL and OHP content seemed to depend on the energy delivery protocol. This observation agrees with our previous in vivo canine argon laser tissue welding study which suggested that collagen crosslinking induced by a specific laser protocol plays a role in the tissue fusion mechanism $[5,6]$. In that study, we reported an increase in DHLNL and OHP levels under certain conditions following laser exposure, and observed a possible correlation between increased DHLNL and OHP content and improved acute weld strength and patency rate; however, the long-term status of the welds was not investigated. Many factors, including temperature, tissue type, and the fact that the argon laser welds were performed in vivo, could account for the discrepant OHP observations between the two studies. Nevertheless, covalent crosslink counts were modified (DHLNL content, in particular, was increased) by laser exposure in both studies.

Perturbations in the crosslinking process generated by laser exposure could result in long-term adverse effects ranging from failure to heal and inadequate wound strength to hypertrophic scarring and fibrosis [1]. In particular, studies have shown that increased DHLNL content with relatively low levels of OHP relative to control values, such as was observed in this 
study, is indicative of fibrosis [11]. Also, an abnomally high DHLNL to HLNL ratio has been suggested to be indicative of fibrotic insult [12] A selective increase in DHLNL has
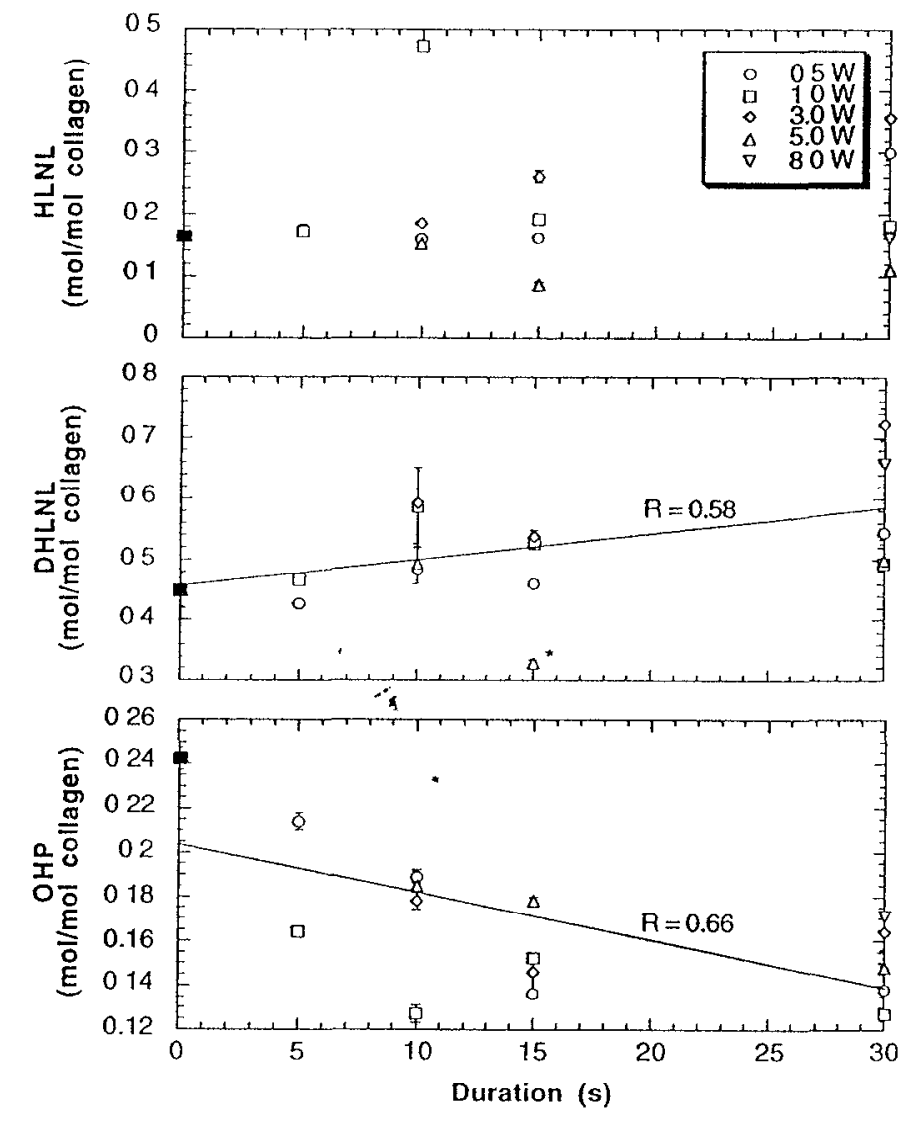

Fig. 6. Concentration of HLNL, DHLNL, and OHP as a function of exposure duration for various laser powers. Exposure duration is correlated with both DHLNL (0.05 significance level) and OHP (0.025 significance level). The DHLNL outlier $(5.0 \mathrm{~W}, 15 \mathrm{~s})$ marked by the asterisk $\left(^{*}\right)$ was not included in the linear fit. Native levels are indicated by the black square at Duration $=0$. The error bars represent the standard error. also been reported in models of hyperglycemia, hypertrophic scarring, recurrent hip dislocation, and Dupuytren's contracture [13]. Though histological examination has shown that laser welding generally demonstrates normal healing $[14,15]$, the fact that crosslinking perturbations can be introduced suggests that caution should be exercised. Because the effects of crosslinking modifications are not immediately evident, an initially strong weld is not necessarily a safe marker for a successful procedure.

The possible correlation between the increase in DHLNL and the decrease in OHP suggests that the 
normal precursor-product relationship may have been reversed in some instances. That is, OHP degraded to the precursor stage, accounting for the increase in DHLNL. Since the maturation of DHLNL into

OHP is associated with aging in normal tissue, the laser radiation effectively returned the crosslink content to a "younger" state. It is also possible that OHP degraded beyond the precursor stage in some cases, which suggests that new DHLNL crosstinks formed independently of OHP degradation. The data in Figure 7 shows that a reduction of OHP was not always accompanied by an increase in DHLNL, which implies that OHP degraded

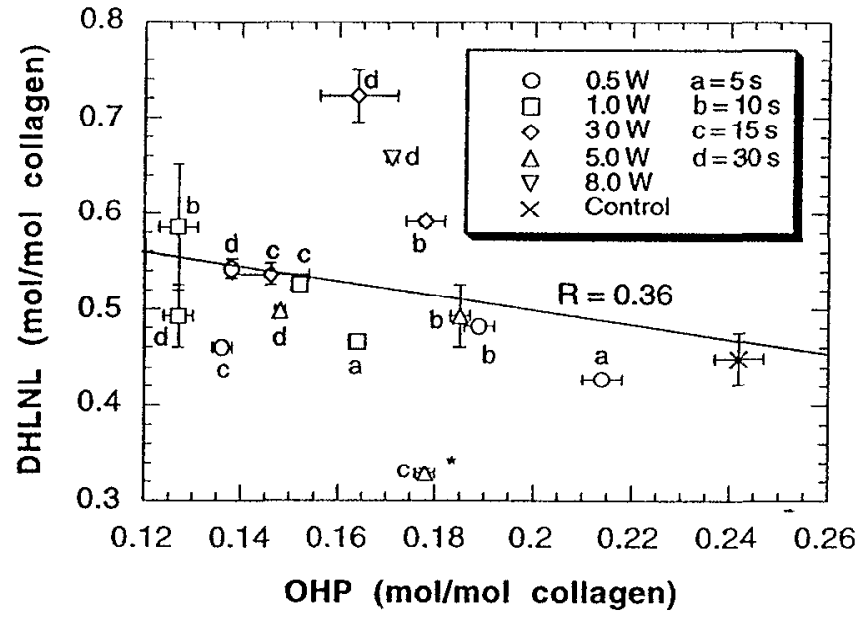

Fig. 7. Relationship between the precursor DHLNL and its maturational product OHP. The two crosslink concentrations exhibit a slight correlation ( 0.20 significance level). The DHLNL outlier $(5.0 \mathrm{~W}, 15 \mathrm{~s})$ marked by the asterisk $\left(^{*}\right)$ was not included in the linear fit. The error bars represent the standard error.

beyond the precursor stage. Also, the observation that the decrease in OHP was generally smaller than the increase in DHLNL indicates that DHLNL formation occurred separately.

\section{CONCLUSIONS}

Biochemical analysis following $527 \mathrm{~nm}$ laser exposure revealed that the content of the collagen crosslinks HLNL, DHLNL, and OHP in artery was altered with respect to native controls in many cases. The general increase in DHLNL concentration was correlated with 
the total energy delivered by the laser; the increase was also independently correlated with the laser power and exposure duration. The decrease in OHP concentration caused by laser irradiation was strongly correlated with exposure duration Under some conditions, OHP may have degraded to the precursor stage, accounting for the increase in DHLNL. However, new DHLNL crosslinks may also have formed separately as a result of the deposition of laser energy in the tissue. Though mature crosslinks may be reduced, optimal laser exposure conditions may exist which do not destroy (and sometimes increase) the precursors for a given tissue. The duration of laser exposure is particularly critical to the precursor/product content. Because modified crosslink distributions are associated with abnormal healing, alteration of the normal number of crosslinks present may significantly affect the- strength and stability of laser welded tissues. Because wound healing is a major factor in the success of laser tissue welding, any disruption which could impede its function should be taken into consideration.

\section{ACKNOWLEDGMENTS}

This work was performed under the auspices of the U.S. Department of Energy by Lawrence

Livermore National Laboratory under Contract W-7405-ENG-48 as part of the Cooperative Research and Development Agreement TC-1085-95 with Conversion Energy Enterprises of Spring Valley, NY, and the Intra-university Memorandum Agreement B291526 between Lawrence Livermore National Laboratory and the University of California, Davis.

\section{REFERENCES}

1. Reiser K, McCormick RJ, Rucker RB. Enzymatic and nonenzymatic cross-linking of collagen and elastin. FASEB J 1992; 6:2439-2449.

2. Reiser KM. Nonenzymatic glycation and enzymatic crosslinking in a model of wound healing. The effects of aging, diet, and modulating agents. J Ger Derm 1993; 1:90-99.

3 Guthrie CR, Murray LW, Kopchok GE, Rosenbaum D, White RA Biochemical mechanisms of laser vascular tissuc fusion. J Invest Surg 1991; 4:3-12. 
4. Murray LW, Su L, Kopchok GE, White RA. Crosslinking of extracellular matrix proteins: A preliminary report on a possible mechanism of argon laser welding. Lasers Surg Med 1989;9・490-496.

5 Small IV W, Celliers PM, Kopchok Gi, et al, In vivo argon laser vascular welding using thermal feedback: open and closed loop patency and collagen crosslinking. In: Lasers in Surgery: Advanced Characterization, Therapeutics, and Systems VII, Proc. SPIE $1997 ; 2970: 252-256$.

6. Small IV W, Celliers PM, Kopchok GE, et al. Temperature feedback and collagen crosslinking in argon laser vascular welding. Lasers Med Sci, in press.

7. Buckingham B, Reiser KM. Relationship between the content of lysyl oxidasedependent cross-links in skin collagen, non-enzymatic glycosylation, and long-term complications in type 1 diabetes mellitus. J Clin Invest 1990; 86:1046-1054.

8. Wu JJ, Eyre DR. Identification of hydroxypyridinium cross-linking sites in type II collagen of bovine articular cartilage. Biochemistry 1984; 23:1850-1857.

9. Hanson DA, Eyre DR. Molecular site specificity of pyridinoline and pyrrole cross-links in type I collagen of human bone. Journal of Biological Chemistry 1996; 271:2650826516.

10. Conover WJ. (1980). Practical Nomparametric Statistics. New York: John Wiley \& Sons, pp. 256-258, 458.

11. Last JA, Armstrong LG, Reiser KM. Biosynthesis of collagen crosslinks. Int $\mathbf{J}$ Biochem $1990 ; 22: 559-564$.

12. Last JA, King TE; Nerlich $A G$, Reiser KM. Collagen cross-linking in adult patients with acute and chronic fihrotic lung disease. Am Rev Respir Dis 1990; 141:307-313.

13. Reiser KM, Crouch EC, Chang K, Williamson JR. Lysyl oxidase-mediated crosslinking in granulation tissue collagen in two models of hyperglycemia. Biochim Biophys Acta $1991 ; 1097: 55-61$.

14. Bass LS, Treat MR. Laser tissue welding: A comprehensive review of current and future clinical applications. Lasers Surg Med 1995; 17:315-349.

15. Chikamatsu E, Sakura, T, Nishikimi N, Yano T, Nimura Y. Comparison of laser vascular welding, interrupted sutures, and continuous sutures in growing vascular

- anastomoses. Lasers Surg Med 1995; 16:34-40. 


\title{
Chapter 8
}

Spectroscopic Study of the Effect of Laser Heating on Collagen Stability:

Implications for Tissue Welding

\begin{abstract}
Collagen is believed to play a major role in laser tissue welding. Furthermore, the fundamental fusion mechanism(s) may include thermal denaturation of the collagen fibers. An in vitro investigation of the effect of laser heating (1.9 $\mu \mathrm{m}$ diode laser) on collagen conformation was performed- Fourier transform infrared (FTIR) spectra of native and heated porcine cornea were obtained. A lowfrequency shift in the amide A band of collagen around $3320 \mathrm{~cm}^{-1}$ indicated that conformational changes associated with denaturation occurred. Samples heated using a temperature feedback controlled $1.9 \mu \mathrm{m}$ diode laser showed a gradual decrease in the amide A peak frequency with increasing temperature, as did samples heated in a water bath. Complete denaturation was achieved at temperatures above $85^{\circ} \mathrm{C}$ for both heating protocols. Water loss induced by laser heating may have reduced the mobility of the collagen polypeptide chains, and contributed to the elevated denaturation temperature.
\end{abstract}

\section{INTRODUCTION}

From the visible to infrared laser wavelengths, the inherently strong triple helical protein collagen is believed to play a major role in laser tissue welding [1]. Furthermore, the fundamental fusion mechanism(s) may include the thermal denaturation (unravelling) of the collagen triple helix and subsequent random intertwining of adjacent collagen fibers [1]. Tissue fusion, like protein denaturation, depends on the temperature history at the weld site. As the tissue is heated by laser 
radiation, inevitably evaporation occurs, resulting in water loss [2-4]. This study investigates the effect of laser heating on collagen conformation.

Because vibrations of the collagen peptide linkages (i.e., bonds between amino acids in each of the three polypeptide chains) are sensitive to conformational changes caused by denaturation $[5,6]$, vibrational spectra of native and heated porcine cornea were obtained using Fourier transform infrared (FTIR) spectroscopy. A low-frequency shift of the amide A band of collagen around 3320 $\mathrm{cm}^{-1}$ compared to native tissue indicates a conformational change associated with denaturation $[5,6]$. Of the heated samples, some were heated in a water bath and the others were heated using a $1.9 \mu \mathrm{m}$ diode laser which caused severe tissue dehydration. The collagen conformation changes associated with each heating method were identified.

\section{MATERIALS AND METHODS}

\section{Tissue preparation}

Porcine eyeballs were harvested (no rinsing during harvest) immediately after sacrifice and refrigerated $\left(5^{\circ} \mathrm{C}\right)$ for several hours until use. The eyeballs were either heated in a water bath or subjected to laser radiation (1.9 $\mathrm{m}$ diode laser) at constant temperature for $100 \mathrm{~s}$. Immediately after heating, each eyeball was flash frozen in liquid nitrogen and a corneal slice $50 \mu \mathrm{m}$ thick within the top $200 \mu \mathrm{m}$ of the cornea was obtained using a microtome. The slices were placed in distilled water for about $5 \mathrm{~min}$ prior to FTIR analysis. The same procedure was used for native controls (unheated).

\section{Heating protocols}

Eyeballs were either submersed directly in a water bath at temperatures of $65,70,75,80,85$, or $95^{\circ} \mathrm{C}$ for $100 \mathrm{~s}$, or their corneas were heated (in situ) using a fiber-coupled $1.9 \mu \mathrm{m}$ diode laser (maximum 
output power $\approx 700 \mathrm{~mW}$ ) in a temperature feedback control loop at temperatures of $60,65,70,80$, 85,90 , or $95^{\circ} \mathrm{C}$ for $100 \mathrm{~s}$ at a single spot $(\approx 2 \mathrm{~mm}$ diameter $)$. A low-OH $600 \mu \mathrm{m}$ diameter silica fiber was used to deliver the laser radiation to the cornea. In order to ensure a sufficiently large heated region for FTIR analysis, several adjacent spots were irradiated (each for $100 \mathrm{~s}$ at the temperature setpoint).

\section{Feedback control system}

Temperature feedback control of the laser was maintained via a hollow glass optical fiber-based twocolor infrared thermometer previously described in detail [7-9]. The hollow glass fiber and the laser delivery fiber, contained in a handpiece with a height-positioning guidewire $[8,9]$, are directed to a

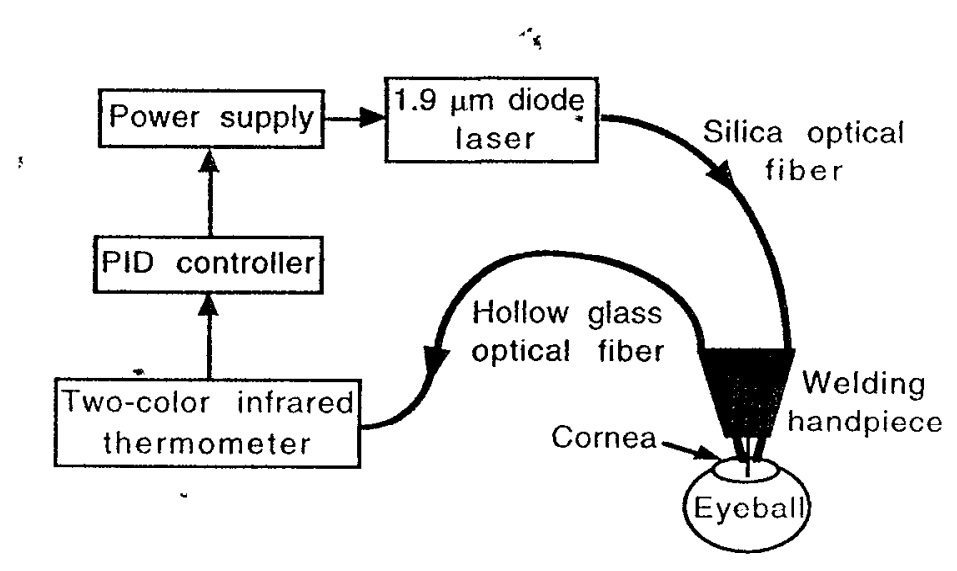

Fig. 1. Temperature feedback control loop for laser irradiation. The two-color infrared thermometer measures the surface temperature at the laser spot and the PID controller modulates the diode laser current to maintain a set temperature. common spot on the cornea surface. In this study, the handpiece was mounted above the corneal surface and was not moved during irradiation. The spatial resolution of the temperature measurement (governed by the numerical aperture of the hollow glass fiber) is less than $1 \mathrm{~mm}$. Because the laser wavelength lies within the detection band of the infrared thermometer, the laser was operated at a $90 \%$ duty cycle and the temperature was synchronously

measured only when the laser was off every $60 \mathrm{~ms}(\approx 17 \mathrm{~Hz})$. A PID controller modulated the diode current based on the measured surface temperature to maintain a steady temperature at the desired 
setpoint $\left( \pm 1.5^{\circ} \mathrm{C}\right)$. The temperature feedback control loop is shown in Figure 1 and a typical surface temperature history is shown in Figure 2.

\section{FTIR spectroscopy}

The FTIR analysis was performed on intact tissues; the samples were neither ground with $\mathrm{KBr}$ and pressed into pellets nor dissolved to form a thin film. The tissue samples obtained using the microtome were sufficiently thin to permit transmission mode FTIR spectroscopy; the radiation from the broadband infrared source was detected .immediately after passing through the sample. The FTIR infrared beam was approximately 2 at a setpoint of $85.0 \pm 1.5^{\circ} \mathrm{C}$.

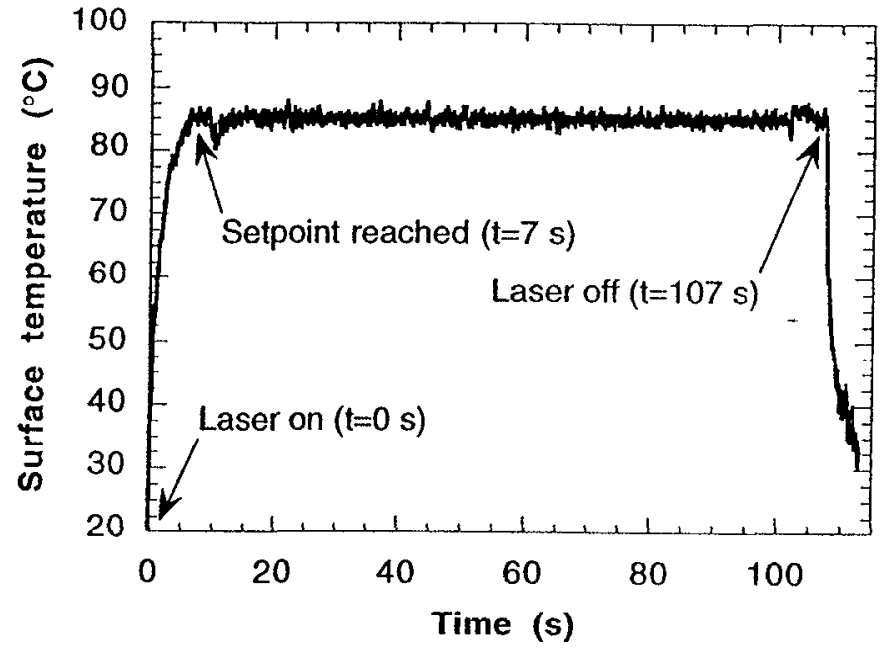

Fig. 2. Sample temperature history of the laser spot using the temperature feedback control system. In this case, the temperature was maintained $\mathrm{mm}$ in diameter.

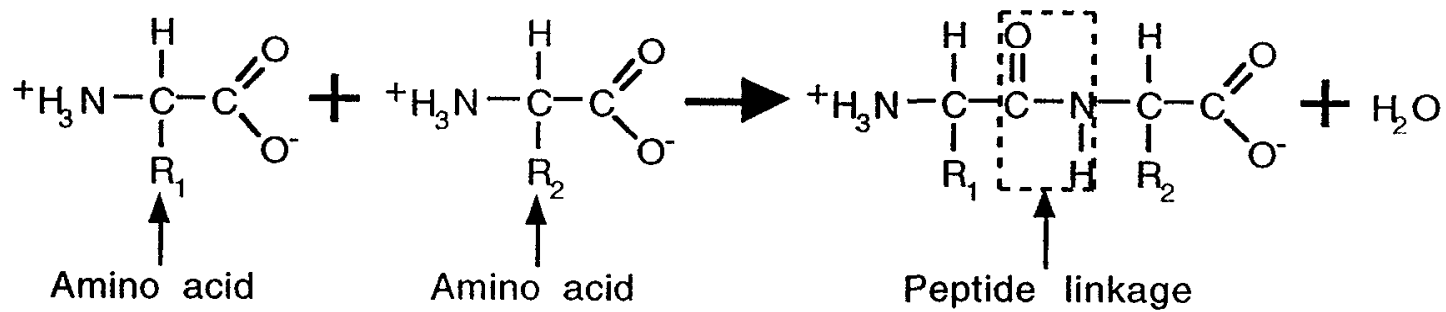

Fig. 3. Formation of a peptide linkage. The joining of adjacent amino acids (side chains labelled by $\mathrm{R} 1$ and $\mathrm{R} 2$ ) results in a polypeptide chain. The three polypeptide chains of collagen each contain about 1000 amino acids. 
The spectrometer was purged with dry nitrogen and a background spectra of a $\mathrm{CaF}_{2}$ window alone was acquired. The sample was placed on the $\mathrm{CaF}_{2}$ window and allowed to dry out at room temperature for approximately $30 \mathrm{~min}$ prior to FTIR analysis. Because the region of interest for collagen denaturation is around $3320 \mathrm{~cm}^{-1}$, which is assigned to the $\mathrm{N}-\mathrm{H}$ stretching vibration of the peptide linkages (Figure 3 ) in the three polypeptide chains of the tropocollagen molecule, drying of the sample reduced the contribution from the water absorption bands around $3277 \mathrm{~cm}^{-1}(\mathrm{O}-\mathrm{H}$ stretch) and $1642 \mathrm{~cm}^{-1}$ (O-H bend) [6] in the acquired spectra. Spectral resolution of the instrument was $4 \mathrm{~cm}^{-1}$.

\section{RESULTS}

\section{Native collagen spectra}

The FTIR spectrum (absorbance versus wavenumber) of native porcine cornea (dehydrated, but not heated) is shown in Figure 4. The collagen amide $\mathrm{A}$ and amide $\mathrm{B}$ bands, corresponding to the $\mathrm{N}-\mathrm{H}$ stretching vibration $[5,10]$, are centered at $3323 \mathrm{~cm}^{-1}$ and $3081 \mathrm{~cm}^{-1}$, respectively. Also noted are the amide I band at $1660 \mathrm{~cm}^{-1}(\mathrm{C}=\mathrm{O}$ stretch), and the amide II band at $1545 \mathrm{~cm}^{-1}$ and amide III band at $1235 \mathrm{~cm}^{-1}(\mathrm{~N}-\mathrm{H}$ bend and $\mathrm{C}-\mathrm{N}$

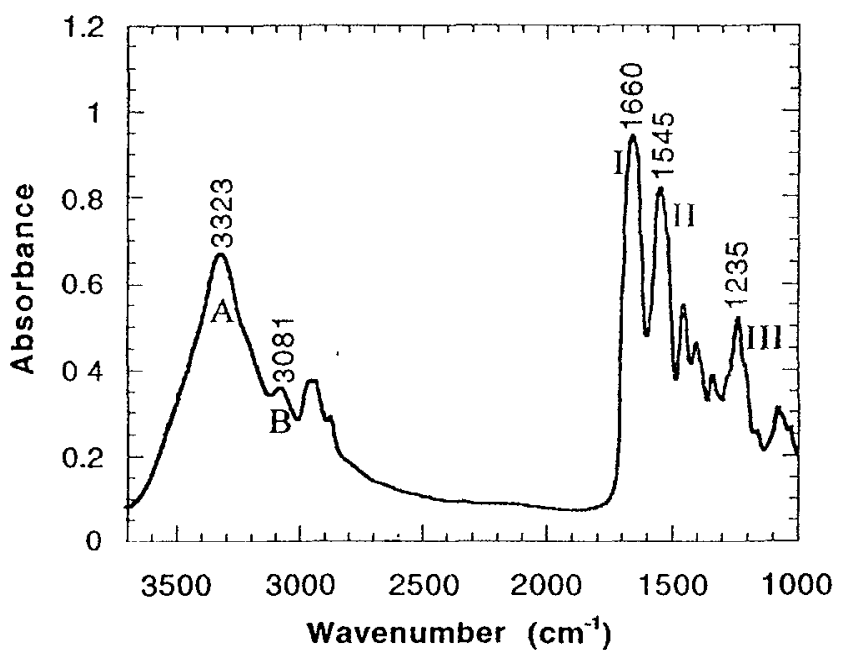

Fig. 4. FTIR spectrum of native porcine cornea. The collagen amide A, B, I, II, and III bands are labelled and their peak values are noted. stretch) $[5,10]$. 


\section{Heated collagen spectra}

Amide $\mathrm{A}$ bands associated with the laser heating and water bath protocols are shown in Figures 5 and 6 , respectively. Values of the amide A peaks associated with the different heating protocols are shown in Figure 7 as a function of temperature. In general, samples subjected to higher temperatures showed a larger low-frequency shift of the Amide A band. The laser and water bath heated samples showed initial low-frequency shifts of the amide A peak relative to the native peak at temperatures above $\approx 65^{\circ} \mathrm{C}$, indicating the onset of conformational changes of the collagen triple helix. Above $\approx 85^{\circ} \mathrm{C}$ all samples experienced a peak shift of approximately $-17 \mathrm{~cm}^{-1}$. Dehydration occurred in all laser heated samples (visually determined). The corneas heated in the water bath appeared cloudy, which may also be due to dehydration.

\section{DISCUSSION}

\section{Heating depth}

Based on the absorption coefficient of water $[11]$ and the negligible scattering of the infrared radiation, the optical penetration depth of the $1.9 \mu \mathrm{m}$ laser wavelength in cornea is roughly $150 \mu \mathrm{m}$. Each analyzed $50 \mu \mathrm{m}$ thick tissue slice includes corneal depths from about 150 to $200 \mu \mathrm{m}$. As a result 
of the relatively long heating time $(100 \mathrm{~s})$, the heating depth is extended via thermal diffusion to several times the penetration depth [12] such that the FTIR sampled tissue slice was well within the heated region. Moreover, since the slices were obtained within the optical penetration depth, they achieved temperatures near the surface temperature. Based on the heating depth due to thermal diffusion described above, the slices obtained from corneas heated in the water bath also achieved the temperatures of the surrounding water.

\section{Sample denaturation}

A previous study by Doyle et al [5] reported an amide $A$ peak shift of about $-20 \mathrm{~cm}^{-1}$ due to collagen denaturation; however, denaturation of the collagen was achieved in a solvent enviroment, which may result if a more homogenous denaturation as opposed to laser heating. It is possible that the amide A shifts observed in this study, particularly those at "transitional"

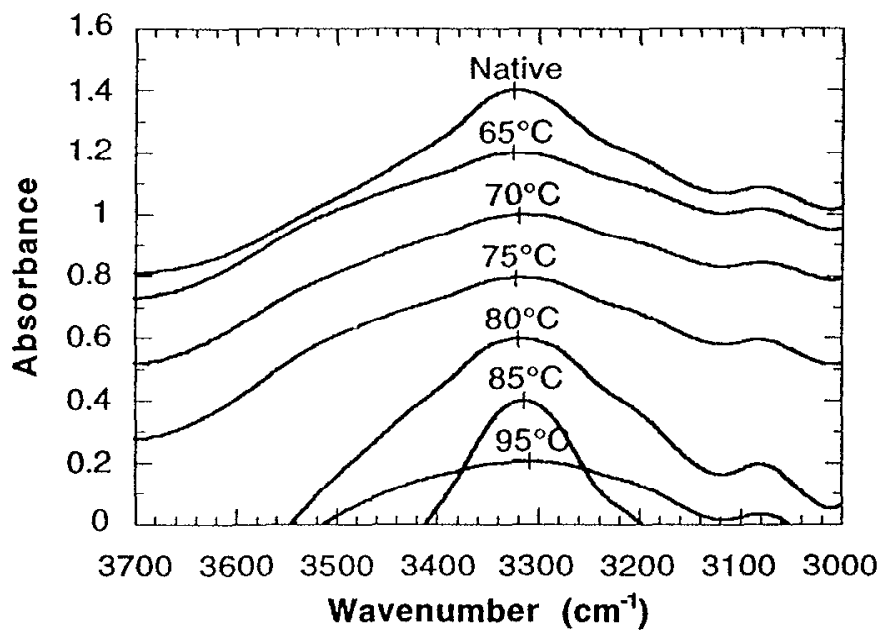

Fig. 6. Collagen amide $A$ bands of cornea heated in a water bath at various temperatures. The locations of the peaks are indicated. Each sample was maintained at the given temperature for $100 \mathrm{~s}$. The bands were shifted vertically for clarity. temperatures from 65 to $85^{\circ} \mathrm{C}$, resulted from incomplete denaturation (i.e., not all areas of the tissue sampled by the FTIR beam were denatured, or the collagen triple helix still maintained some degree of helicity). Further, the fact that the collagen was not extracted from the cornea prior to heating may influence the spectral changes--the collagen may be more thermally stable in situ which may result in a less drastic conformational change upon denaturation or may impede the denaturation process. We assume that a larger low-frequency shift corresponds to more thorough denaturation. Because denaturation is a 
rate process, longer heating times may have resulted in larger shifts at the same temperatures, which may have improved the agreement with Doyle et al [5].

\section{Effect of hydration level on collagen stability}

According to the infrared study by Susi et al [10] and the collagen structural model of Ramachandran and Chandrasekharan [13], water molecules are firmly bound to the backbone of the tropocollagen

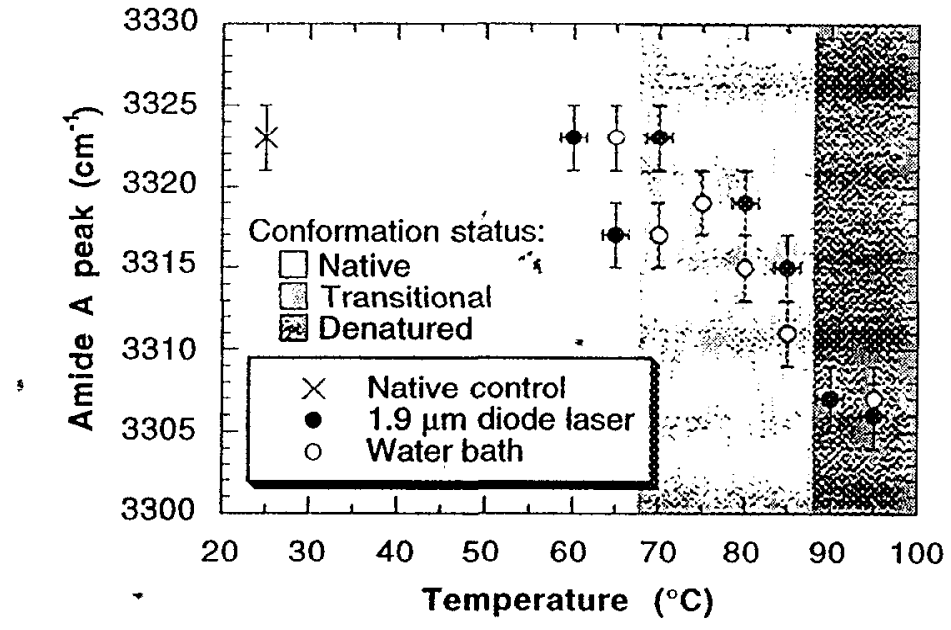

Fig. 7. Amide A peak values for $1.9 \mu \mathrm{m}$ diode laser and water bath heated cornea versus temperature. Above $\approx 65^{\circ} \mathrm{C}$ the amide $\mathrm{A}$ peak begins to shift to lower frequency due to a change in the collagen conformation (indicated as a "transitional" conformation). By $\approx 90^{\circ} \mathrm{C}$, the collagen is fully denatured. The vertical error bars are an estimate of the uncertainty of the peak value, and the horizontal error bars represent the temperature variation during laser heating. triple helix. These water molecules are believed to be involved in interchain hydrogen bonds which help stabilize the triple helix. Luescher et al [14] also suggested that the hydrogen bonds of water within the triple helix stabilize the collagen structure, and found that the temperatures of pure collagen denaturation decrease with increasing water content, which agrees with the results presented here. It was suggested that the denaturation temperature increase upon water loss may be due to decreased chain mobility and the elimination of secondary water molecules which interact with the primary stabilizing water molecules. 
Collagen denatures at $62-67^{\circ} \mathrm{C}$ in physiologically buffered solution [15]. Both the water bath and laser heating results suggest that corneal collagen heated in situ may have a higher denaturation threshold temperature. Though the laser heated tissues were more severely dehydrated, those heated in the water bath were less hydrated than extracted collagen in solution, which may explain the elevated denaturation temperature. Also, the molecular mobility of the collagen fibers in situ may be reduced compared to dissolved collagen.

The influence of dehydration on collagen denaturation during laser irradiation is apparent in the high tissue welding temperatures of $80^{\circ} \mathrm{C}$ using a $1.9 \mu \mathrm{m}$ diode laser [16] and $90^{\circ} \mathrm{C}$ using an argon laser $(488-515 \mathrm{~nm})$ or Ho:YAG laser $(2.09 \mu \mathrm{m})[17,18]$--neither of these studies used an extrinsic solder material, which may help maintain adequate hydration levels in the underlying tissue [19]. In contrast, successful argon laser welling experiments in which a hydrating saline drip was continuously applied to the weld site were accomplished at temperatures below $60^{\circ} \mathrm{C}[20]$. It should be noted that other mechanisms, such as covalent bonds, in addition to collagen denaturation may be responsible for tissue fusion $[8,9]$.

\section{CONCLUSIONS}

FTIR spectroscopy is a useful tool for measuring conformational changes in collagenous tissue. In particular, a low--frequency shift of the collagen amide A band, which is sensitive to peptide linkage vibrations, indicates the uncoiling of the collagen triple helix (denaturation). As a result of accelerated water loss due to evaporation during irradiation, the denaturation temperature of corneal collagen heated with a $1.9 \mu \mathrm{m}$ diode laser in situ is higher than that for collagen denatured in a solvent environment in vitro. In cases where collagen denaturation is the primary tissue fusion mechanism, this phenomenon may influence the optimal laser tissue welding heating protocol (e.g., time-temperature history). Desiccation of the tissue during the welding procedure may impose a need for welding temperatures above the nominal collagen denaturation temperature. In order to achieve 
sufficient collagen denaturation without inflicting excessive collateral thermal damage during the welding procedure, it may be necessary to maintain adequate hydration levels in the tissue.

\section{ACKNOWLEDGMENTS}

This work was performed under the auspices of the U.S. Department of Energy by Lawrence Livermore National Laboratory under Contract W-7405-ENG-48 and supported by a Summer Research Grant from the American Society for Laser Medicine and Surgery. The authors wish to thank N. Heredia, P. Celliers, and D. Maitland for their technical assistance, J. Cox and K. Haney for their help in fabricating the infrared thermometer, and J. Harrington for providing the hollow glass fiber.

\section{REFERENCES}

1. Bass LS, Treat MR. Laser tissue welding: A comprehensive review of current and future clinical applications. Lasers Surg Med 1995; 17:315-349.

2. Maitland DJ, Eder DC, London RA, et al. Dynamic simulations of tissue welding. In: Lasers in Surgery: Advanced Characterization, Therapeutics, and Systems VI. Proc SPIE 1996; 2671:234-242.

3. Torres JH, Motamedi M, Pearce JA, Welch AJ. Experimental evaluation of mathematical models for predicting the thermal response of tissue to laser irradiation. Appl Opt 1993; 32:597-606.

4. Small IV W, Maitland DJ, Heredia NJ, et al. Investigation of laser tissue welding dynamics via experiment and modeling. Journal of Clinical Laser Medicine and Surgery 1997; 15:3-7.

5. Doyle BB, Bendit EG, Blout ER. Infrared spectroscopy of collagen and collagen-like polypeptides. Biopolymers 1975; 14:937-957.

6. Payne KJ, Veis A. Fourier transform IR spectroscopy of collagen and gelatin solutions: Deconvolution of the amide I band for conformational studies. Biopolymers $1988 ; 27: 1749$ 1760.

7. Small IV W, Celliers PM, Da Silva LB, Matthews DL, Soltz BA. Two-color mid-infrared thermometer for low-temperature measurement using a hollow glass optical fiber. In: Specialty Fiber Optics for Biomedical and Industrial Applications. Proc SPIE 1997; 2977:115-120.

8. Small IV W, Celliers PM, Kopchok GE, et al. In vivo argon laser welding using thermal feedback: open and closed loop patency and collagen crosslinking. In: Lasers in Surgery: Advanced Characterization, Therapeutics, and Systems VII. Proc SPIE 1997; 2970:252-256.

9. Small IV W, Celliers PM, Kopchok GE, et al. Temperature feedback and collagen crosslinking in argon laser vascular welding. Lasers Med Sci, in press.

10. Susi $\mathrm{H}$, Ard JS, Carroll RJ. The infrared spectrum and water binding of collagen as a function of relative humidity. Biopolymers $1971 ; 10: 1597-1604$. 
11. Luck WAP. Zur assoziation des wassers III: Die temperaturabhangigkeit der wasserbanden bis zum kritischen punkt. Ber Bunsenges Phys Chem 1965; 69:626-637.

12. Kung RTV, Stewart RB, Zelt DT, L'Italien GJ, LaMuraglia GM. Absorption characteristics at $1.9 \mu \mathrm{m}$ : Effect on vascular welding. Lasers Surg Med 1993; 13:12-17.

13. Ramachandran GN, Chandrasekharan R. Biopolymers 1968; 6:1649-1658

14. Luescher $M$, Ruegg $M$, Schindler $P$. Effect of hydration upon the thermal stability of tropocollagen and its dependence on the presence of neutral salts. Biopolymers 1974; 13:24892503.

15. Florkin $\mathrm{M}$, Stotz EH (eds). Extracellular and supporting structure. In: Comprehensive Biochemistry, Vol 26c. Amsterdam: Elscvicr, 1971.

16. Stewart RB, Benbrahim A, LaMuraglia GM, et al. Laser assisted vascular welding with real time temperature control. Lasers Surg Med 1996; 19:9-16.

17. Cilesiz I, Thomsen S, Welch AJ. Controlled temperature tissue fusion: Argon laser welding of rat intestine in vivo, part one. Lasers Surg Med 1997; 21:269-277.

18. Cilesiz I, Thomsen S, Welch AJ, Chan EK. Controlled temperature tissue fusion: Ho:YAG laser welding of rat intestine in vivo, part two. Lasers Surg Med 1997; 21:278-286.

19. Small IV W, Heredia NJ, Maitland DJ, et al. Experimental and computational laser tissue welding using a protein patch. Journal of Biomedical Optics 1998; 3(1):1-6.

20. Kopchok G, White RA, Grundfest WS, et al. Thermal studies of in-vivo vascular tissue fusion by argon laser. J Invest Surg 1988; 1(1):5-12. 


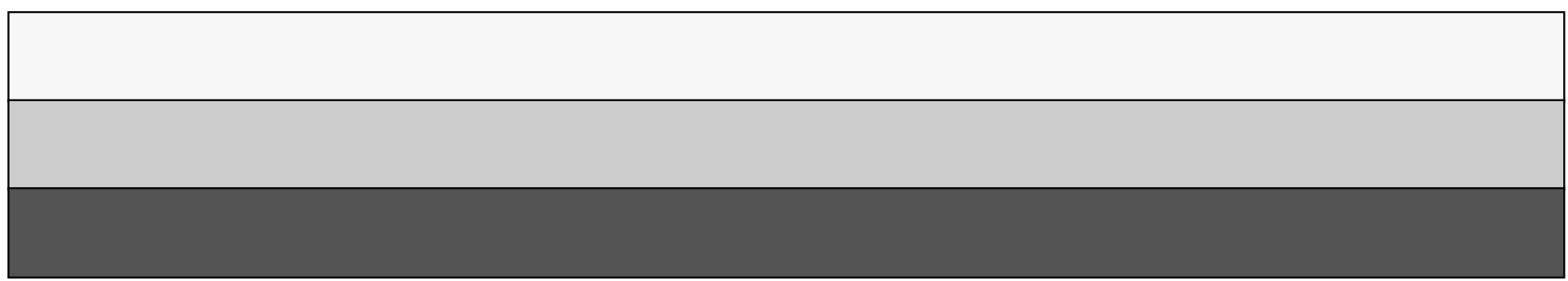

